Federal Reserve Bank of Dallas

Globalization and Monetary Policy Institute

Working Paper No. 46

http://www.dallasfed.org/assets/documents/institute/wpapers/2010/0046.pdf

\title{
What Determines European Real Exchange Rates?*
}

\author{
Martin Berka \\ Massey University \\ Michael B. Devereux \\ University of British Columbia \\ CEPR \\ NBER
}

April 2010

\begin{abstract}
We study a newly constructed panel data set of relative prices of a large number of consumer goods among 31 European countries. We find that there is a substantial and non-diminishing deviation from PPP at all levels of aggregation, even among eurozone members. However, real exchange rates are very closely tied to relative GDP per capita within Europe, both across countries and over time. This relationship is highly robust at all levels of aggregation. We construct a simple two-sector endowment economy model of real exchange rate determination. Simulating the model using the historical relative GDP per capita for each country, we find that for most (but not all) countries there is a very close fit between the actual and simulated real exchange rate.
\end{abstract}

JEL codes: F41, F31

\footnotetext{
* Martin Berka, Department of Economics and Finance, Massey University, P.O. Box 102 904, NSMC, Auckland, New Zealand. + 6494140800 ext. 9474. m.berka@massey.az.nc. Michael B. Devereux, Department of Economics, University of British Columbia, 997-1873 East Mall, Vancouver, B.C. Canada V6T 1Z. 604-822-2542. devm@interchange.ubc.ca We thank Paul Konijn of Eurostat for the provision of the data and patient responses to numerous questions. We also thank seminar participants at the Federal Reserve Bank of Dallas and HKUST for comments. Devereux thanks SSHRC, the Royal Bank, and the Bank of Canada for financial support. Part of the paper was written when the second author was visiting the RBA, and the HKIMR, and their hospitality is much appreciated. The views in this paper are those of the authors and do not necessarily reflect the views of the Federal Reserve Bank of Dallas or the Federal Reserve System.
} 


\section{Introduction}

One of the principal objectives of international macroeconomics is the understanding of international relative prices. Empirical observations over many countries and time periods show very large variations in cross-country relative prices of goods, both when measured for similar goods at the micro level, and for good bundles at a more aggregated level. Early open economy models used to assume that free international trade would equalize relative prices, so that PPP held in the small and the large. But it is now universally recognized that there are persistent deviations from equality of prices across countries both for individual goods and at the aggregate level. Equivalently, real exchange rates measured at the level of goods, or in terms of aggregate price indices, display large and persistent departures from PPP.

Despite consensus on the broad facts, there is little agreement on the explanation of these departures from PPP. Many competing theories have been put forward, highlighting nominal price rigidities, trade costs, nontraded goods, compositional effects, aggregation bias, and other features, as well as combinations of these elements ${ }^{1}$. One of the difficulties in providing a good account of the source of relative price movements across countries is the absence of a large panel of detailed comparable data on goods prices at the disaggregated level. Another, related problem is that most disaggregated time series price data used in international studies are in the form of indices, rather than price levels. This rules out the possibility of comparing prices across countries at a moment in time, instead allowing only studies of the movement in cross-country relative prices over time. What is necessary therefore, is to obtain a representative panel involving observations of price levels on a large number of similar goods across a large number of countries over time.

This paper employs a newly constructed data set of European price levels to conduct such a study. The data are comprised of relative prices for a large number of categories of consumer goods across 31 European countries over a 13 year period. This includes the high income countries of Western Europe, including the eurozone countries, both before and after the inception of the Euro, as well as the floating exchange rate countries. In addition, for a slightly shorter sample period, the data includes the emerging countries of

\footnotetext{
${ }^{1}$ Recent contributions include Engel (1999), Imbs et al (2005), Burstein et al. (2003), Crucini, Telmer and Zachariadis (2005), Carvalho and Nechio (2008), Drodz and Nosal (2008), among many others.
} 
Eastern and Southern Europe.

From these data we can construct measures of real exchange rates at both disaggregated and aggregate levels. We find that there are large and persistent deviations from absolute PPP among all European countries. These deviations hold for all categories of goods, but are much more pronounced among goods categorized as non-tradable than for tradable goods. The deviations have not been eliminated by membership of the single currency area. Even among eurozone members, there are persistent departures from PPP that show no obvious signs of erosion within the sample. For emerging Eastern Europe countries, the conclusions are somewhat nuanced. For these countries, the deviations from PPP are much larger, but there is much greater evidence of convergence in price levels towards the European average, while still, at least in the sample, remaining quite far away from PPP.

While the data show very persistent departures from PPP, this does not mean that such divergences in real exchange rates cannot be rationalized. In fact, we find that real exchange rates are very closely tied to relative GDP per capita, both in comparisons across countries, and in movement over time, at all levels of aggregation ${ }^{2}$. The data show that some countries displayed declining relative GDP per capita over time, combined with persistent depreciation in their real exchange rate - in particular this applied to the 'OldEurope' countries; France, Germany, the Netherlands, Belgium, and Austria, while other countries displayed substantial appreciation combined with increasing relative GDP per capita - notably Ireland, UK, some Scandinavian countries, as well as many countries of emerging Eastern Europe.

Relative GDP per capita is an important determinant of the real exchange rate not just in the aggregate, but also at the level of individual goods. Almost 50 percent of the variation in individual product based real exchange rates - i.e. real exchange rates at the most disaggregated level, measured across goods, time and countries, is explained by relative GDP per capita differences across countries and movements over time. Quantitatively we find that, roughly speaking, a one percent increase in the relative GDP per capita for a given country towards the European average leads to a 0.35 to 0.40 percent appreciation of the real exchange rate to the European average. When broken down into non-tradable and tradable goods separately, the real appreciation coefficient becomes 0.5 percent and 0.2 percent, respectively.

\footnotetext{
${ }^{2}$ A similar finding is reported in Crucini et al. (2005), looking at cross country variations in prices for a smaller sample of European countries.
} 
This implies that for all categories of goods, movements in relative GDP per capita are associated with less than proportionate movements in real exchange rates. We find a striking pattern in the relationship between relative GDP per capita and real exchange rates for a number of countries. For countries such as Ireland, where relative GDP per capita moved from being below the EU average to being above the EU average over the sample, the deviation of relative GDP from the EU average switched from being below the real exchange rate deviation (relative to the EU average) at the beginning of the sample to being above the real exchange rate deviation at the end of the sample. In this sense, movements through through the rankings of relative GDP per capita among European countries are matched by movements in real exchange rate rankings.

An interesting question concerns the relationship between nominal and real exchange rate flexibility. Not surprisingly, floating exchange rate countries exhibit greater time variation in real exchange rates. Nonetheless, it is striking how much real exchange rate movement has taken place among eurozone members or between the euro area and euro-pegging Eastern European countries. Generally, we find little evidence that membership of the euro area has stymied adjustments in real exchange rates. Moreover, when we look at disaggregated real exchange rates, we find that there is much less difference in volatility between eurozone members and floating exchange rate countries.

Having explored the characteristics of real exchange rates in the data, we go on to develop a highly stylized model of real exchange rate determination. We deliberately employ a 'minimalist' model of the real exchange rate based on a two-sector endowment economy with traded and non-traded goods. As in the classic Balassa-Samuelson model, real exchange rates in the model are driven by growth differences across countries, and growth that is biased towards tradable goods sectors. Countries with real GDP growth above the average will exhibit real appreciation. For each country, we simulate the model by choosing a path for GDP that matches the historical sample. We find that the simulated real exchange rate from the model very closely tracks the sample real exchange rate, in levels and rates of change, for most countries in the dataset. Thus, for most European countries, relative per capita GDP can well account for the level and time path of real exchange rates.

The following section presents a short literature survey. Section 3 discusses the data in detail. Section 4 describes the properties of real exchange rates, both at the aggregate level and the disaggregated level. Section 5 dis- 
cusses the relationship between real exchange rates and relative GDP, and between real exchange rates and nominal exchange rate volatility. Section 6 shows that a simple structural model based on relative GDP, distance, and euro membership can account for a large part of the variation in real exchange rates both at the aggregate and disaggregated level. Finally, section 6 discusses the extent to which the empirical findings are consistent with a simple general equilibrium model of exchange rate determination.

\section{Literature Review}

There has been a large literature discussing the properties of real exchange rates and relative price comparisons across countries, using both aggregate and disaggregated data. Engel and Rogers (1996) study movements in price indices across Canadian and US cities, and find that both distance and border matter for relative price variability. Engel and Rogers (2001) use European data, and separate the border into two factors; a) "real barriers" effect caused by barriers to market integration and b) a "sticky consumer price-volatile exchange rate" factor. They find the second factor to be empirically more important. Similar to our findings below, Engel and Rogers (2004) find no evidence for prices in Europe to converge after euro's introduction in 1999.

Crucini, et al. (2005) present a study quite similar to that of our paper, using a more disaggregated data set on European prices, for four separate sample years for up to $13 \mathrm{EU}$ countries. They argue that PPP holds quite well in these data, especially when adjusting for GDP per capita. Our paper differs from theirs in that we have a panel covering up to thirteen years, we focus on a more aggregated sample of consumer products (see the discussion below for the differences in aggregation levels), and we examine a much larger set of countries, including both EU countries and non-EU countries, emerging economies in Eastern Europe, floating and fixed exchange rate countries, and pre-and post Eurozone countries. We find less compelling evidence for PPP in our study. In addition, our study extrapolates from the results to the implications for general equilibrium modelling of real exchange rates.

Faber and Stokman (2009) also study price level convergence in Europe using HICP data for the EU15 countries, but over a longer time period than we study. They construct price levels from HICP data by mapping the indices from the HICP into absolute price levels from surveys at various intervals. They show that the EU15 countries exhibited substantial absolute 
price convergence from 1980 onwards, but not much convergence after the late 1990's. Their study differs from ours in a number of ways. They focus on a smaller group of countries. In addition, they employ quite a different data at a different level of aggregation than ours. Their data is based on a small bundle of HICP categories at a relatively high level of aggregation. Most importantly, because our data begins in the mid 1990's, we cannot study that type of long run price convergence that they find. In a short section below however, we do follow the Faber and Stokman strategy of linking HICP indices to our data on price levels. This allows us a check on our main results by giving us the ability to study relative prices at higher frequencies than those of the main data-set.

Crucini and Telmer (2007) using EIU data on city prices find that crosssectional variance in long-run absolute deviations from LOP is large relative to time-series variance and time series variance in changes in LOP deviations is dominated by idiosyncratic variation, rather than country-specific variation (such as would be driven by nominal exchange rate movements). Our findings are consistent with their paper in the sense that, when we focus on the volatility of real exchange rates at the disaggregated level, we find much less difference in the average volatility between Eurozone countries (or europegging countries) and floating exchange rate countries that the equivalent volatility at the level of the aggregate real exchange rate.

Finally, our paper is related the literature documenting a relationship between price levels and GDP per capita (sometimes called the 'Penn' effect, after Summers and Heston (1991)). This has led to large number of papers exploring the 'Balassa-Samuelson' mechanism (e.g. Asea and Mendoza 1994), which can rationalize this relationship. An alternative explanation is explored by Bergstrand (1991). He argues that a 'demand-side' explanation, due to the property that the income elasticity of demand for services exceeds unity, plays an important role in explaining the relationship. Our paper provides a further documentation of the nature of this relationship for European countries. We argue that the relationship holds almost in the same way both across countries and over time. Furthermore, we explore the extent to which these findings are consistent with a simple general equilibrium model based loosely on a Balassa-Samuelson type mechanism. 


\section{Data-Description}

\subsection{Annual Price Level Indices}

We use a dataset on European price levels for a large number of European countries over the 1995-2007 period. The data are annual Price Level Indices, or PLI's, constructed by Eurostat as part of the Eurostat-OECD PPP Programme. They give the price of the good heading at a given time and for a given country, relative to the price in the reference country. The level of aggregation of the PLI is at the 'Basic Heading'. Basic Headings are constructed as unweighted averages of product level observations in each country. Basic Headings are then aggregated using expenditure weights to form HICP categories used at a higher level of aggregation. For our purposes, for the full sample 1995-2007, PLI's are available for 146 consumer expenditure headings on goods and services, 36 government expenditure headings, and 32 headings for expenditures on gross fixed capital formation. In this paper, we focus on consumer PLI's. The 1995-2007 sample extends across 18 western European countries. The countries are: Belgium, Germany, Greece, Spain, France, Ireland, Italy, Luxembourg, the Netherlands, Austria, Portugal, Finland, Denmark, Sweden, UK, Iceland, Norway, and Switzerland. In addition, for 1999-2007, we have an identical sample for 13 additional countries, mostly Eastern European ${ }^{3}$. PLI's are derived from Basic Heading-level PPP's, and are measured relative to the 15 members of the EU area ${ }^{4}$. The PPP for any country and good is just the ratio of the good price for that country to the average price of that good for the EU15. For the euro area countries (after the euro, 1999), the PLI is just equal to the PPP (multiplied by 100). For non-euro are members, the PLI for the country-good is obtained by dividing the PPP by the exchange rate, relative to the euro, so as to obtain the price in the same units. In each year, the EU15 price for each good is scaled to 100, so prices above 100 for a country-good in any year represents a price above the EU15 average price. Thus, for each country-good-year, the PLI gives us a measure of the good-level real exchange rate against the EU15. Denote the individual PLI for good $i$, country $j$, time $t$ as $p_{i, j, t}$. Thus, from

\footnotetext{
${ }^{3}$ The countries are Cyprus, the Czech Republic, Estonia, Hungary, Latvia, Lithuania, Malta, Poland, Slovakia, Slovenia, Bulgaria, Romania, and Turkey.

${ }^{4}$ That is, Austria, Belgium, Denmark, France, Germany, Greece, Ireland, Italy, Luxembourg, the Netherlands, Spain, Sweden, Portugal, Finland, and the United Kingdom.
} 
our definition, we have that:

$$
p_{i, j, t}=P P P_{i, j, t} / S_{j, t}=\frac{P_{i, j, t}}{S_{j, t} P_{i, t}^{*}},
$$

where $S_{j, t}$ is the exchange rate of country $j$ against the EU15, $P_{i, j, t}$ is price of good $i$ for country $j$, and $P_{i, t}^{*}$ is the price of good $i$ for the EU15.

Table 1 gives a list of good categories included in the consumer PLI's, while Figure 1 gives some examples of the level and time path of categories for some countries.

\subsection{Monthly HICP price levels}

While the PLI's have the advantage of being expressed in terms of price levels, they have the drawback of being published only at annual frequencies. By contrast, the European Harmonized Index of Consumer Prices (HICP) for all countries in Europe is reported at a monthly frequency. The HICP has the converse disadvantage of being an index, rather than a price level, however. But it is possible to use the PLI's and the HICP's in combination, so as to produce a monthly series of price level equivalents ${ }^{5}$. We do this by using Eurostat expenditure weights to aggregate from the Basic Heading PLI level of prices up to the HICP level ${ }^{6}$. Since the BH-PPP PLI's are in terms of levels, relative to the EU average, we can then compute a proxy relative price level for categories in the HICP, and then using the rates of change of the HICP indices for each category, derive a monthly frequency series in relative price levels for all countries in the sample. The difficulty of aggregating up from the annual PLI frequency to the monthy HICP frequency is handled by using a Eurostat provided set of 'temporal adjustment factors' which are used to go from the annual frequency of the PLI's to the implied PLI for any month. A matrix of these temporal adjustment factors is available for years 2003-2006.

In the discussion below, we report some preliminary results for comparative prices using the monthly price series. One drawback of this analysis is that missing data in the HICP series reduces significantly the number of goods that can be used in a balanced panel of monthly HICP level prices. A second complicating factor is the extreme seasonality in many of the individual HICP series, with seasonal movements for similar products differing

\footnotetext{
${ }^{5}$ For a similar methodology, see Faber and Stokman (2009).

${ }^{6}$ This uses the EKS method of aggregation (see Eurostat Manual).
} 
considerably across different countries. We resolve this by applying a common seasonal adjustment algorithm for all countries and all prices.

\section{Characteristics of PLI's}

\subsection{Mean Comparisons across Countries}

We first focus on the properties of annual PLI's. PLI's can be thought of as good-level real exchange rates. Average PLI's then represent a measure of aggregate real exchange rates. Define the aggregate real exchange rate for country $\mathrm{j}$ as:

$$
p_{j, t}=\frac{1}{N} \sum_{i}^{N} p_{i, j, t} .
$$

where $N$ is the number of goods in the aggregate. In this definition, aggregate real exchange rates are unweighted. Eurostat does provide expenditure weights for good categories, but since we wish to focus on deviations from PPP (or the law of one price) at the micro level, we find it more compelling to report unweighted averages of PLI's. In the Appendix, it is shown that the properties of the weighted averages, using expenditure weights, are very similar to those of the unweighted averages.

We begin by reporting the characteristics of $p_{j, t}$ for the sample of 18 Western European countries. The top left panel of Figure 2 describes the path of $p_{j, t}$ for all 12 countries in the eurozone, while the bottom left panel shows the prices for the group of 6 countries with independent currencies and floating exchange rates.

It is clear that, even within the eurozone, and particularly outside the eurozone, there is a substantial and continuing departure from PPP in the aggregated data. Although there is some tendency for price differentials across countries to narrow over time (as discussed below), this fall in dispersion across countries is very small relative to the departures from overall PPP.

If we focus on the eurozone countries in particular, there is admittedly some evidence of a narrowing of price differentials in the average over time. This is shown on the right hand panel of Figure 2, which shows two measures of the movement in the dispersion of $p_{j, t}$ across countries over time. The first measure is simply the standard deviation: 


$$
S D_{t}=\sqrt{\frac{1}{M} \sum_{j}\left(\frac{1}{N} \sum_{i} p_{i, j, t}-\frac{1}{M N} \sum_{j} \sum_{i} p_{i, j, t}\right)^{2}} .
$$

where $M$ is the number of countries in the grouping. Since the PLI's are measured relative to the EU15 scaled average of 100 however, it is possible that the standard deviation for a given group of countries is small, but there is still a significant departure of parity with the EU15. Therefore, we define an alternative measure of dispersion across countries as

$$
M A D_{t}=\operatorname{mean}_{j}\left(\operatorname{ABS}\left(p_{j t}-100\right)\right) .
$$

If the sample of countries are evenly dispersed above and below the EU15 average, then the two measures will be very close. But $M A D_{t}$ may be considerably higher than $S D_{t}$ for a group of countries whose price is far above or below the EU15 average.

Over the whole sample period, there was a significant reduction in the dispersion of real exchange rates across countries that later made up the eurozone, using either measure of cross country dispersion. But all of this fall in relative price dispersion took place before the euro came into effect in 1999. There has been no change in dispersion between 2000 and $2007 .{ }^{7}$ Interestingly however, this conclusion depends solely on the presence of one country; Ireland. Without Ireland, Figure 3 shows that the average dispersion across the eurozone countries continued to fall slowly even after 1999.

An inspection of Figure 2 reveals interesting patterns among the eurozone countries and the nature of the convergence in average price levels. Six of the high real exchange rate countries at the beginning of the sample Germany, France, Belgium, Austria, Luxembourg, and the Netherlands, have persistently depreciating real exchange rates over the sample. Two countries with initially low real exchange rates, Ireland and Italy, have substantial real appreciations over the sample. Ireland went from being below the EU average in 1995 to being considerably above the average by 2007. On the other hand, Greece, Spain, and Portugal show little convergence, with real exchange rates 10-15 percent below the European average for the full sample. Finally, Finland remains an outlier, remaining $15-20 \%$ above the EU average over the whole sample.

\footnotetext{
${ }^{7} \mathrm{~A}$ similar point, using a different data-set, is made in Engel and Rogers (2004), and Faber and Stokman (2009).
} 
For the non-eurozone countries of Western Europe, there is no evidence at all of convergence over time in real exchange rates. For almost all of the sample, these countries have higher prices than the EU average. This leads to the $M A D_{t}$ measure of dispersion being significantly larger than the $S D_{t}$ measure. Moreover, as to be anticipated, for the freely floating countries, real exchange rate year to year variation over the sample is much higher than that for the eurozone countries.

Figure 4 illustrates the PLI's for the additional, Eastern and Southern European countries for the shorter sample of 1999-2007. The key feature of these countries is that their real exchange rates are far lower than the EU average. Since most of these countries had a much lower GDP per capita than Western Europe, it may not be too surprising to find considerably lower prices. Nevertheless, there was substantial upwards convergence over the sample. Figure 4 shows the average deviation from PPP relative to the EU average fell progressively over the sample. This still remains considerably higher than the equivalent measure for the Western European countries however - on average the Western European countries were about 15 percent away from PPP over the whole sample. For the Eastern and Southern European countries, the average was over 34 percent.

How representative are the mean PLI's of the individual prices at the disaggregated level? Figure 5 illustrates the deviation from PPP of each of the 146 consumer goods for three separate years in the sample for both groups of countries, respectively. It is apparent that the mean PLI's are quite representative. For for the central European group of countries (Belgium, Germany, Netherlands, France and Austria), there is an even distribution above and below PPP across the goods. For the Scandinavian countries, most goods are above PPP, while for the southern European countries, most goods are below PPP. In addition, the time variation seen in the means can be seen across the range of goods, for Ireland, UK, Iceland, and Switzerland, for instance.

Figure 5 also shows that for the Eastern European countries, almost all goods are substantially below PPP relative to the EU15. For some countries, the comparison is quite dramatic. For instance, in 2007, Bulgaria had only 6 of the total 146 good categories with prices at or above the EU average.

Thus, the evidence from Figures 1-5 makes clear that, at both the mean level and at the level of individual goods, there is substantial and continuing deviation from equality within European consumer goods prices. Moreover, average real exchange rate departures from PPP are strongly representative 
of PPP departures at the individual good level, for most countries. Equivalently, if a country's average real exchange rate is far above (below) PPP relative to the EU average, almost all individual real exchange rates are above (below) PPP.

\subsection{Dispersion within countries}

We now focus in more detail the nature of price dispersion within countries. Recall that each individual price is measured relative to the EU average set equal to 100 in each year. Thus, in each year, the degree of price dispersion measures the variation across goods in real exchange rates for a country. The measure of dispersion we focus on is the country-dated coefficient of variation:

$$
c v_{j, t}=\frac{\sqrt{\frac{1}{N} \sum_{i}^{N}\left(p_{i, j, t}-p_{j, t}\right)^{2}}}{p_{j, t}} .
$$

Since Figures 2 and 3 indicate that there are large persistent differences in country means, $p_{j, t}$, the coefficient of variation $c v_{j, t}$ is a more accurate measure of within-country price dispersion than the simple standard deviation of prices across goods.

Figure 6 illustrates the path of $c v_{j, t}$ for the three groups of countries. Price dispersion is lowest for the eurozone countries, and highest for the Eastern and Southern European group of countries. Price dispersion tends to fall over time in each of the three groups, particularly so in the Eastern and Southern European group. The picture also seems to suggest that price dispersion is higher for the countries with real exchange rates further away from the EU average. Figure 7 confirms this. It shows the relationship between the mean average departure from PPP (over the whole sample) and the mean of price dispersion. There is a clear positive relationship between the departure from PPP and the dispersion of within country prices. Countries with PLI's further away from the EU average have a higher degree of price dispersion.

Figure 8 gives an alternative representation of price dispersion. It displays the kernel densities of the PLI's for each country, for three separate years. The densities have narrowed for the central European countries, although, consistent with the evidence above, most of this reduction took place before 2000. The densities show substantial instability for the floating rate countries - particulary Iceland and the UK, which had large movement in the euro-based nominal exchange rates over the sample. As we see below, nomi- 
nal and real exchange rates move closely together for these countries, over the sample. In addition however, even some euro area members (e.g. Ireland and Italy) showed substantial shifts up over time in their kernel densities. For the Eastern European countries, the densities are much wider, and also tend to shift up over time. Note again, that while there is substantial movement in the densities, there is a large and continued distance between densities for the highest real exchange rate countries (e.g. Finland, Denmark, and the lowest real exchange rate countries of Southern and Eastern Europe).

A final perspective on price dispersion can be seen in Figure 9. Here we show the kernel density over all goods, for the three separate groupings of countries, for all years. The distribution for the Euro area countries is narrow and stable over time, compared to that for the floating countries, which is wider, further to the right on average, and substantially more volatile across years. For the Eastern European countries, the distribution is far to the left of those of the other two groupings, and wider, but tends to shift up progressively over time. Again, we note that the differences in the means of the densities still persist when measured in this way.

\subsection{Decomposition into Traded and Non-Traded}

We now decompose real exchange rates and price dispersion separately into tradable and non-tradable goods (see Table 1). A minimal theoretical presumption is that the departures from PPP in real exchange rates is lower in traded goods than in non-traded goods. Figure 10 shows the separate breakdown of the country level PLI's for traded and non-traded goods for the eurozone countries. The properties of average traded and non-traded goods PLI's, in terms of deviations from the EU average, are similar to the overall PLI's. Even for traded goods, there is significant and continued departure from PPP in both directions. Spain and Portugal have real exchange rates for traded goods equal to 90 percent of the EU average, and show no indications of convergence. Finland's real exchange rate in traded goods is persistently more than 15 percent above the EU average. Again Ireland and Italy go from being below to being above the average. France, Germany, Belgium, Austria and the Netherlands display gradual downward convergence as before.

For the non-traded goods categories we see basically the same features, except that the magnitude of departures from PPP are substantially greater for the countries both above and below the EU average. Given that retail prices of all goods should contain some non-tradable component, this pat- 
tern of persistent departures from PPP in both tradable and non-tradable categories is quite consistent with standard theory. This statement is made more precise in Section 6 below.

For both categories of goods, there is a significant convergence of prices just prior to the euro, and little convergence thereafter. But the key difference is that the average departure from PPP for the eurozone countries is twice as great for the non-traded goods category as that for traded goods.

Figure 11 show the same results for the floating exchange rate countries of Western Europe. The average departure from PPP is much higher for the non-traded category, although again, there are significant departures from PPP for the traded category, and the time series properties of real exchange rates are essentially identical for both traded and non-traded categories. In terms of convergence in average real exchange rates across countries for these group of countries, Figures 11 show that in non-traded goods, there is significant divergence over time, while in traded goods, there is no convergence at all over the whole sample path.

Finally, Figure 12 describes the pattern of movement in tradable and nontradable categories for the countries of Eastern and Southern Europe. As for the other groups of countries, there are large and persistent departures from PPP in both categories of goods, but those for traded goods are roughly 50 percent less than for non-traded goods.

\section{Real Exchange Rate Determinants}

\subsection{Real Exchange Rates and Relative GDP per capita}

If PPP was satisfied in the data, we would not need to investigate the determinants of real exchange rates. But the evidence clearly establishes the presence of wide departures from PPP, even among the eurozone countries, and even more-so for the non-eurozone Western European countries and the Eastern European countries. What explains the patterns in real exchange rates, both over time and among countries? It is well known that in levels, real exchange rates tend to be positively correlated with per capita income. This is implied for instance, by the celebrated Balassa-Samuelson framework, (Obstfeld and Rogoff, 1995), although other theories make similar predictions (e.g. Neary 1988).

With this channel in mind, Figure 13 illustrates the relationship between 
relative GDP per capita and country level average real exchange rates for each of the countries in the sample. Relative GDP is defined as US dollar GDP per capita, relative to the EU15 average US dollar GDP per capita ${ }^{8}$. Then, if real exchange rate differentials were driven primarily by differences in income per capita, we should anticipate that countries with GDP per capita equal to the EU average should have real exchange rates at the EU average (i.e. PPP should hold when compared to the EU15). Figure 13 shows that this principle holds fairly accurately for the Western European sample. Belgium, Germany, France, Austria and the Netherlands all have GDP per capita close to the EU average, and the same holds for their real exchange rates. For Greece, Spain and Portugal, real exchange rates and relative GDP's are considerably below the EU average, while the Scandinavian countries, both real GDP per capita and real exchange rates are substantially above the EU average. For most countries, the deviation of GDP per capita from the EU average exceeds that of the real exchange rate, in absolute terms. That is, for the relative poorer countries of Greece, Spain and Portugal, the deviation from PPP is far less than the deviation of GDP per capita. A similar characteristic is seen in the opposite direction for Luxembourg, Switzerland, Norway and the Netherlands; real GDP per capita is proportionally more above the EU average that are their real exchange rates.

Likewise, for the Eastern and Southern European countries, real GDP per capita is far below the EU average, as is the real exchange rate for these countries, and again, the deviation of the relative price from the EU average is substantially less than that of GDP per capita.

Figures 13 suggests that the relationship between GDP per capita and real exchanges holds both in the cross section and over time. Across countries, high real exchange rates are associated with higher GDP per capita. But also within countries, movements in relative GDP per capita tend to be associated with movements in real exchange rates in the same direction. This is particularly true for the floating exchange rate countries; i.e. Sweden, UK, Iceland, Norway and Switzerland ${ }^{9}$. Moreover, both across countries and over

\footnotetext{
${ }^{8}$ Since the purpose is to explore the relationship between GDP per capita and real exchange rates, we use actual GDP per capita rather than PPP adjusted GDP per capita.

${ }^{9}$ Note, because we are using relative GDP per capita, rather than PPP adjusted GDP, there is a tendency for movements in GDP to follow relative nominal exchange rates, given slow movements in GDP deflators. Hence it is not surprising to see a high correlation between relative GDP per capita and real exchange rates for the floating exchange rate
} 
time, there is a less than proportional response of the real exchange rate to movements in relative GDP. This leads to a particularly striking feature about the relationship between real exchange rates and relative GDP. For a country that begins with a GDP per capita below the average, relative GDP is below the real exchange rate. But as the country catches up and overtakes the average, the relative GDP line cuts the real exchange rate from below, and converges to a position where relative GDP is above the real exchange rate. In Figure 13, Ireland is a key example of this. But the dynamic also holds in reverse, as seen for Belgium, Germany, Austria, and Denmark, who experience falling relative GDP and real depreciation over the sample. In these cases, the relative GDP locus cuts the real exchange rate locus from above. In Section 5 below, we see that this convergence-related feature of the link between relative GDP and real exchange rates is predicted by a simple structural model of the real exchange rate.

Figure 14 gives a broader illustration of the relationship between relative GDP and real exchange rates. The figure presents a scatter plot of real exchange rates and GDP per capita over all countries and time periods in the sample. We see a close association, aside from outliers due to Luxembourg, which, from Figure 13, has a relative GDP per capita substantially out of proportion to its real exchange rate. The Figure also supports the observation made above that, unconditionally, the real exchange rate increases by less than in proportion to relative GDP. Countries with lower (higher) than average relative GDP have lower (higher) real exchange rates, but closer to the EU average than for relative GDP.

\subsection{Real and Nominal Exchange Rates}

Figure 15 illustrates the relationship between real and nominal exchange rates. The Euro area countries have zero nominal exchange rate variability after 1999. It is well known that for most countries and exchange rates, real exchange rate volatility against a reference currency or basket of currencies is much higher when the nominal exchange rate floats against those currencies. If nominal prices are slow to adjust, then fixed exchange rates may inhibit real exchange rate adjustment. Figure 15 shows that for the floaters, annual real and nominal exchange rate variability is much higher than for the

countries. But, as is seen in Figure 15 below, the relationship between the nominal and real exchange rates for the floating countries is not perfect. 
euro area countries, and there is a high correlation between nominal and real exchange rate variability. But at the same time, many euro area countries achieved considerable real exchange rate adjustment over the sample without movements in nominal exchange rates. In particular, Germany France, Austria and to a lesser extent Belgium and the Netherlands experienced substantial real depreciation even after entry into the euro area, while Ireland, Italy, Spain and Portugal went through real appreciation without changes in the nominal exchange rate. The mean annual standard deviation of the real exchange rate for the floating countries is 4.24 percent over the sample, while it is 1.9 percent for the euro area countries. It is thus not apparent that euro membership inhibited real exchange rate adjustment.

An even more striking pattern is seen for the Eastern European countries. The annual real exchange rate volatility for many countries is substantially greater than nominal volatility, even for the floating exchange rate countries. Effectively, much of the real exchange rate movements between Eastern European countries and the euro area took place via differential inflation rates. This 'convergence based' real exchange rate volatility is conceptually very different from traditional interpretations of the real exchange rate based on the combination of sticky prices and nominal exchange rate volatility.

Table 2 further investigates the impact of alternative exchange rate regimes on real exchange rate adjustment, but at the level of disaggregated prices rather than the aggregate real exchange rate. We measure the average standard deviation of real exchange rate changes across all 146 consumer goods over the full sample, for all countries. The difference in volatility of these micro level real exchange rates when comparing the floaters to the euro area countries is much less pronounced than in the aggregate real exchange rates. The average standard deviation across euro area members is 6.7 percent, while among the floating rate countries of Western Europe the average volatility is 8.9 percent. Thus, the proportional difference in real exchange rate adjustment among euro area members and floaters at the disaggregated level is much less than at the aggregate level. ${ }^{10}$ In describing disaggregated real exchange rates, there seems little indication of that the euro inhibited exchange rate adjustment. For the Eastern European countries, the average volatility is also 6.7 percent, the same as that for the eurozone.

\footnotetext{
${ }^{10}$ This accords with the results of Crucini and Telmer (2007).
} 


\subsection{Real Exchange Rates at Monthly Frequency}

Figures (16)-(18) describe the equivalent measures for relative prices and price dispersion at monthly frequencies, for the three groups of countries. Due to lack of complete coverage of HICP data for the full sample of countries and months, and the higher level of aggregation for the HICP series, relative to the BH-PPP data, these data are restricted to 38 good categories of HICP series, in 25 countries. The Figures show that the general features of the real exchange rates in the annual series carry over to the monthly data, but these measures of real exchange rates exhibit substantially more volatility. One interesting feature of the monthly data is the more distinct tendency cross country price dispersion to fall in the post 2000 period for the eurozone countries. Comparing Figure 2 and Figure 16, there is a clear tendency for monthly cross country price dispersion to fall after 2004 .

\section{Structural Determinants of Real Exchange Rates}

We now provide a more careful statistical investigation of the determinants of real exchange rates. From the figures above, relative GDP is clearly a key driver of country-level real exchange rates. But from the theoretical literature, it is likely that other variables are important for real exchange rates, both across countries and over time. One obvious factor is the existence of trade barriers or trade costs. While PPP should hold for pure traded goods in the absence of any restrictions to international trade, empirical studies have identified the existence of significant trade costs (Anderson Van Wincoop, 2004). As an proxy measure for trade costs, we use distance of the national capital from Frankfurt. To the extent that trade costs are proportional to the shipping distance involved, this should be a roughly accurate representation of the costs of arbitrage over traded goods ${ }^{11}$. A second important variable is whether the country is a member of the euro area. The transparency of price comparisons implied by membership of the European single currency area may impart forces towards price convergence that do

\footnotetext{
${ }^{11}$ Of course it must be noted that the PLI's we are examining are not pure traded goods, but represent measures of retail level prices paid by consumers, which incorporate local service content for distribution, marketing, etc. We do not have information on differences in marketing and distribution across countries however.
} 
not operate for other countries, even if they maintain stable exchange rates vis a vis the euro. 11 countries entered the euro area at its inception in 1999, followed by 4 more at various dates up to the end of our sample. The Euro variable introduces a dummy for the year and country for which euro membership applies.

Retail prices also include expenditure taxes, notably the VAT, which is levied in all countries in our sample. VAT rates differ among European countries, even for countries within the eurozone. Because over the sample period, VAT rates have been fixed for most countries, the presence of differential expenditure taxes should be picked up in regressions allowing for fixed effects. In the numerical simulations of the theoretical model developed in Section 6 below, we incorporate differential rates of VAT into the analysis. From the results of that Section, as well as the regression results we see momentarily, we find that differential rates of VAT can explain at best only a small part of the real exchange rate variation among European economies.

Table 3 reports results from an OLS regression of country level real exchange rates on RGDP, Distance, and Euro for the full sample. The elasticity of the real exchange rate to relative GDP is highly significant and equal to 0.35. Euro membership is significantly negative, while distance has a significantly positive coefficient. Relative GDP has an influence on real exchange rates that is important in both the cross section and over time. When country fixed effects are included, the coefficient on relative GDP is essentially unchanged. On average, within countries, a 1 percent increase in relative GDP per capita is associated with a 0.35 percent increase in the real exchange rate. Interestingly, the significance of the euro dummy (Euro) is eliminated when including country fixed effects. This is consistent with the pattern in the figures above, showing that most of the price convergence among euro members took place before entry into the euro system. The coefficient on Distance increases after the inclusion of country fixed effects ${ }^{12}$. Intuitively, without country fixed effects, Distance is partially proxying for time-invariant real exchange rate differences across countries. Thus, the pure effect of Distance is corrupted by other cross country fixed differences in prices.

Table 3 also provides a breakdown of these regressions separately into tradable and non-tradable goods . For tradables, the coefficient on relative GDP falls to approximately 0.28 , but remains highly significant. Euro and

\footnotetext{
${ }^{12}$ Since Distance is linearly dependent on the full set of country dummy vectors, when Distance is included, we drop one country from the fixed effects matrix.
} 
Distance are still significant in the basic specification, but again, Euro loses significance when fixed effects are allowed. In the non-tradables case, the GDP coefficient is much higher - around 0.55, and again highly significant under all specifications. In this case, Euro is insignificant even without the inclusion of fixed effects.

Table 4 decomposes the regressions separately for Western Europe and Eastern Europe. The main message from here is that the relationship between GDP and the real exchange rate is stronger for Western European countries, although still, in all cases, the coefficient is highly significant, both for all goods and for tradable and non-tradable goods separately.

In the aggregate then, the relationship between real exchange rates and real GDP per capita is very close. But real exchange rates in the aggregate mask considerable heterogeneity among different consumer categories of goods. How much variability at the disaggregated level can be explained by relative GDP per capita? Table 5 reports the results of a regression using all the individual PLI's across all countries and dates. The coefficient on RGDP is very significant, and even higher than before. With or without fixed effects, the elasticity is about 0.4. The striking feature of this regression however is that even at this disaggregated level, the $R^{2}$ is 0.5. Thus, even at level of disaggregated individual prices, relative GDP, Euro, and Distance can explain 50 percent of the price variability across countries and over time.

\section{A Simple General Equilibrium Model}

The key feature of the European data is the strong cross-country and timeseries relationship between real exchange rates and relative GDP. In general, countries with relative GDP above (below) the EU average have higher (lower) real exchange rates than the EU average, with the deviation in the real exchange rate from the EU average being 35-40 percent of the deviation in relative GDP, on average. Moreover, an increase in relative GDP from below to above the EU average leads to a real exchange rate appreciation from below to above the EU average, with a 'crossing' point for the relative GDP and real exchange rate locus. The opposite mechanism holds for most countries that have had relative GDP falling from above to below the EU average.

Is this relationship consistent with a theoretical model of real exchange rate determination? We now construct a rudimentary structural model of 
the real exchange rate to ask this question. To be consistent with the data, the model should be capable of reproducing the relationship between relative GDP per capita and the real exchange rate, in both cross country and time series dimensions.

We take a two country endowment economy model. Denote the countries as 'Home' and 'Rest of World', with the Home country consumption aggregate defined as

$$
C=\left(\gamma^{\frac{1}{\theta}} C_{T}^{1-\frac{1}{\theta}}+(1-\gamma)^{\frac{1}{\theta}} C_{N}^{1-\frac{1}{\theta}}\right)^{\frac{\theta}{1-\theta}}
$$

where $C_{T}$ and $C_{N}$ represent respectively, the composite consumption of tradable and non-tradable goods. The elasticity of substitution between tradable and non-tradable goods is $\theta$. Tradable consumption in turn is decomposed into consumption of home goods (exportable), and foreign goods (importables), as follows:

$$
C_{T}=\left(\mu^{\frac{1}{\lambda}} \omega^{\frac{1}{\lambda}} C_{X}^{1-\frac{1}{\lambda}}+(1-\omega)^{\frac{1}{\lambda}} C_{M}^{1-\frac{1}{\lambda}}\right)^{\frac{\lambda}{1-\lambda}},
$$

where $\omega$ represents the relative size of the home country, in both population terms, and in the measure of total tradable goods produced in the world economy, and $\lambda$ is the elasticity of substitution between home and foreign tradables. In addition, $\mu \geq 1$ is a home bias parameter, indicating a preference for home goods in tradable consumption, above and beyond the share of such goods in world tradables.

These consumption aggregates imply the following price index definitions:

$$
\begin{gathered}
P=\left(\gamma P_{T}^{1-\theta}+(1-\gamma) P_{N}^{1-\theta}\right)^{\frac{1}{1-\theta}}, \\
P_{T}=\left(\mu \omega P_{X}^{1-\lambda}+(1-\omega) P_{M}^{1-\lambda}\right)^{\frac{1}{1-\lambda}},
\end{gathered}
$$

where $P_{T}$ and $P_{N}$ represent tradable and non-tradable price levels, and $P_{X}$ and $P_{M}$ are retail prices of home exportables and foreign importables. The analogue of the real exchange rate variable $p_{j, t}$ above is defined as the price of the home good, relative to the rest of the world. Thus we define the real exchange rate as:

$$
R E R=\frac{P}{P^{*}}
$$


where an asterisk indicates the 'Rest of World' price level. Since we are focusing purely on a flexible price model, we may ignore the presence of nominal exchange rates. In addition, given that we are primarily interested in accounting for relative prices, and not quantities, we abstract from endogenous labour supply and capital accumulation. The output of non-tradable and tradable goods are assumed to evolve exogenously.

The evidence presented above indicated that relative prices move in proportion to relative GDP for all categories of goods, both tradable and nontradable. In order to account for this, we allow for a difference between wholesale and retail prices. Retail goods in the tradable sector are produced using a combination of raw wholesale goods and non-tradable goods as inputs. This captures the presence of a marketing or distribution sector. There is strong evidence for the role of distribution costs in retail pricing of tradable goods (e.g. Corsetti et al. 2008, and references therein). Here, we assume that the production of consumption retail goods in sectors $X$ and $M$ are produced according to:

$$
\begin{aligned}
C_{X} & =\left(\kappa_{1} I_{X}^{\left(1-\phi_{1}\right)}+\left(1-\kappa_{1}\right) I_{X N}^{1-\phi_{1}}\right)^{\frac{1}{1-\phi_{1}}} \\
C_{M} & =\left(\kappa_{2} I_{M}^{\left(1-\phi_{2}\right)}+\left(1-\kappa_{2}\right) I_{M N}^{1-\phi_{2}}\right)^{\frac{1}{1-\phi_{2}}}
\end{aligned}
$$

where $I_{X}\left(I_{M}\right)$, represents the direct use of wholesale tradable goods in producing retail consumables for $X$ and $M$, respectively, and $I_{X N}\left(I_{M N}\right)$ represents the use of non-tradable distribution services.

The model is closed with the addition of a home country budget constraint, and goods market clearing conditions. The home budget constraint is given by:

$$
P C=P_{X} Y_{X}+P_{N} Y_{N}
$$

where $Y_{X}\left(Y_{N}\right)$ indicates output of good $X(N)$, and it is assumed that there is no intertemporal borrowing or lending across countries. This is a simplifying assumption, but it unlikely to have first order implications for the evolution of the real exchange rate, at least over the sample period in question for European exchange rates. 
Goods market clearing conditions are given as:

$$
\begin{aligned}
\omega Y_{X} & =\omega I_{X}+(1-\omega) I_{X}^{*}, \\
(1-\omega) Y_{M} & =\omega I_{M}+(1-\omega) I_{M}^{*}, \\
Y_{N} & =C_{N}+I_{X N}+I_{M N} \\
Y_{N}^{*} & =C_{N}^{*}+I_{X N}^{*}+I_{M N}^{*} .
\end{aligned}
$$

We use the model to look at the relationship between different real exchange rate measures, as defined above, and relative GDP. In the model without investment or government spending, relative GDP is just defined as relative real consumption, or

$$
\frac{C}{C^{*}}=\frac{P_{X} Y_{X}+P_{N} Y_{N}}{P_{M}^{*} Y_{M}^{*}+P_{N}^{*} Y_{N}^{*}} \frac{P^{*}}{P} .
$$

The relationship between the real exchange rate and relative GDP will obviously depend on the calibration of the model, as well as the assumptions about the drivers of GDP growth. Our approach here is to choose the path of endowments $Y_{X}, Y_{N}, Y_{M}^{*}$, and $Y_{N}^{*}$ to exactly replicate the relative GDP per capita position for each country over the historical sample path. Given the calibration, and simulating the two country equilibrium model, this will imply a path of the real exchange rate for each country. For each country, we can then compare the simulated path for the real exchange rate with that of the historical sample path, for each country.

For our calibration, we take a very standard set of parameter values. As regards sectoral shares, we set $\gamma=0.7$ so that the non-tradable goods sector would represent thirty percent of consumption in a steady state with $P_{N}=P_{T}=1$. Assume that the home country is relatively small as a part of the European economy, so that $\omega=0.1$. For now, we abstract away from home bias in preferences, so that $\mu=1$ is assumed. We assume that distribution services make up approximately 30 percent of the value-added in the consumption of retail tradable goods, so that $\kappa_{1}=\kappa_{2}=0.7$. This, in combination with $\gamma=0.7$, implies that in total, non-traded goods would make up 50 percent of total production in a steady state with $P_{N}=P_{T}=1$.

As regards elasticities, we use the standard assumption of a low elasticity between tradable and non-tradable goods, in both final consumption and in distribution services. We follow Mendoza (1995), and use an elasticity of 0.65. Thus, we set $\lambda=\phi_{1}=\phi_{2}=0.65$. Finally, the elasticity of substitution between home and foreign goods is an important parameter. If this 
elasticity is too low, then economic growth will lead to a large terms of trade deterioration and a real exchange rate depreciation, even if growth is quite concentrated in the traded goods sector. The recent literature has emphasized a distinction between short run and long run elasticities of substitution (e.g. Ruhl 2008). For annual data, the international business cycle literature has typically used elasticities lower than the long run estimates. We follow this lead, and set $\theta=2$. This is lower than estimates of 5 or 6 found in long run trade estimates, but in the range of the estimates used in the macro literature. In fact, the results are not particularly sensitive to different values of $\theta$ in the range of 2 to 5 .

We wish to examine the implications of differential levels and growth rates of relative GDP on real exchange rates. Given all other parameters in the model, the real exchange rate will depend on cross-country differences in the relative supply of exportables to non-tradables within a country. Even if the home country's GDP per capita was lower than that of the rest of the world, this would not necessarily imply a lower real exchange rate unless it also implied that the ratio of tradable goods to non-tradable goods, at the wholesale level, was also less than that in the rest of the world. Likewise, growth over time in relative GDP per capita will be associated with real appreciation only if the growth rate of tradable goods exceeds that of non-tradable goods. Although our model does not include endogenous labour supply or capital accumulation, the interaction between GDP and the real exchange rate are identical to those implied by the Balassa-Samuelson model, which explicitly incorporates these features, and focuses on the real exchange rate process as being driven by productivity growth differentials across sectors.

Our results above indicate an empirical elasticity of the real exchange rate to relative GDP per capita of 0.35 to 0.4 , both across countries and over time. We use the model to reproduce this elasticity in both dimensions. Since there is no physical capital and no borrowing or lending, then the comparison of two periods with different values of GDP per capita is equivalent to a comparison of two small countries, both interacting with the rest of the world, but one country having the same difference in GDP per capita relative to the other country.

The key aspect of the model calibration is to determine the relationship between growth in real GDP per capita and movements in the real exchange rate. Without loss of generality, we set the ratio of $Y_{M}$ to $Y_{N}^{*}$ in the rest of the world economy to unity, and assume a zero growth rate in $Y_{M}$ and $Y_{N}^{*}$. This is simply a benchmark for comparison with the home economy, and 
neatly accords with the data, which is expressed in relative terms. Then, we assume that process for $Y_{N}$ in the home economy is given by:

$$
Y_{N}=a Y^{b}
$$

where $a$ is a constant, $Y$ is real GDP per capita, relative to the rest of the world, and $b$ satisfies $0 \leq b \leq 1$. The solution procedure involves preassigning $Y$, substituting for (5), and then solving (??),(3), and (4) for the 6 variables $C, C^{*}, P_{N}, P_{N}^{*}, P_{M}^{*}$, and $Y_{X}$, with the home traded good $X$ taken as the numeraire. The combination of parameters $a$ and $b$ determine the level and the slope of the real exchange rate locus as a function of $Y$, for any given time, or the evolution of the real exchange rate over time, as $Y$ moves along its historical path. More specifically, if we take the case $a=Y_{M}=Y_{N}^{*}=1$, then for $Y=1$, it must be that $R E R=1$, since all endowments are equal across sectors and countries in this case, and by symmetry, full PPP holds. On the other hand, if $b=1$ then the real exchange rate is constant (not necessarily equal to unity, unless $a=1$ also), since $Y_{N}$ and $Y_{X}$ then move in proportion to one another as relative GDP per capita $(Y)$ moves. That model simulation involves choosing the path of $Y_{X}$ to reproduce the historical series for $Y$, given the condition (5). Lower values of $b$ reduce the proportionate response to $Y_{N}$ to changes in $Y$ as $Y_{X}$ changes, and as a consequence, involve a higher elasticity of the real exchange rate to $Y$. Intuitively, for a low value of $b$, movements in $Y_{X}$ are not accompanied by proportional movements in $Y_{N}$ and hence must be accompanied by greater relative price change.

Since the evidence suggests that, on average, countries with GDP per capita above the EU average (below the EU average) have real exchange rates above (below) unity, in what follows, we choose $a=1$ as a level benchmark. This ensures that the average country has a real exchange rate equal to unity. This leaves the parameter $b$ to be chosen. The estimates above suggest that the elasticity of the real exchange rate to relative GDP in the cross section and time dimension is between 0.35 and 0.4 . The choice of $b$ will determine this elasticity in the model. The elasticity is not independent of the value of $Y$ itself however. For given $b$, the elasticity is higher, for higher $Y$. We choose $b=.7$. This value reproduces an elasticity of 0.39 at the symmetric point $Y=R E R=1$.

Figure 19, illustrates the workings of the model for a case where the home economy is growing relative to the rest of the world at 4 percent per year. The Figure illustrates the path of the home country's relative GDP and the 
real exchange rate. The second panel of the Figure illustrates the analogue of the empirical elasticity of the real exchange rate to relative GDP. It is the ratio of the rate of change of the real exchange rate to the rate of change of relative GDP per capita, as a function of relative GDP per capita (on the $\mathrm{x}$-axis). The simulation illustrates the key properties of the real exchange rate seen in the data - the deviations in relative GDP per capita are larger than the deviations in the real exchange rate from PPP, and as relative GDP per capita transits from below average to above average, the real exchange rate moves from being below $\mathrm{PPP}$ to being above $\mathrm{PPP}$, with the relative GDP per capita locus intersecting the real exchange rate locus from below.

We now take this exact calibration and apply it to to observed GDP data for all countries in the sample. What we are doing then is to use the same calibration for all countries, but solving the model as described above so as to reproduce the observed movements in relative GDP per capita for each country.

One important issue we have not dealt with up to now is the presence of differential tax rates on goods across European countries. VAT rates and other expenditure taxes are not identical in the 31 economies in our sample. This will make a difference to the price comparisons, since retail prices are measured inclusive of taxes. In the initial simulations reported in Figures 20-22, we ignore expenditure taxes. Later on, we incorporate differences in tax rates using published VAT rates for European countries and report how the results are affected by this inclusion.

Figures 20-22 report the initial results for the three groups of countries. Figure 20 gives the path of relative GDP per capita, the historical sample path of the real exchange rate, and the simulated model-generated real exchange rate for the eurozone countries. The evaluation of the model hinges on the closeness of the sample path and the simulated real exchange rates. For all countries except Finland and Luxembourg, the average simulated model real exchange rate is close to the sample average. That is, the model gets the levels right in most cases. In particular, Greece, Spain and Portugal, with relative GDP per capita significantly below the European average, have real exchange rates about 15-20 percent below the European average. The model tracks this very accurately. Likewise the average sample and simulated real exchange rates are very close for the Western European countries.

Of particular interest is the question of how the model tracks the time path of real exchange rate movements. That is, can the model track the dynamics of the real exchange rate? For most countries, the answer is yes. 
The Western European countries that experienced persistent depreciation of the sample were Belgium, Germany, Austria, France, and the Netherlands. The simulated real exchange rates very closely track the historical sample for Belgium Germany and Austria, and are quite close for France and somewhat less close for the Netherlands. As these countries experienced declines in their relative GDP per capita, the magnitude of real exchange rate depreciation implied by the model is very accurately accounted for by the model. The opposite phenomenon takes place for the Ireland simulation. The model very accurately tracks the path of real appreciation in Ireland, following the transition in relative GDP from below the European average to above the European average. In both cases (i.e. for Western European countries and for Ireland), we see exactly the same transition in the model as in the data - for countries moving from below (above) the European average to below (above) the European average, the real exchange rate follows the same process, and the relative GDP line cuts the RER locus from below (above). Italy presents a puzzle, from the point of view of the model. Italy experienced considerable real appreciation over the sample, almost as much as Ireland. But Italy's relative per capita GDP growth stalled in the late 1990's, and thereafter fell back. This is not seen in the behaviour of the Italian real exchange rate.

Figure 21 presents the same information for the floating exchange rate countries. The model-generated real exchange rate for Switzerland is very close to that in the data. For the UK, the model real exchange rate follows the rising income over the sample path, but fails to account for the extent of the UK real appreciation in the late 1990's. For the Scandinavian countries; Iceland, Sweden, Norway, and Denmark, the sample real exchange rate is substantially above that produced by the model simulation - as was the case for Finland in Figure 20. It seems that prices in these countries are much higher than could be accounted for by the basic sectoral demand effects generated by our model. When we extend the analysis to allow for differential rates of VAT below however, we see that the model offers an improved picture for these countries.

Figure 22 illustrates the path of real GDP, simulated and sample real exchange rates for the countries of Eastern and Southern Europe over the shorter, 1999-2007 sample. As we noted previously, these countries have very low real exchange rates relative to the EU15. Despite this, the modelsimulated exchange rate fits remarkably well for most countries. With the exception of Cyprus, Turkey, and Malta, in all cases, the average real ex- 
change rate produced by the model over the sample is very close to that in the data, so that, in level terms, the model can quite accurately account for the real exchange rates for Eastern and Southern European countries. But in addition, in all cases, the model quite accurately captures the process of real appreciation over the sample path. In the model, this is driven by the catch-up process of economic growth, which is driven by the historical sample path of increasing relative GDP per capita experienced by these countries.

From these three groups of countries we may conclude that a bare-bones, rudimentary endowment economy model of real exchange rate determination, driven by differential sectoral growth rates produces a real exchange rate path remarkably close to the observed historical sample path of real exchange rates for most of the 31 European countries in our sample. It is worth emphasizing that the model simulations are not calibrated country by country. In each case, the simulated model is based on exactly the same calibration. Moreover, the key driver of the real exchange rate in all cases is the assumption implicit in equation (5), which contains only a single parameter - the elasticity of the growth rate of non-tradable goods to changes in real GDP. We set this parameter to 0.7, the same for all 31 countries, independently of substantial differences in per capita GDP levels across countries. Despite this extreme simplicity in calibration, the model does a very good job of reproducing both the levels and time paths of most country's real exchange rates.

The real exchange rate in the theoretical model is proportional to the relative price of non-traded to traded goods. As relative GDP per capita rises, this relative price rises, driving up the overall price level, relative to the rest of the world. In a celebrated paper, Engel (1999) questions whether much real exchange rate variation can be attributed to movements in the internal relative price of goods within countries, as opposed to movements in the relative prices of all goods across countries. In our model, as in the data, growth in relative GDP per capita will drive up the prices of both traded and non-traded goods, relative to the rest of the world. Thus, the movement in the internal relative price will be less than the overall movement in the real exchange rate. Nevertheless, it is still true the model implies that an appreciating real exchange rate will be accompanied by a rising relative price of non-traded to traded goods. Figure 23 shows that for most countries in our sample, the path of this relative price in the data follows the path of the real exchange rate. Countries in Western Europe that had persistent real appreciation experienced, for the most part, declining relative prices of 
nontraded goods, whereas countries that had persistent appreciation over the sample display, on average, increases in the relative price of nontraded goods. 13

We noted above that the simple simulation model did not account for differential VAT rates across different European countries. While all countries make extensive use of VAT as a revenue raising device, the tax rates differ considerably across countries. Southern European countries such as Greece, Spain and Portugal generally have low rates of VAT, while Scandinavian countries have high VAT rates. Table 6 shows estimates of VAT rates for the full sample of countries.

How does the presence of VAT affect our results for the real exchange rate? We explore this by incorporating VAT explicitly into the model. We make the simplifying assumption that VAT is set at a uniform rate on all goods, domestic and imported. Thus, taxes do not affect the relative price of any good faced by consumers in the model. It then follows that we can adjust the real exchange rates implied by the model by the difference between each countries effective VAT rate and that of the European average.

Figures 26 - 28 illustrate the results when the model is extended to allow for differential VAT rates. The adjustment affects only the levels, and not the rate of changes of the simulated real exchange rates. Broadly speaking, the results are as before. The main difference is that the real exchange rates of the Scandinavian countries no longer look so anomalous, relative to the model-generated real exchange rates. In particular, Norways model generated real exchange rate is very close to that of the historical sample. On the other hand, for some European countries (e.g. France, and Germany) the model generated real exchange rate is somewhat less than that of the historical sample. Among the floating exchange rate countries, Switzerland's real exchange rate now looks somewhat anomalous, since Switzerland has a relatively low VAT rate. Finally, the results for the Eastern and Southern

\footnotetext{
${ }^{13}$ We do not try to match this relative price with the model, since we may not be fully confident in our choice of non-traded goods categorization, and our calibration of the size of the distribution sector employing non-traded goods. Despite this ambiguity, our simulation for the aggregate real exchange rate will remain relatively unchanged by alternative values for these structural parameters. The reason is that the key aspect of the calibration is to adjust the parameter $\mathrm{b}$ in (5) so as to reproduce the elasticity of the real exchange rate to relative GDP per capita. Once this is set to match the data, the simulated real exchange rate in the model will behave in a manner very similar to Figures 20-22, and so will closely match the historical sample path
} 
European countries are not much changed. Overall, we can conclude that the incorporation of differential VAT rates into the model does not substantially change the good performance of the model in accounting for the pattern of real exchange rates in Europe.

\section{Conclusions}

This paper has explored the characteristics of European real exchange rates at both an aggregated and disaggregated level, using a new micro data set on prices of a large number of consumer goods for a broad sample of European countries over a thirteen year period. The key advantage of the data-set is that it allows for an explicit comparison of price levels across countries, so that we can explore the characteristics of real exchange rates in the cross section and the time series. Our results showed that there is a substantial departure from the PPP at both the aggregate and disaggregate levels, both in the euro area countries and the non-euro countries. Moreover, with the exception of the emerging Eastern European countries, there is little in the data to suggest that departures from PPP are diminishing over time.

While real exchange rates display continuing departure from PPP, we find that both in the cross section and time series, relative GDP per capita can explain a substantial part of the variation in European real exchange rates, for both the eurozone countries, the floating exchange rate countries, and the emerging countries of Eastern Europe.

Finally, we employed a simple textbook general equilibrium model of the real exchange rate, in which real exchanges were driven by differential growth rates in traded relative to non-traded sectors. When we simulate the model to match the historical sample path of relative GDP for each country in our sample, we find that, for most countries, the implied path of the real exchange rate is remarkably close to the sample real exchange rate, both in levels and rates of change over time. 


\section{References}

[1] James E. Anderson and Eric van Wincoop. Trade costs. Journal of Economic Literature, 42(3):691-751, September 2004.

[2] Manuel Arellano. Computing robust standard errors for within-group estimators. Oxford Bulletin of Economics and Statistics, 49(4):431-434, November 1987.

[3] Patrick K. Asea and Enrique G. Mendoza. The Balassa-Samuelson model: A general-equilibrium appraisal. Review of International Economics, 2:244 - 267, October 1994.

[4] Jeffrey H. Bergstrand. Structural determinants of real exchange rates and national price levels: Some empirical evidence. American Economic Review, 81(1):325-334, March 1991.

[5] Ariel Burstein, Joao C. Neves, and Sergio Rebelo. Distribution costs and real exchange rate dynamics during exchange-rate-based stabilizations. Journal of Monetary Economics, 50:1189-1214, September 2003.

[6] Carlos Carvalho and Fernanda Nechio. Aggregation and the PPP puzzle in a sticky-price model. Staff Report 351, Federal Reserve Bank of New York, October 2008.

[7] European Comission. VAT rates applied in the member states of the European Community. taxud.d.1(2009)307669 - EN, July 2009.

[8] Mario Crucini and Mototsugu Shintani. Persistence in law-of-one-price deviations: evidence from micro data. Journal of Monetary Economics, 55:629-644, 2008.

[9] Mario Crucini and Chris Telmer. Microeconomic sources of real exchange rate variability. Mimeo, Vanderbilt University, Carnegie Mellon University, April 2007.

[10] Mario Crucini, Chris Telmer, and Marios Zachariadis. Understanding European real exchange rates. American Economic Review, 95(3):724738, June 2005. 
[11] Lukasz A. Drozd and Jaromir B. Nosal. Understanding international prices: Customers as capital. Staff Reports 411, Federal Reserve Bank of Minneapolis, August 2008.

[12] Charles Engel. Accounting for US real exchange rate changes. Journal of Political Economy, 130(3):507-538, June 1999.

[13] Charles Engel and John H. Rogers. How wide is the border? American Economic Review, 86:1112-1125, 1996.

[14] Charles Engel and John H. Rogers. Deviations from purchasing power parity: causes and welfare costs. Journal of International Economics, $55: 29-57,2001$.

[15] Charles Engel and John H. Rogers. European product market integration after the euro. Economic Policy, 39:349-384, July 2004.

[16] Riemer P. Faber and Ad C. J. Stockman. A short history of price level convergence in Europe. Journal of Money, Credit and Banking, 41(23):461-477, March-April 2009.

[17] Task force of the monetary policy committee of the European system of central banks. Competition, productivity and prices in the euro area service sector. Occassional Paper 44, ECB, April 2006.

[18] Jean Imbs, Haroon Mumtaz, Morten O. Ravn, and Helene Rey. PPP strikes back: Aggregation and the real exchange rate. Quarterly Journal of Economics, 120(1):1-43, February 2005.

[19] Enrique G. Mendoza. The terms of trade, the real exchange rate, and economic fluctuations. International Economic Review, 36(1):101-137, 1995.

[20] J. Peter Neary. Determinants of the equilibrium real exchange rate. American Economic Review, 78(1):210-215, March 1988.

[21] Maurice Obstfeld and Kenneth Rogoff. Exchange rate dynamics redux. Journal of Political Economics, 103(3):624-660, 1995.

[22] Kim J. Ruhl. The international elasticity puzzle. Manuscript, March 2008. 
[23] Robert Summers and Alan Heston. The Penn World Table (Mark 5): An expanded set of international comparisons, 1950-1988. Quarterly Journal of Economics, 106(2):327 - 368, May 1991. 


\section{A Appendix: expenditure weights}

Composition of the consumption baskets differs across goods, countries, and time. At the same time, components of inflation are known to co-move strongly with aggregate inflation, suggesting that non-equal weighting should not affect the behaviour of the RER. To explore the degree to which this may influence our results we construct expenditure weights for each good, country, and year, using the local currency expenditures data provided by Eurostat. Specifically, for good $i$, country $j$ and year $t$, we construct a weight $\gamma_{i, j, t}=\frac{\exp p_{i, j}}{\sum_{i}^{M} \exp p_{i, j, t}}$ where exp is the local currency expenditure. We then construct an expenditure-weighted PLI's for all countries using $\gamma_{i, j, t}$, and plot them against the un-weighted PLI's in the figures below.

Equally-weighted and Expenditure-weighted RER's in EU12 countries

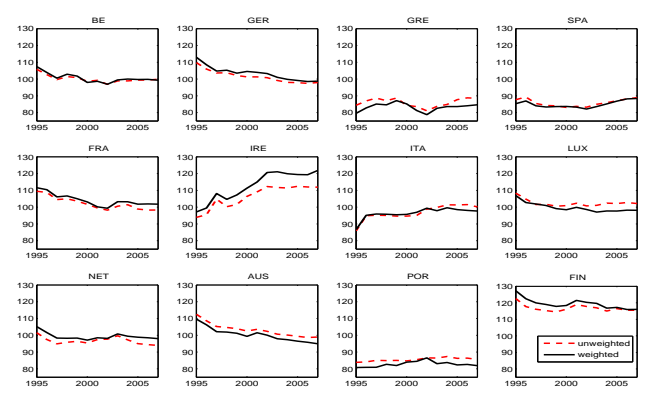

For each country, the figures plot an un-weighted average RER as the red dashed line, as well as the expenditure-weighted RER which is the solid black line. While there are differences between the two, these are small for most countries. Even in situations when there is a level difference between the two, there is a strong co-movement between them. We conclude that our results are not driven by the use of equally-weighted average PLI's.

Weighted and un-weighted RER's in countries with floating currencies and Eastern Europe
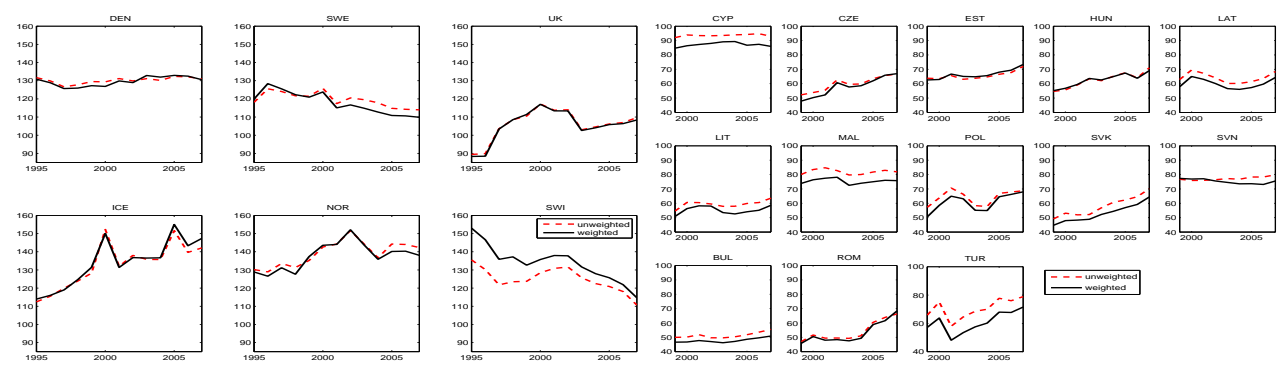


\section{Table 1. PLI basic headings, Household expenditures}

\begin{tabular}{|c|c|c|c|}
\hline $\mathrm{T}$ & Rice & $\mathrm{T}$ & Major tools and equipment \\
\hline $\mathrm{T}$ & Other cereals, flour and other cereal products & $\mathrm{T}$ & Small tools and miscellaneous accessories \\
\hline $\mathrm{T}$ & Bread & $\mathrm{T}$ & Non-durable household goods \\
\hline $\mathrm{T}$ & Other bakery products & NT & Domestic services \\
\hline $\mathrm{T}$ & Pasta products & NT & Household services \\
\hline $\mathrm{T}$ & Beef and Veal & $\mathrm{T}$ & Pharmaceutical products \\
\hline $\mathrm{T}$ & Pork & $\mathrm{T}$ & Other medical products \\
\hline $\mathrm{T}$ & Lamb, mutton and goat & $\mathrm{T}$ & Therapeutical appliances and equipment \\
\hline $\mathrm{T}$ & Poultry & NT & Medical Services \\
\hline $\mathrm{T}$ & Other meats and edible offal & NT & Services of dentists \\
\hline $\mathrm{T}$ & Delicatessen and other meat preparations & NT & Paramedical services \\
\hline $\mathrm{T}$ & Fresh, chilled or frozen fish and seafood & NT & Hospital services \\
\hline $\mathrm{T}$ & Preserved or processed fish and seafood & $\mathrm{T}$ & Motor cars with diesel engine \\
\hline $\mathrm{T}$ & Fresh milk & $\mathrm{T}$ & Motor cars with petrol engine of cubic capacity of less than $1200 \mathrm{cc}$ \\
\hline $\mathrm{T}$ & Preserved milk and other milk products & $\mathrm{T}$ & Motor cars with petrol engine of cubic capacity of $1200 \mathrm{cc}$ to $1699 \mathrm{cc}$ \\
\hline $\mathrm{T}$ & Cheese & $\mathrm{T}$ & Motor cars with petrol engine of cubic capacity of $1700 \mathrm{cc}$ to $2999 \mathrm{cc}$ \\
\hline $\mathrm{T}$ & Eggs and egg-based products & $\mathrm{T}$ & Motor cars with petrol engine of cubic capacity of $3000 \mathrm{cc}$ and over \\
\hline $\mathrm{T}$ & Butter & $\mathrm{T}$ & Motor cycles \\
\hline $\mathrm{T}$ & Margarine & $\mathrm{T}$ & Bicycles \\
\hline $\mathrm{T}$ & Other edible oils and fats & $\mathrm{T}$ & Animal drawn vehicles \\
\hline $\mathrm{T}$ & Fresh or chilled fruit & $\mathrm{T}$ & Spare parts and accessories for personal transport equipment \\
\hline $\mathrm{T}$ & Frozen, preserved or processed fruit & $\mathrm{T}$ & Fuels and lubricants for personal transport equipment \\
\hline $\mathrm{T}$ & Fresh or chilled vegetables other than potatoes & NT & Maintenance and repair of personal transport equipment \\
\hline $\mathrm{T}$ & Fresh or chilled potatoes & NT & Other services in respect of personal transport equipment \\
\hline $\mathrm{T}$ & Frozen, preserved or processed vegetables & NT & Passenger transport by railway \\
\hline $\mathrm{T}$ & Sugar & NT & Passenger transport by road \\
\hline $\mathrm{T}$ & Jams, marmalades and honey & NT & Passenger transport by air \\
\hline $\mathrm{T}$ & Confectionery, chocolate and other cocoa preps & NT & Passenger transport by sea and inland waterway \\
\hline $\mathrm{T}$ & Edible ice, ice cream and sorbet & NT & Combined passenger transport \\
\hline $\mathrm{T}$ & Coffee, tea and cocoa & NT & Other purchased transport services \\
\hline $\mathrm{T}$ & Mineral waters & NT & Postal services \\
\hline $\mathrm{T}$ & Soft drinks and concentrates & $\mathrm{T}$ & Telephone and telefax equipment \\
\hline $\mathrm{T}$ & Fruit and vegetable juices & $\mathrm{nT}$ & Telephone and telefax services \\
\hline $\mathrm{T}$ & Spirits & $\mathrm{T}$ & Equipment for reception, recording and reproduction of sound and pictures \\
\hline $\mathrm{T}$ & Wine & $\mathrm{T}$ & Photographic and cinematographic equipment and optical instruments \\
\hline $\mathrm{T}$ & Beer & $\mathrm{T}$ & Information processing equipment \\
\hline $\mathrm{T}$ & Tobacco & $\mathrm{T}$ & Pre-recorded recording media \\
\hline $\mathrm{T}$ & Narcotics & $\mathrm{T}$ & Unrecorded recording media \\
\hline $\mathrm{T}$ & Other clothing and clothing accessories & NT & Repair of audio-visual, photographic and information processing equipment \\
\hline $\mathrm{T}$ & Clothing materials & $\mathrm{T}$ & Major durables for outdoor recreation \\
\hline $\mathrm{T}$ & Men's clothing & $\mathrm{T}$ & Musical instruments and major durables for indoor recreation \\
\hline $\mathrm{T}$ & Women's clothing & NT & Maintenance and repair of other major durables for recreation and culture \\
\hline $\mathrm{T}$ & Childrens and infants clothing & $\mathrm{T}$ & Games, toys and hobbies \\
\hline $\mathrm{T}$ & Other clothing and clothing accessories & $\mathrm{T}$ & Equipment for sport, camping and open-air recreation \\
\hline NT & Cleaning, repair and hire of clothing & $\mathrm{T}$ & Gardens, plants and flowers \\
\hline $\mathrm{T}$ & Men's footwear & $\mathrm{T}$ & Pets and related products \\
\hline $\mathrm{T}$ & Women's footwear & $\mathrm{T}$ & Veterinary and other services for pets \\
\hline $\mathrm{T}$ & Children's and infant's footwear & NT & Recreational and sporting services \\
\hline NT & Repair and hire of footwear & NT & Photographic services \\
\hline NT & Actual rentals for housing & NT & Other cultural services \\
\hline NT & Imputed rentals for housing & $\mathrm{T}$ & Games of chance \\
\hline $\mathrm{T}$ & Materials for maintenance and repair of dwelling & $\mathrm{T}$ & Books \\
\hline NT & Services for maintenance and repair of dwelling & $\mathrm{T}$ & Newspapers and periodicals \\
\hline $\mathrm{T}$ & Water supply oils and fats & $\mathrm{T}$ & Miscellaneous printed matter, stationery and drawing materials \\
\hline NT & Miscellaneous services relating to the dwelling & $\mathrm{T}$ & Package holidays \\
\hline $\mathrm{T}$ & Electricity & NT & Pre-primary and primary education \\
\hline $\mathrm{T}$ & Gas & NT & Secondary education \\
\hline $\mathrm{T}$ & Liquid fuels & NT & Post-secondary education \\
\hline $\mathrm{T}$ & Solid fuels & NT & Tertiary education \\
\hline $\mathrm{T}$ & Heat energy & NT & Education not definable by level \\
\hline $\mathrm{T}$ & Kitchen furniture & NT & Restaurant services whatever the type of establishment \\
\hline $\mathrm{T}$ & Bedroom furniture & NT & Pubs, bars, cafs, tea rooms and the like \\
\hline $\mathrm{T}$ & Living-room and dining-room furniture & NT & Canteens \\
\hline $\mathrm{T}$ & Other furniture and furnishings & NT & Accommodation services \\
\hline $\mathrm{T}$ & Carpets and other floor coverings & NT & Hairdressing salons and personal grooming establishments \\
\hline NT & Repair of furniture, furnishings and floors & $\mathrm{T}$ & Electric appliances for personal care \\
\hline $\mathrm{T}$ & Household textiles & $\mathrm{T}$ & Other appliances, articles and products for personal care \\
\hline $\mathrm{T}$ & Major household appliances electric or not & NT & Prostitution \\
\hline NT & Repair of furniture, furnishings and floors & $\mathrm{T}$ & Jewellery, clocks and watches \\
\hline $\mathrm{T}$ & Household textiles & $\mathrm{T}$ & Other personal effects \\
\hline $\mathrm{T}$ & Major household appliances electric or not & NT & Social protection \\
\hline $\mathrm{T}$ & Small electric household appliances & NT & Insurance \\
\hline NT & Repair of household appliances & NT & Net purchases abroad \\
\hline \multirow[t]{2}{*}{$\mathrm{T}$} & Glassware, tableware and household utensils & NT & Other financial services n.e.c. \\
\hline & & NT & Other services n.e.c. \\
\hline
\end{tabular}


Table 2: Mean standard deviation of disaggregated real exchange rates

\begin{tabular}{rr|rr|rr|rr} 
Belgium & 6.2 & Netherlands & 7.1 & Cyprus & 6.5 & Slovenia & 7.5 \\
Denmark & 7 & Austria & 5.7 & Czech Rep. & 6.9 & Bulgaria & 5.8 \\
Germany & 5.5 & Portugal & 7.8 & Estonia & 5.5 & Romania & 7.8 \\
Greece & 7.7 & Finland & 6.1 & Hungary & 7.8 & Turkey & 6.1 \\
Spain & 6.1 & Sweden & 8.2 & Latvia & 5.9 & & \\
France & 6.3 & United Kingdom & 9.7 & Lithuania & 6.7 & & \\
Ireland & 7.7 & Iceland & 13.2 & Malta & 7.2 & & \\
Italy & 7.6 & Norway & 8.8 & Poland & 7.1 & & \\
Luxembourg & 6.5 & Switzerland & 6.4 & Slovakia & 6.9 & & \\
\hline
\end{tabular}



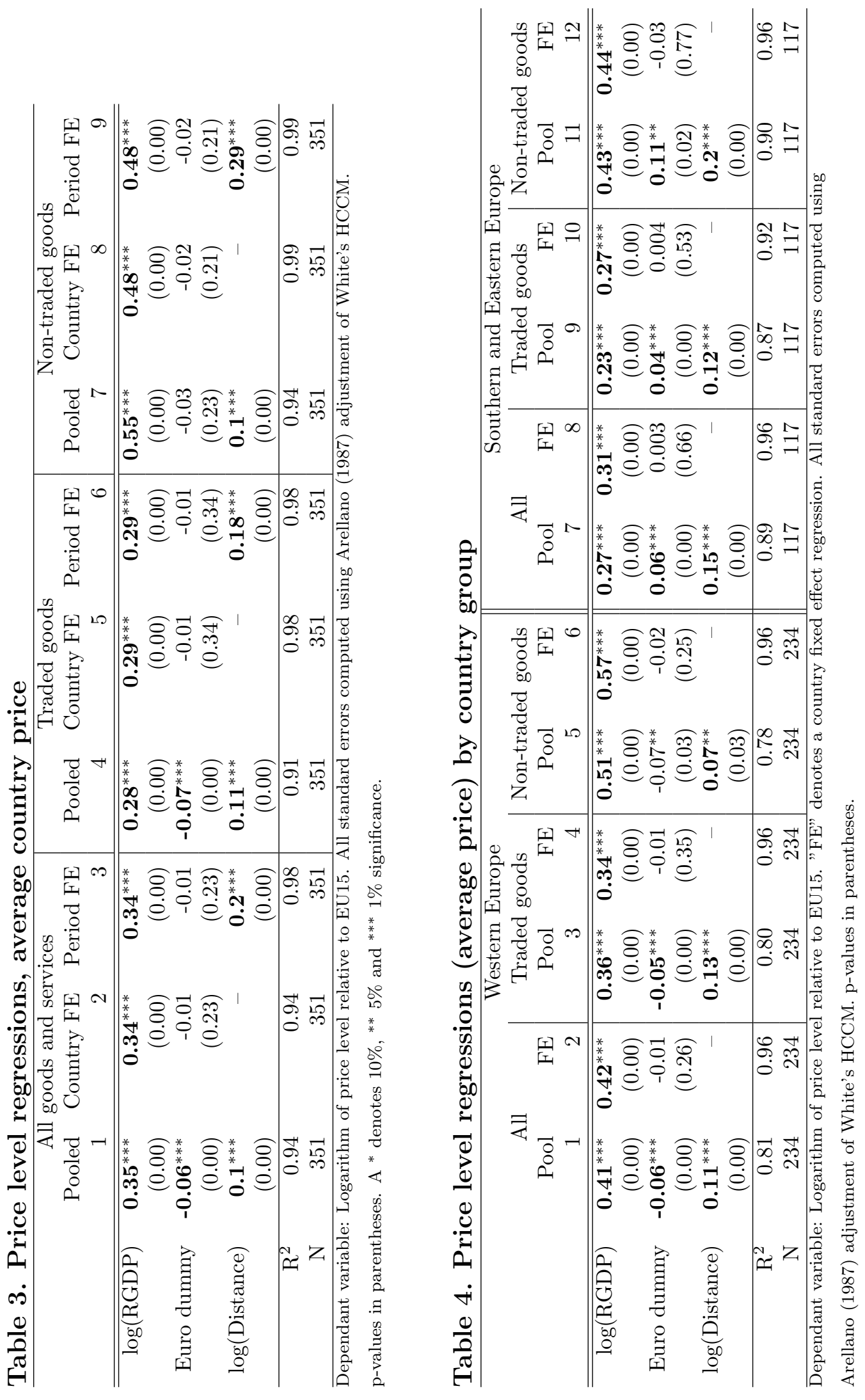
Table 5. Price level regressions, all prices

\begin{tabular}{|c|c|c|c|c|c|c|c|}
\hline & \multicolumn{3}{|c|}{ All goods } & \multicolumn{2}{|c|}{ Traded } & \multicolumn{2}{|c|}{ Non-Traded } \\
\hline & \multirow{2}{*}{$\begin{array}{r}\text { Pooled } \\
1\end{array}$} & \multicolumn{2}{|c|}{ Country dummies } & \multirow{2}{*}{$\begin{array}{r}\text { Pooled } \\
4\end{array}$} & \multirow{2}{*}{$\begin{array}{r}\mathrm{CD} \\
5\end{array}$} & \multirow{2}{*}{$\begin{array}{r}\text { Pooled } \\
6\end{array}$} & \multirow{2}{*}{$\begin{array}{r}\mathrm{CD} \\
7\end{array}$} \\
\hline & & 2 & 3 & & & & \\
\hline \multirow[t]{2}{*}{$\log ($ RGDP $)$} & $0.40^{* * *}$ & $0.39^{* * *}$ & $0.39^{* * *}$ & $0.29^{* * *}$ & $0.35^{* * *}$ & $0.61^{* * *}$ & $\overline{0.53^{* * *}}$ \\
\hline & $(0.00)$ & $(0.00)$ & $(0.00)$ & $(0.00)$ & $(0.00)$ & $(0.00)$ & $(0.00)$ \\
\hline \multirow[t]{2}{*}{ Euro dummy } & $-0.04^{* * *}$ & $-0.01^{* * *}$ & $-0.01^{* * *}$ & $-0.06^{* * *}$ & $-0.01^{* *}$ & $-0.02^{* *}$ & $-0.02^{* *}$ \\
\hline & $(0.00)$ & $(0.00)$ & $(0.00)$ & $(0.00)$ & $(0.03)$ & $(0.02)$ & $(0.04)$ \\
\hline \multirow[t]{2}{*}{$\log ($ Distance $)$} & $0.11^{* * *}$ & - & 0.23 & $0.11^{* * *}$ & - & $0.11^{* * *}$ & $0.38^{*}$ \\
\hline & $(0.00)$ & & $(0.14)$ & $(0.00)$ & & $(0.00)$ & $(0.09)$ \\
\hline $\mathrm{R}^{2}$ & 0.48 & 0.50 & 0.50 & 0.43 & 0.45 & 0.67 & 0.71 \\
\hline $\mathrm{N}$ & 51,246 & 51,246 & 51,246 & 34,047 & 34,047 & 17,199 & 17,199 \\
\hline
\end{tabular}


Table 6. Value Added Tax rates

\begin{tabular}{ll}
\hline \hline Country & VAT rate (in \%) \\
\hline Belgium & 21.0 \\
Germany & 19.0 \\
Greece & 19.0 \\
Spain & 16.0 \\
France & 19.6 \\
Ireland & 21.5 \\
Italy & 20.0 \\
Luxembourg & 15.0 \\
Netherlands & 19.0 \\
Austria & 20.0 \\
Portugal & 20.0 \\
Finland & 22.0 \\
Denmark & 25.0 \\
Sweden & 25.0 \\
UK & 15.0 \\
Iceland & 24.5 \\
Norway & 25.0 \\
Switzerland & 7.6 \\
Cyprus & 15.0 \\
Czech Republic & 19.0 \\
Estonia & 20.0 \\
Hungary & 25.0 \\
Latvia & 21.0 \\
Lithuania & 21.0 \\
Malta & 18.0 \\
Poland & 22.0 \\
Slovakia & 19.0 \\
Slovenia & 20.0 \\
Bulgaria & 20.0 \\
Romania & 19.0 \\
Turkey & 18.0 \\
\hline \hline
\end{tabular}


Figure 1: Examples of prices
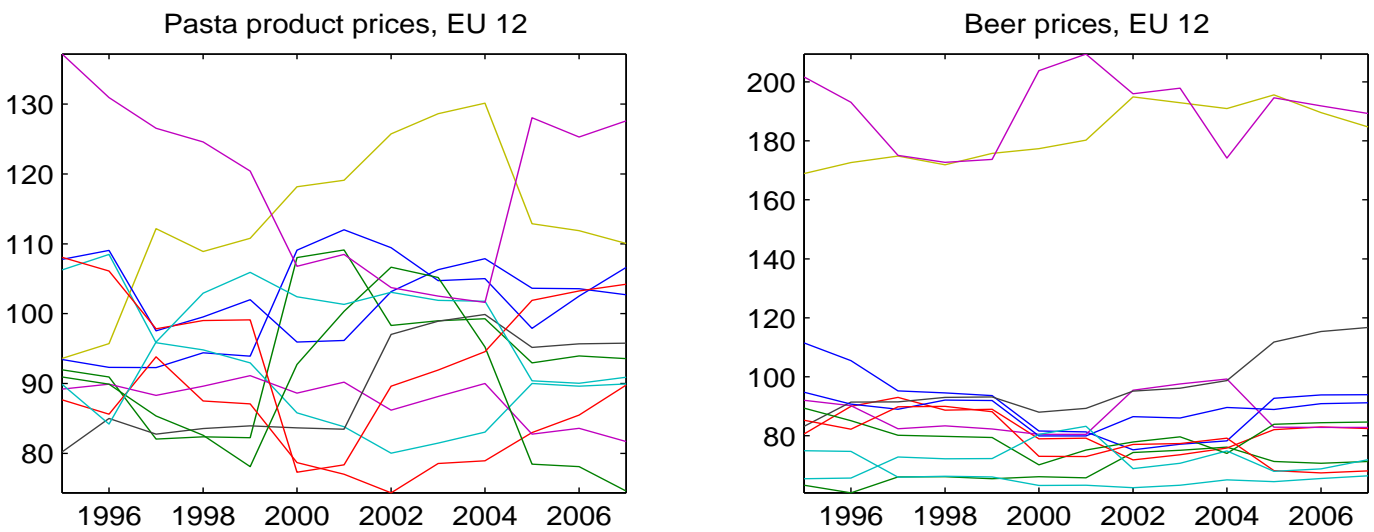

Pasta product prices, floating ER countries
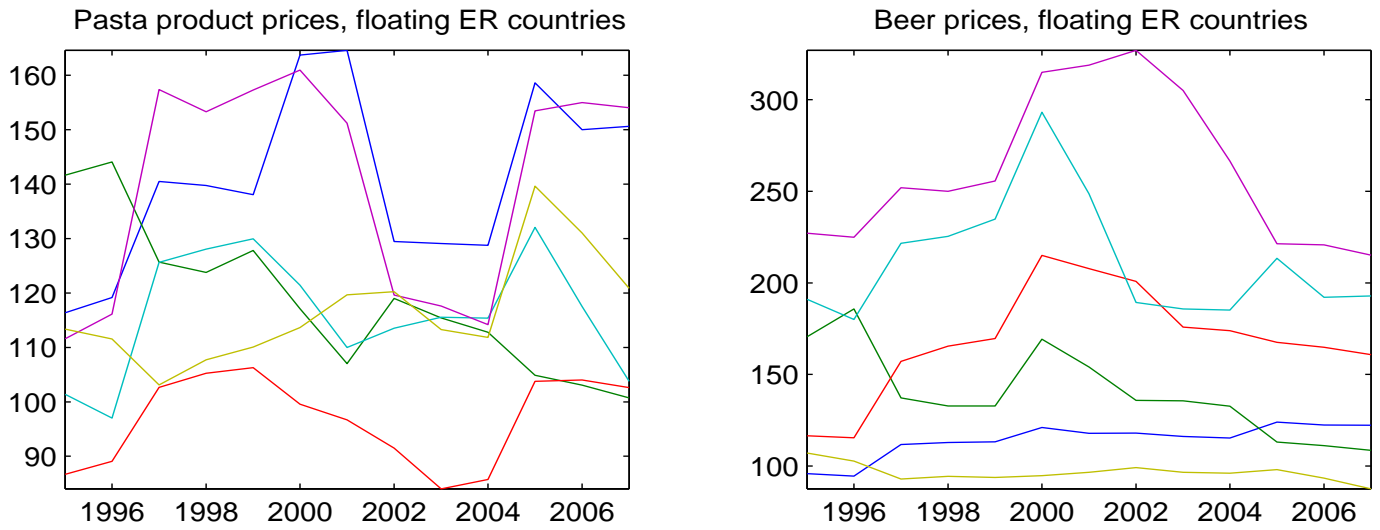

Pasta product prices, Southern and Eastern Europe

Beer prices, Southern and Eastern Europe
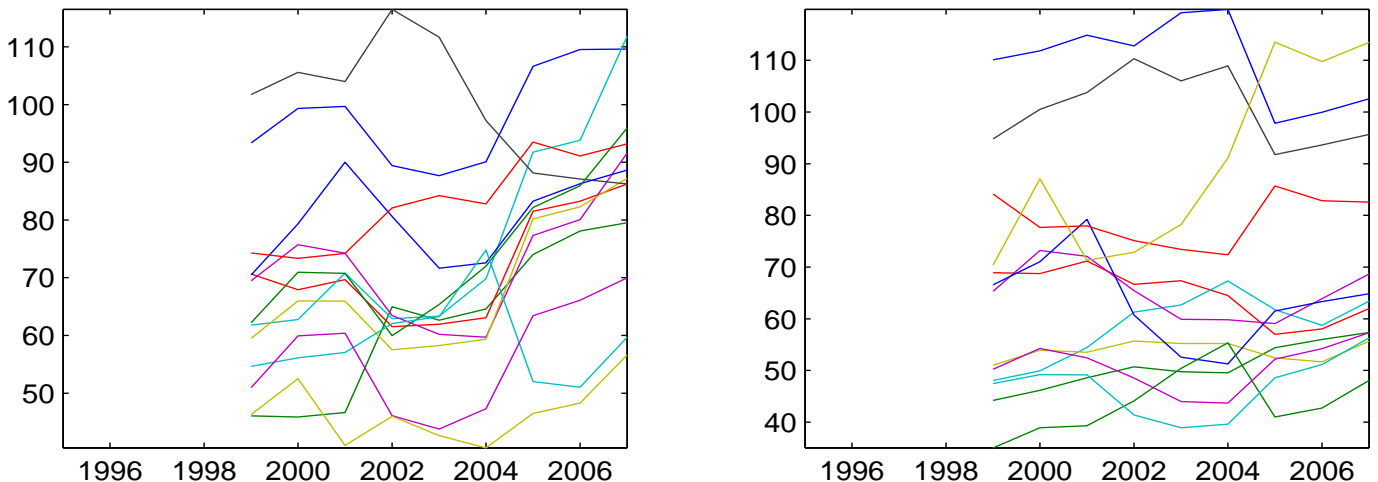
Figure 2: Average PLI's
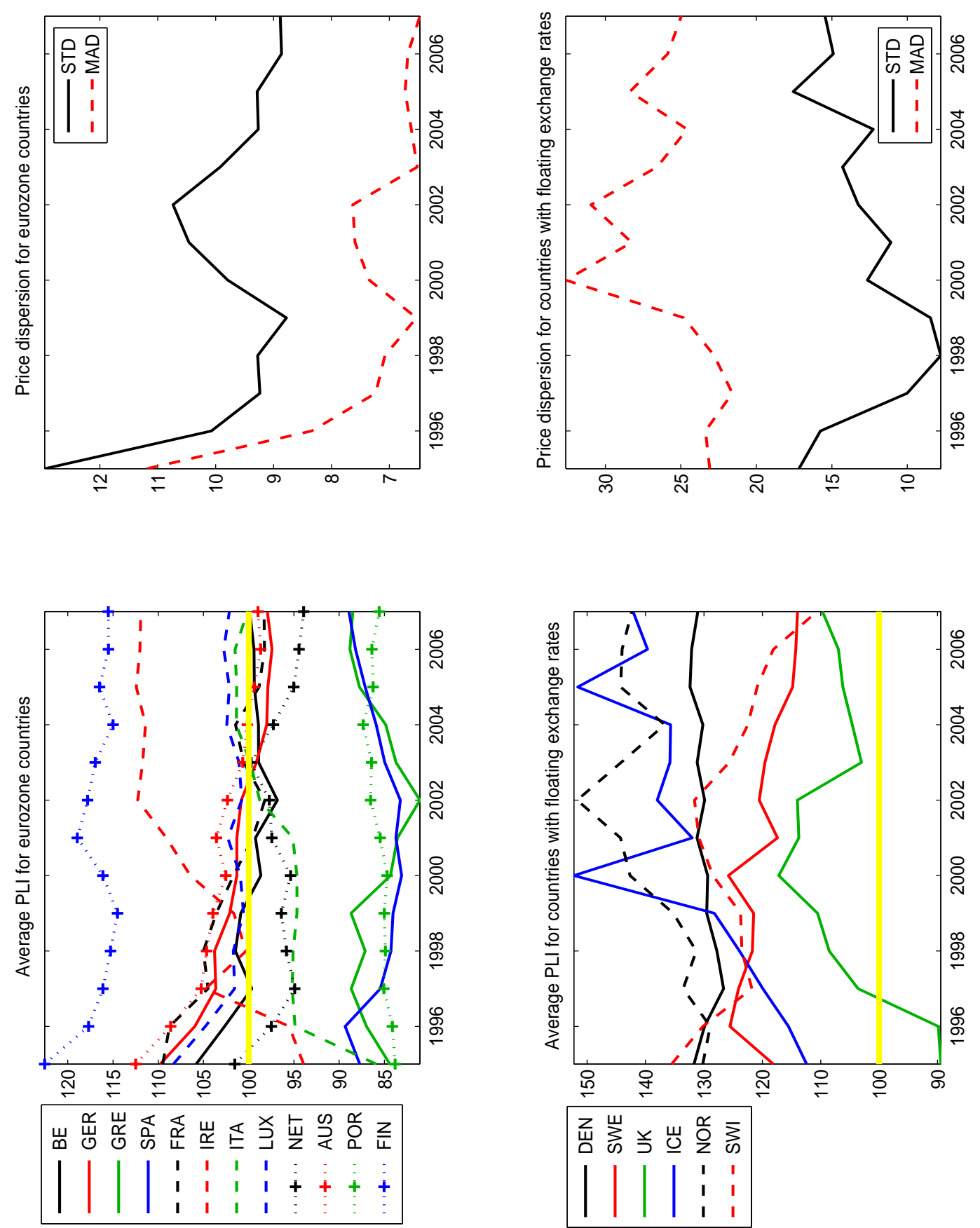
Figure 3: Price dispersion between eurozone countries without Ireland

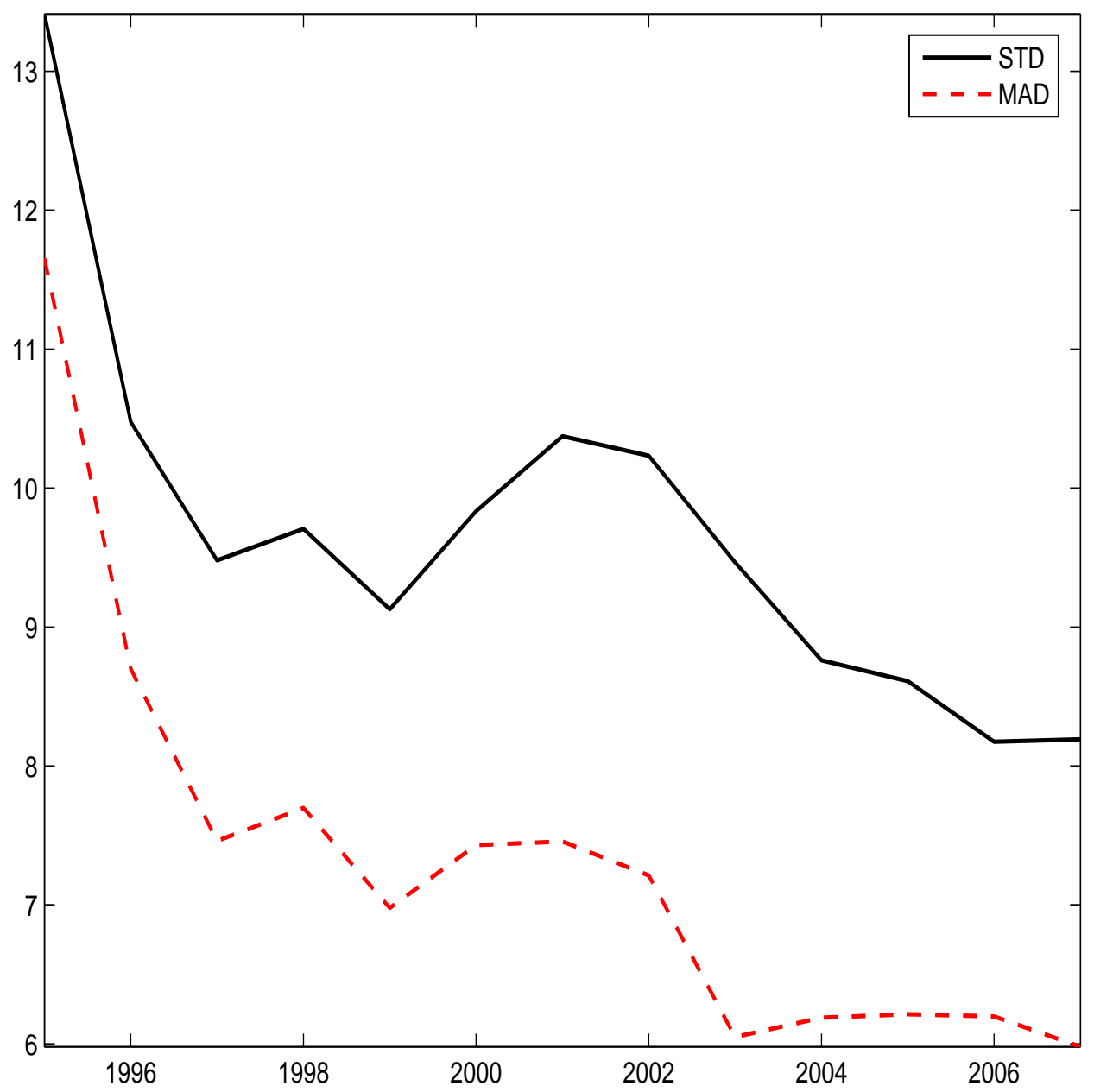


Figure 4: Average PLI's in Southern and Eastern Europe
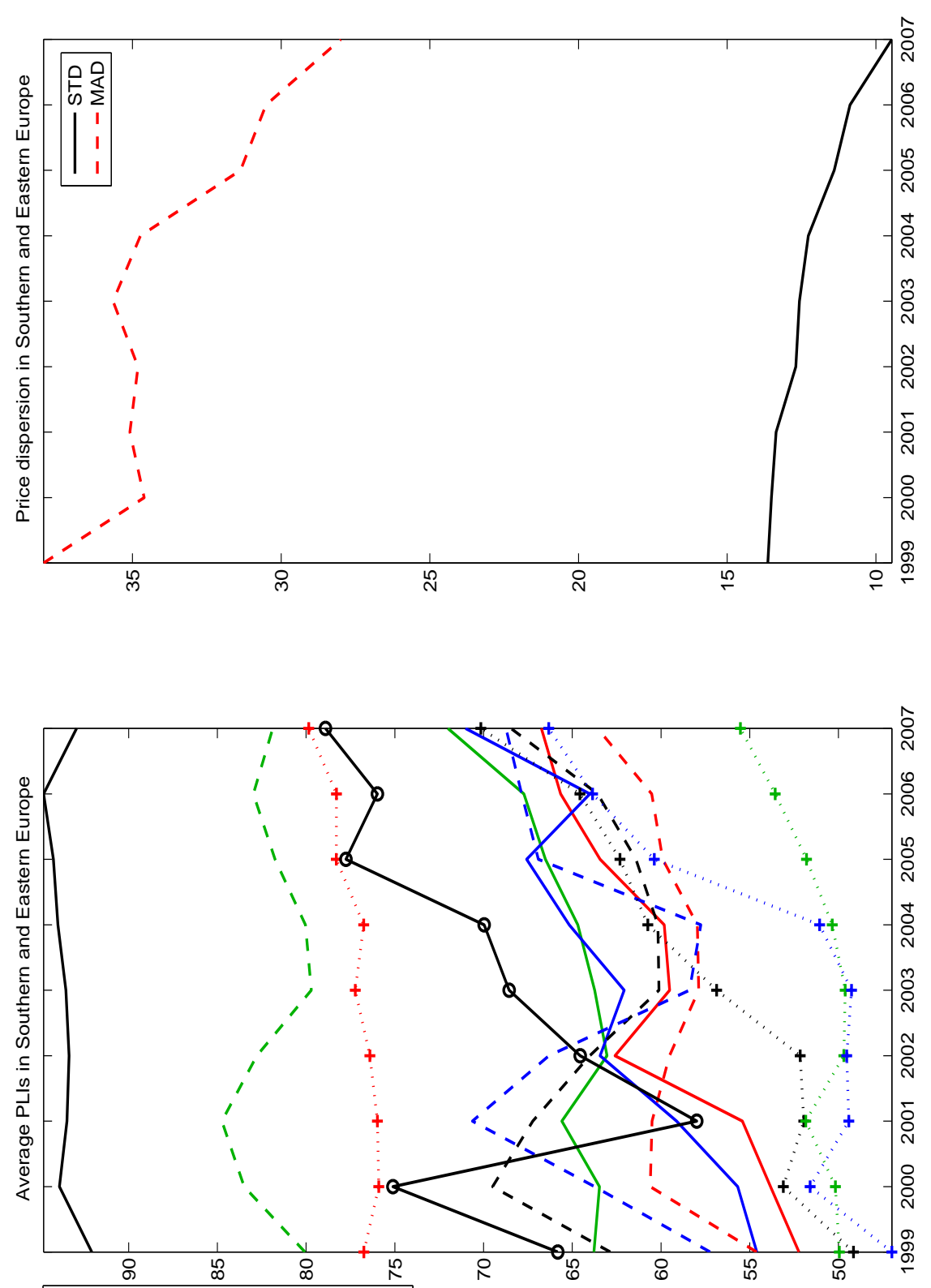

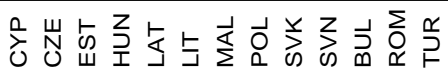

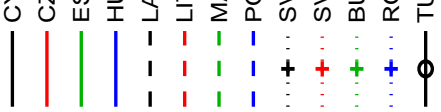


Figure 5: Prices of 146 goods and services vis-a-vis EU15 mean, Western Europe
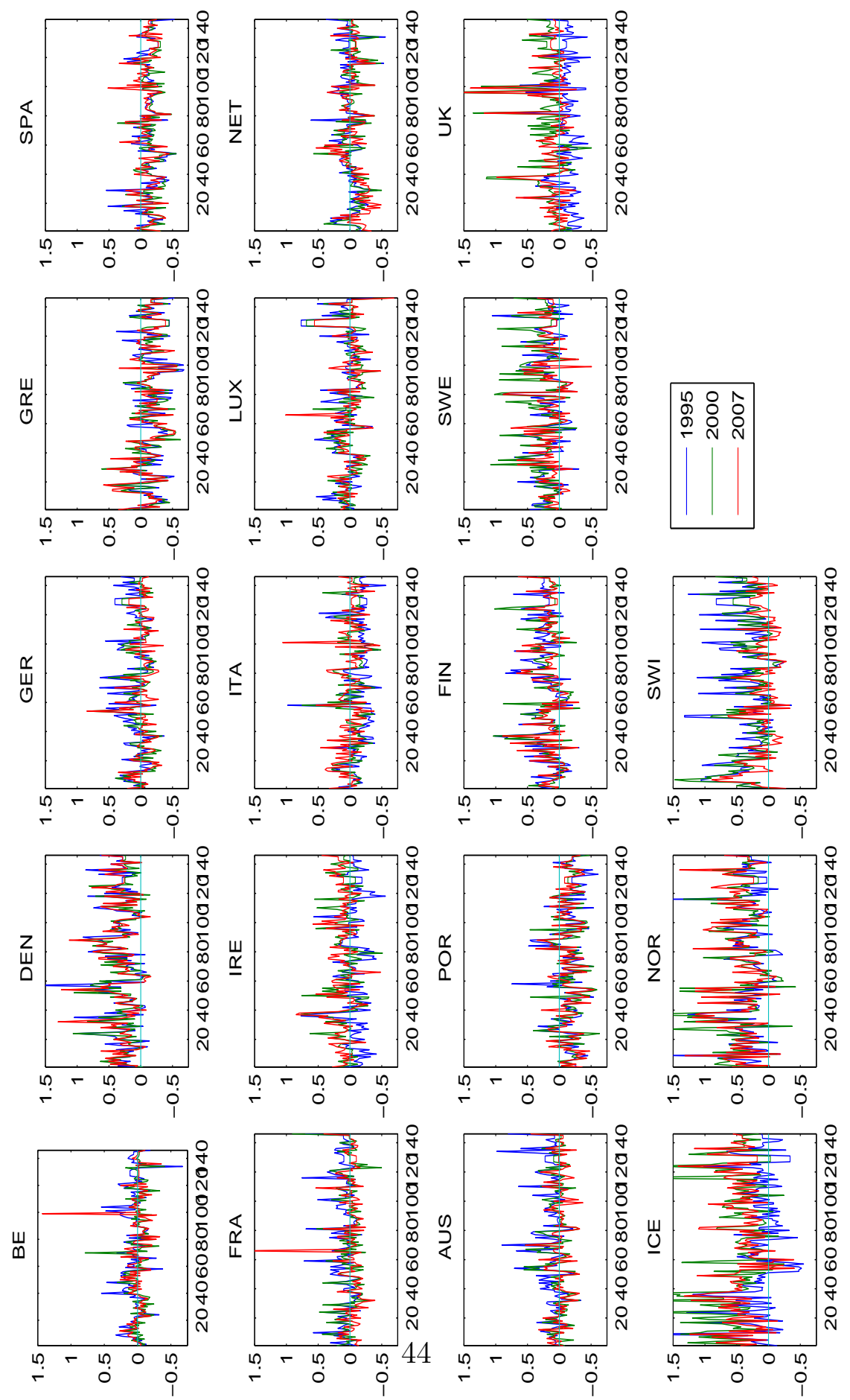
Figure 5 continued: Prices of 146 goods and services vis-a-vis EU15 mean, Southern and Eastern Europe
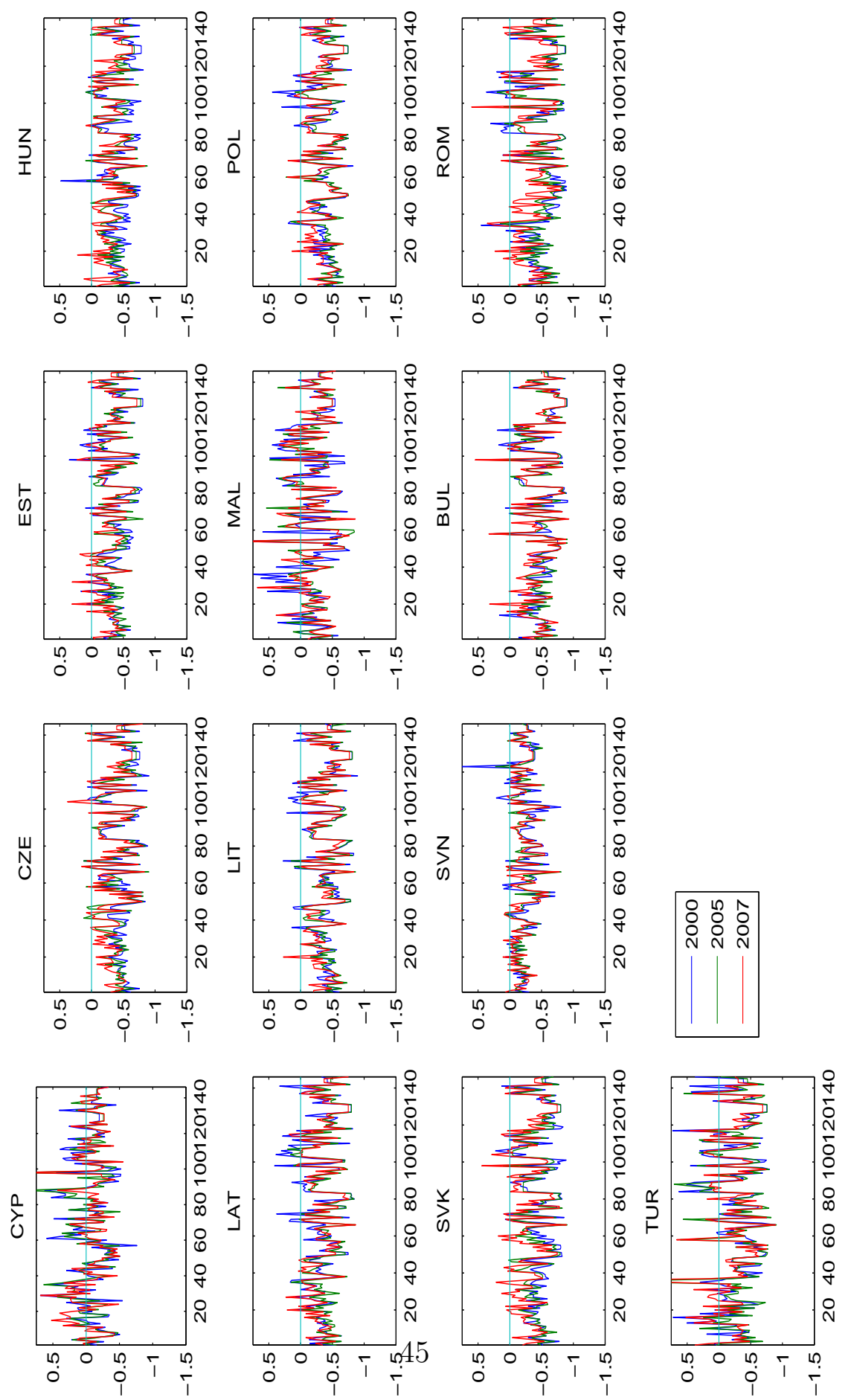
Figure 6: Dispersion within countries
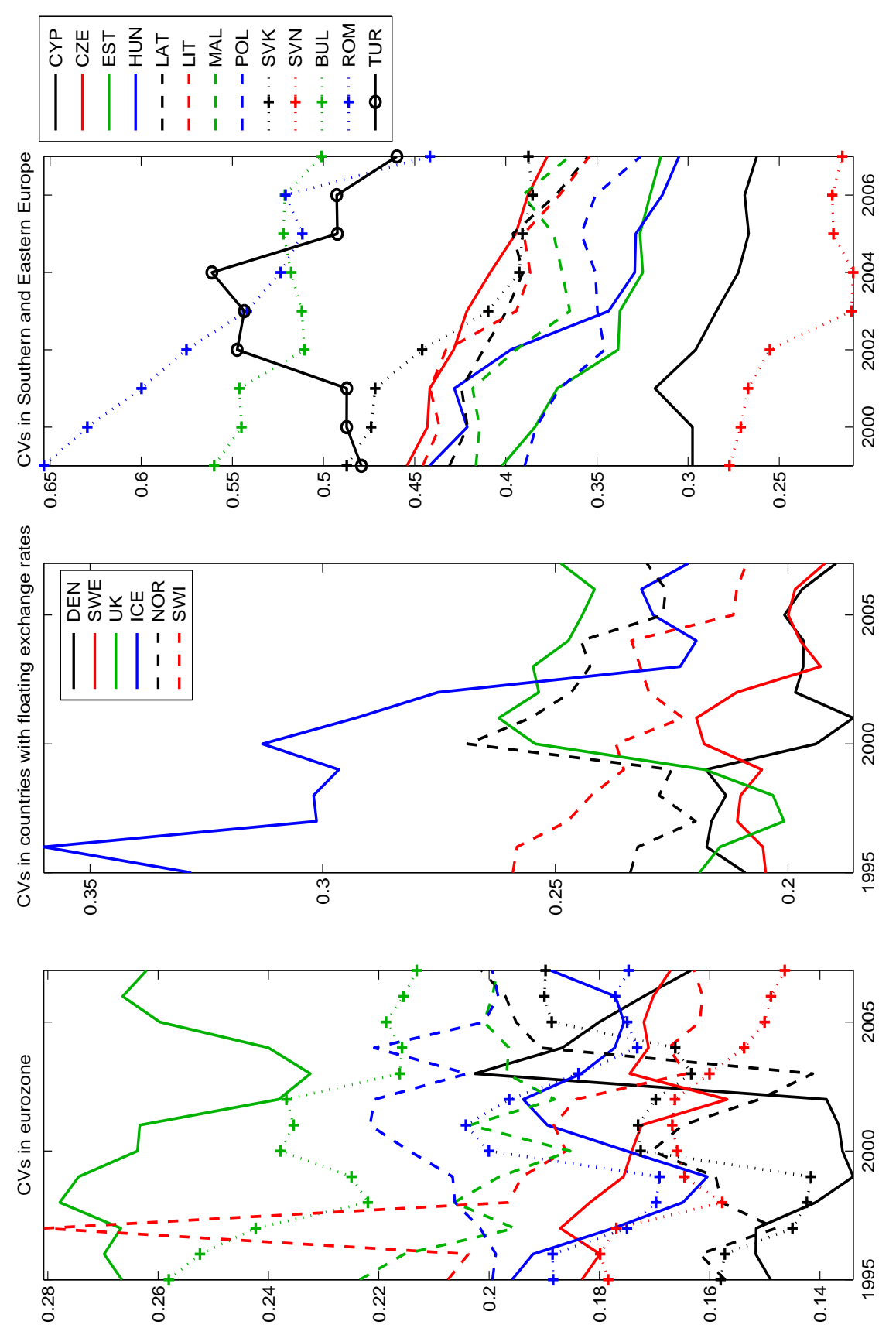

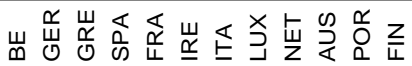

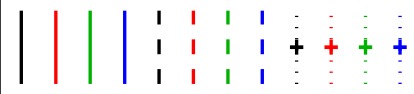


Figure 7: Relationship between mean PLI and price dispersion within country
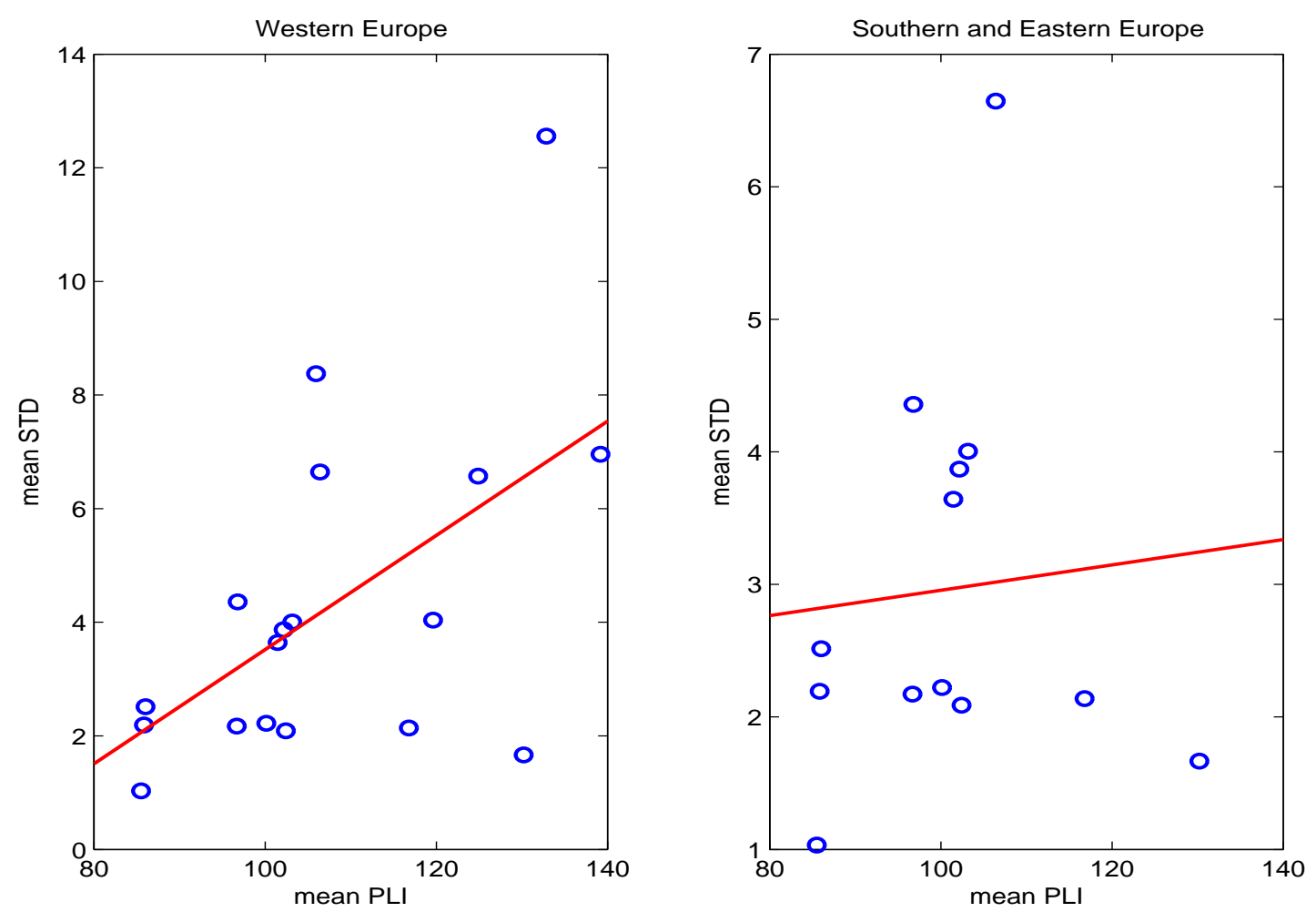
Figure 8: Kernel density estimates of all price levels, Western Europe
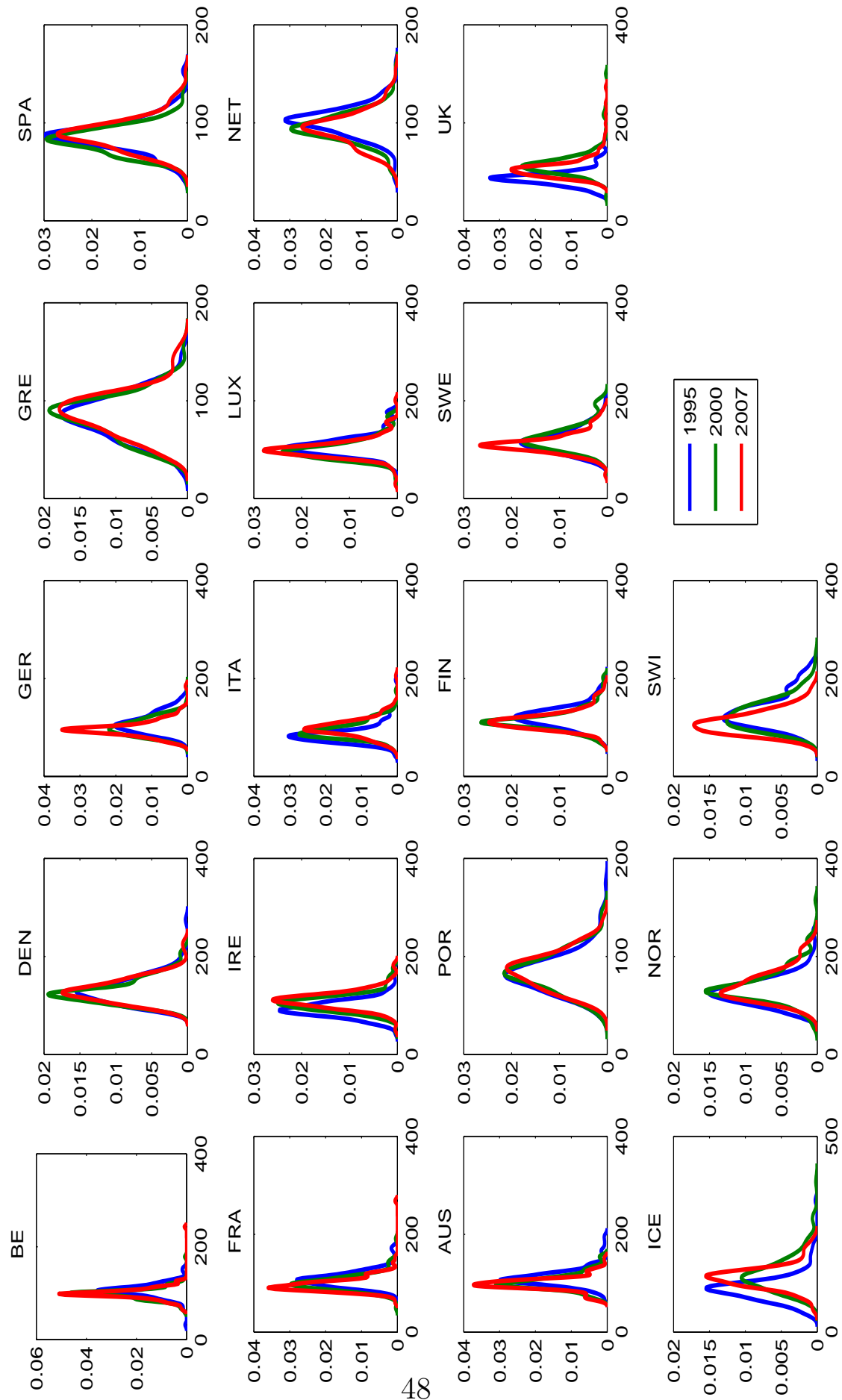
Figure 8 continued: Kernel density estimates of all price levels, Southern and Eastern Europe
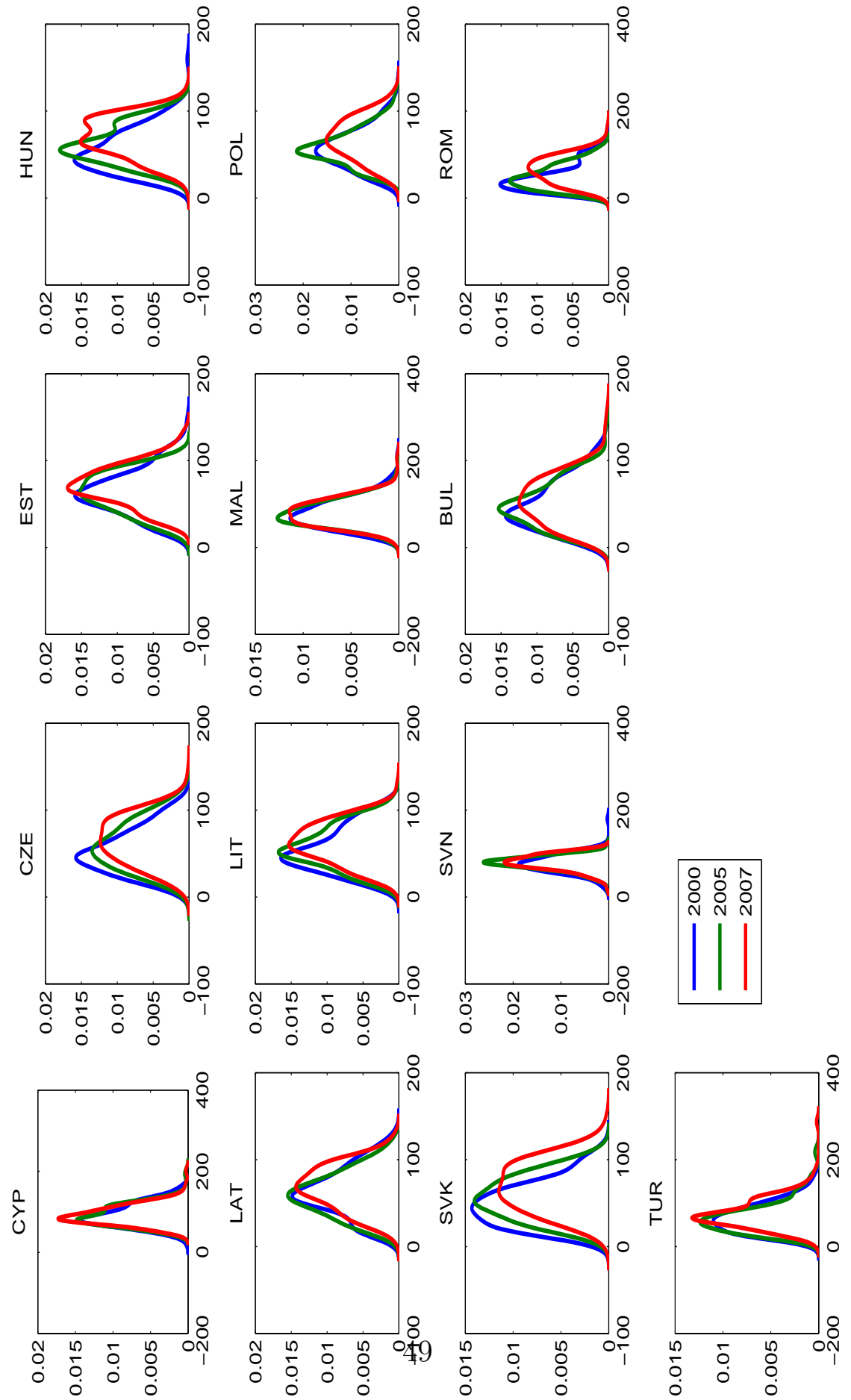
Figure 9: Evolution of price distribution for euro-member countries

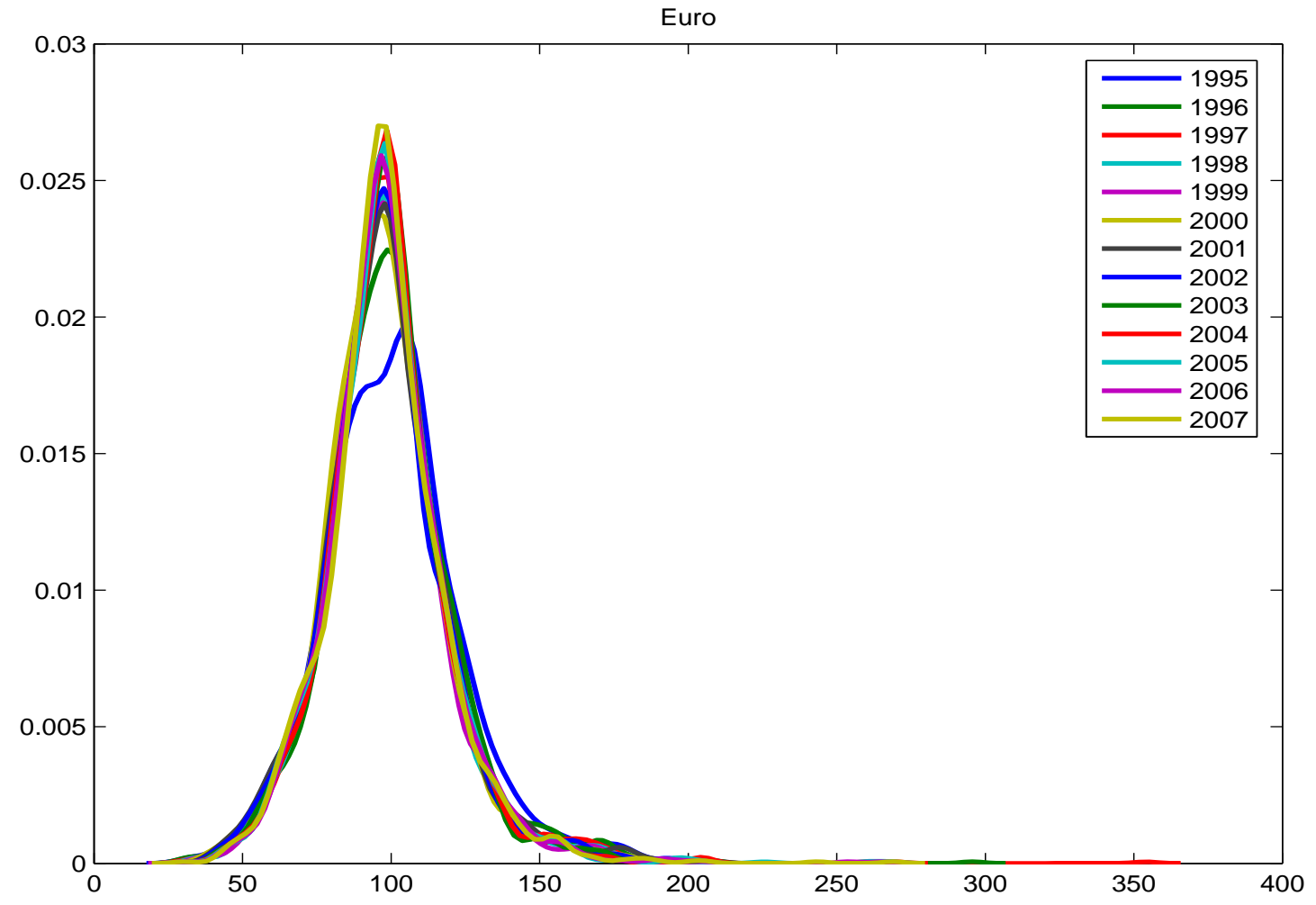


Figure 9 continued: Evolution of price distribution for countries with floating exchange rates

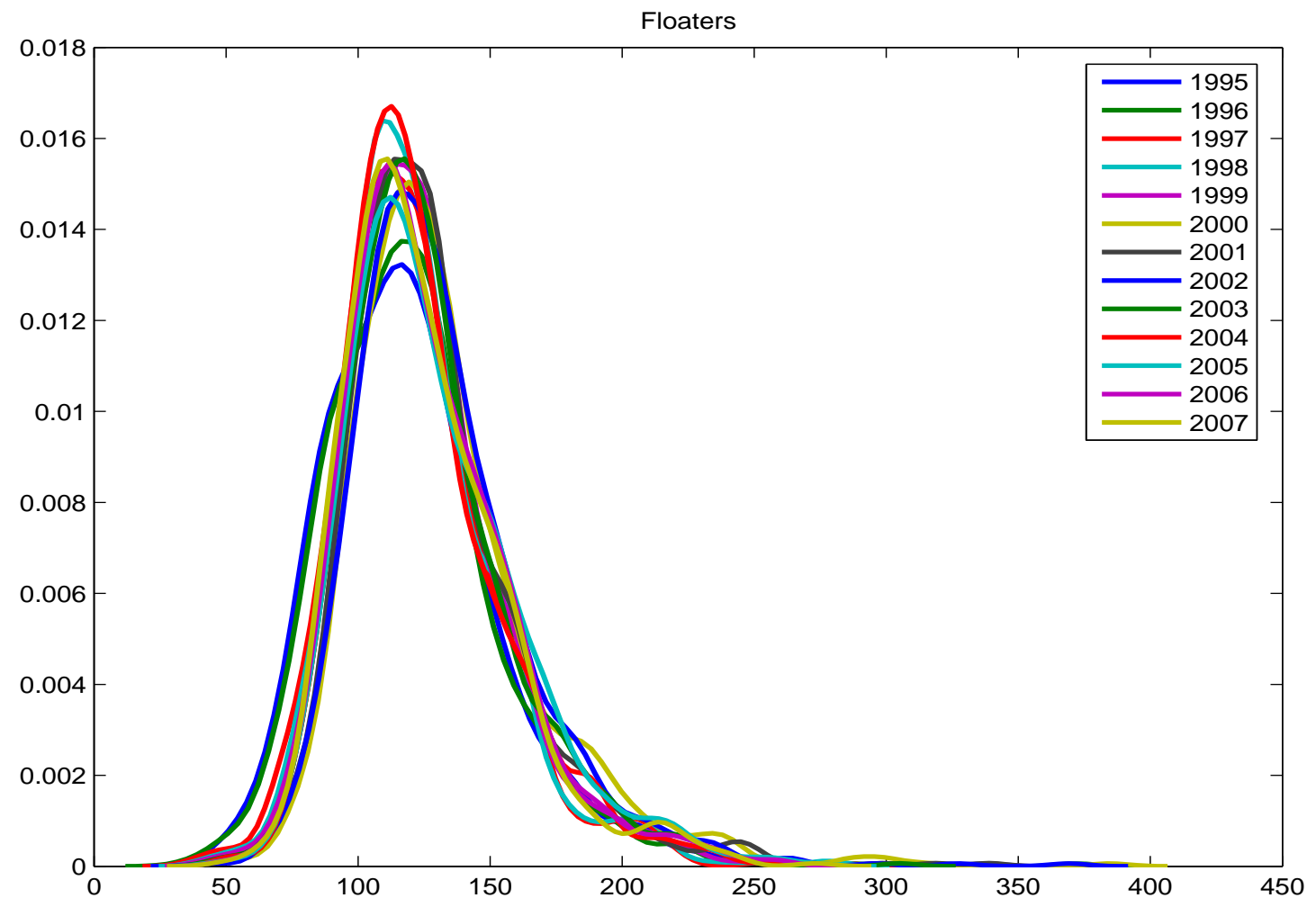


Figure 9 continued: Evolution of price distribution for countries in Southern and Eastern Europe

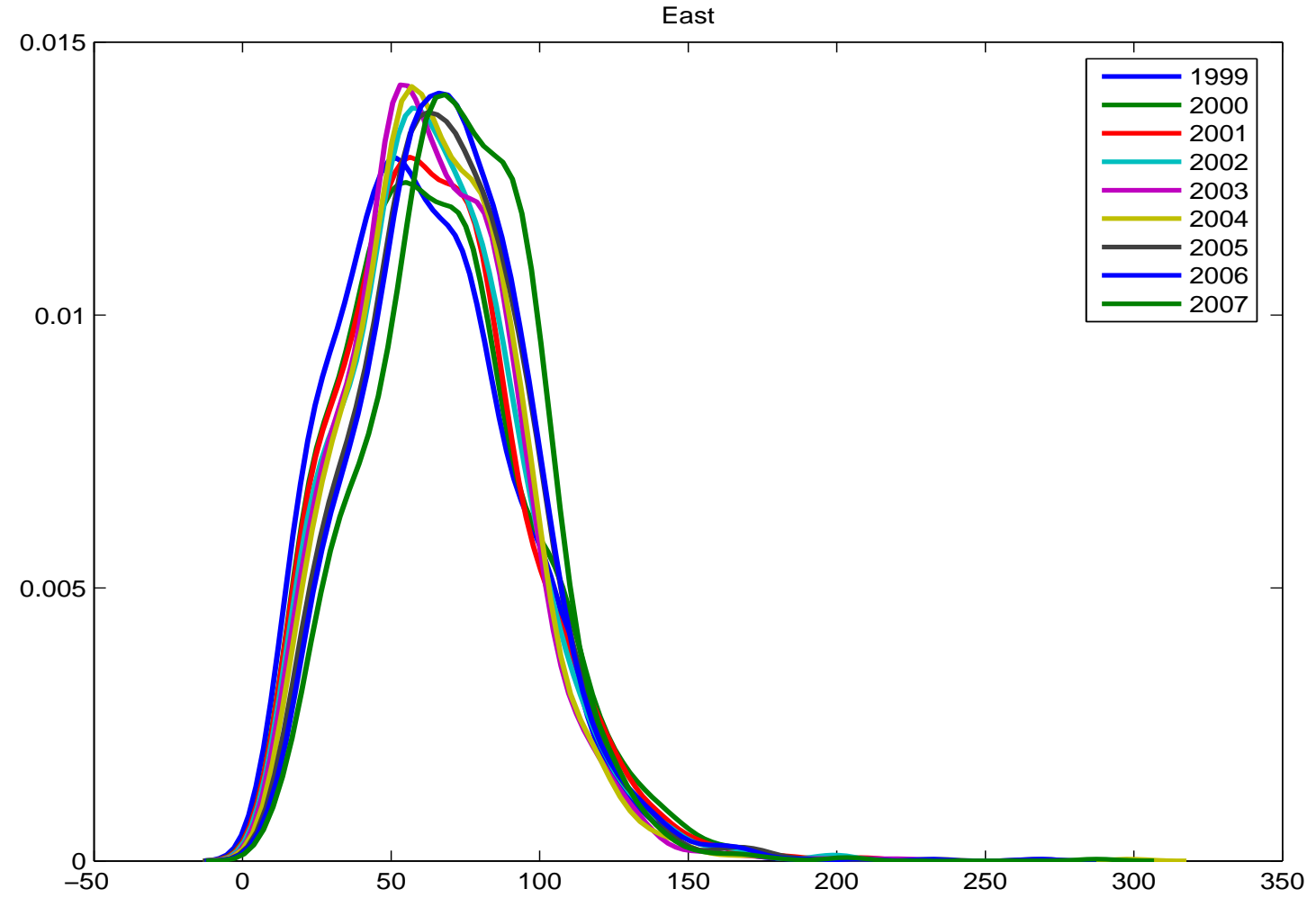


Figure 10: Decomposition into Traded and Non-Traded, Western Europe
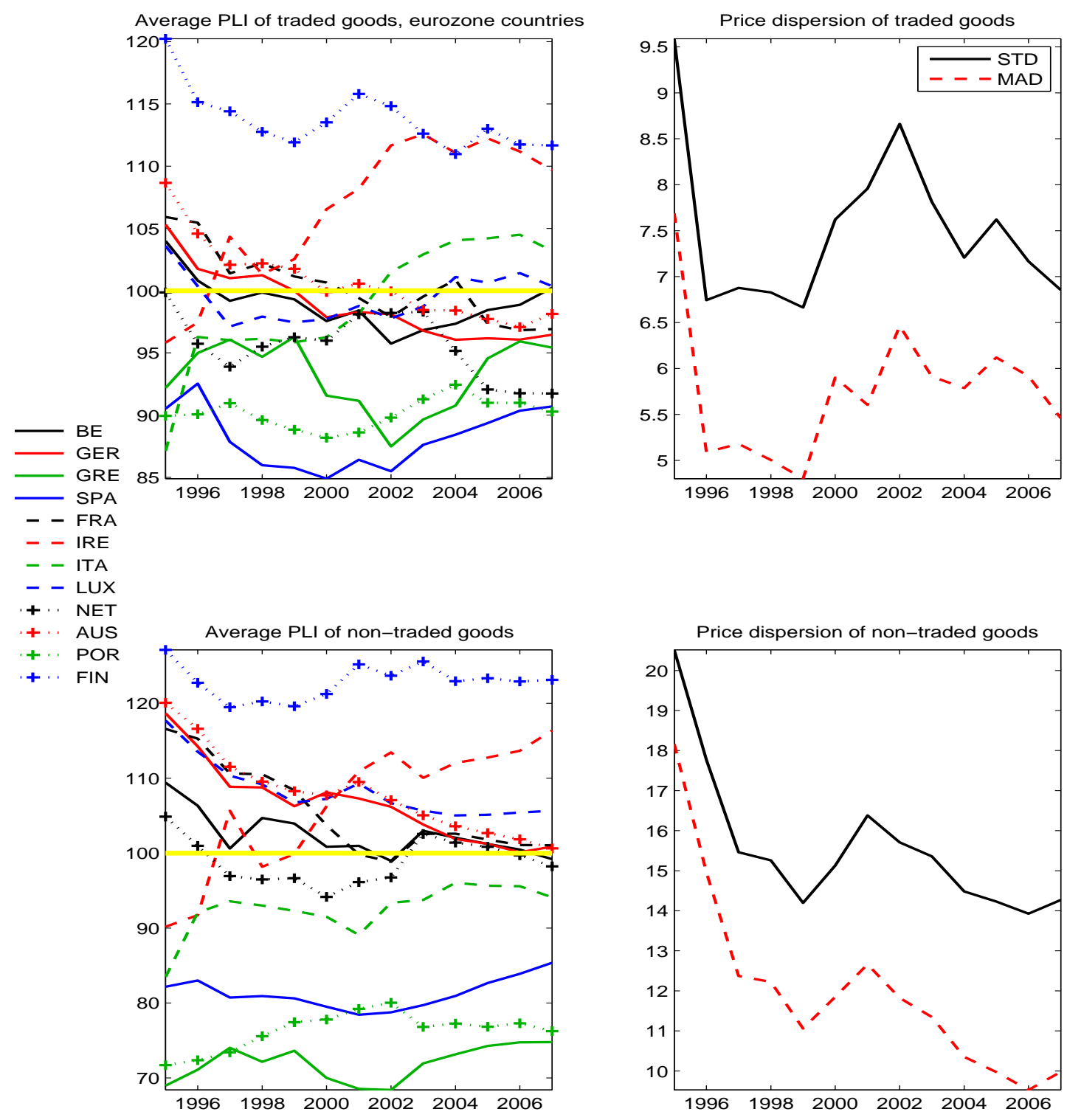
Figure 11: Decomposition into Traded and Non-Traded, countries in Western Europe with floating exchange rates

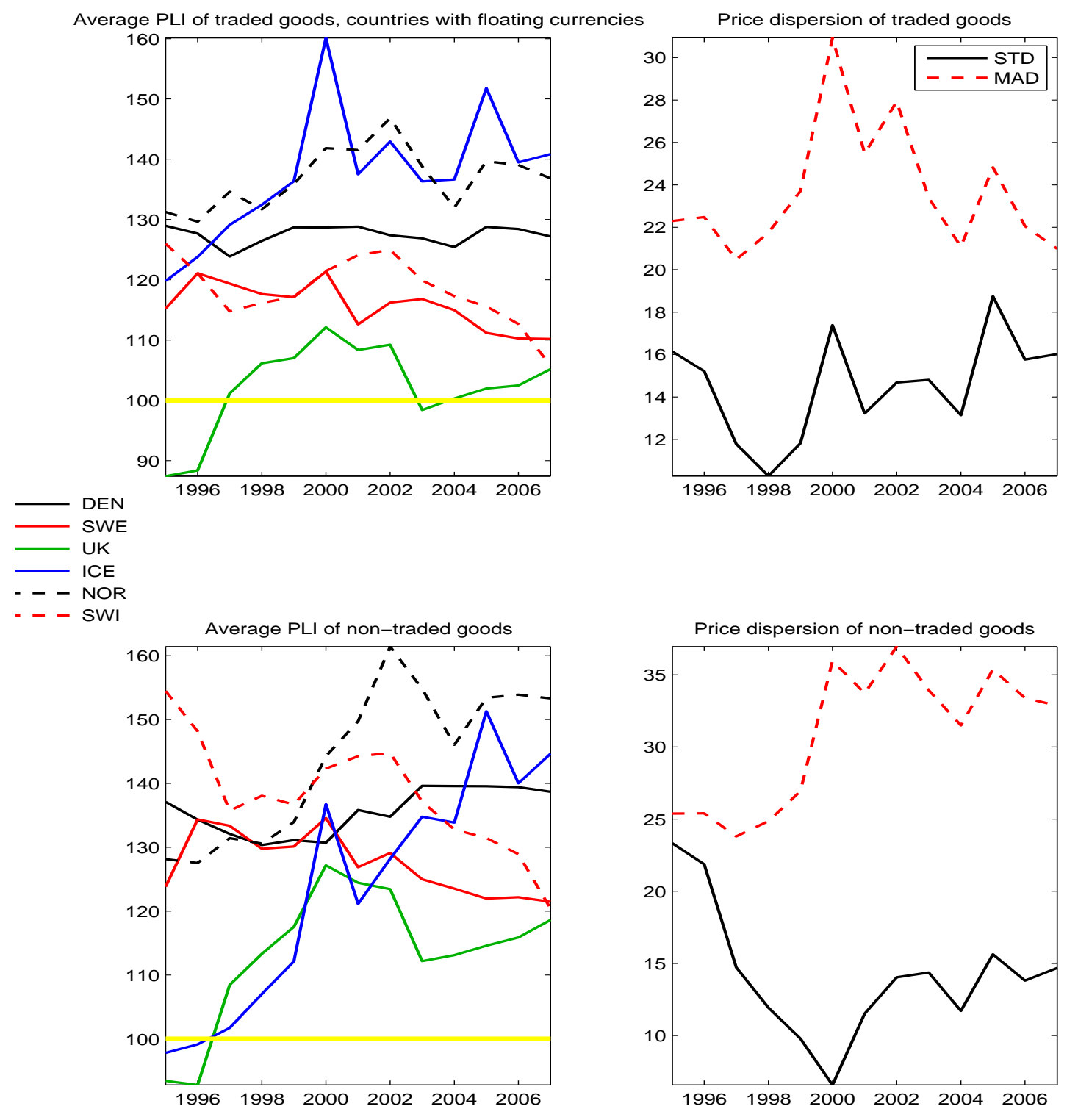


Figure 12: Decomposition into Traded and Non-Traded, Southern and Eastern Europe
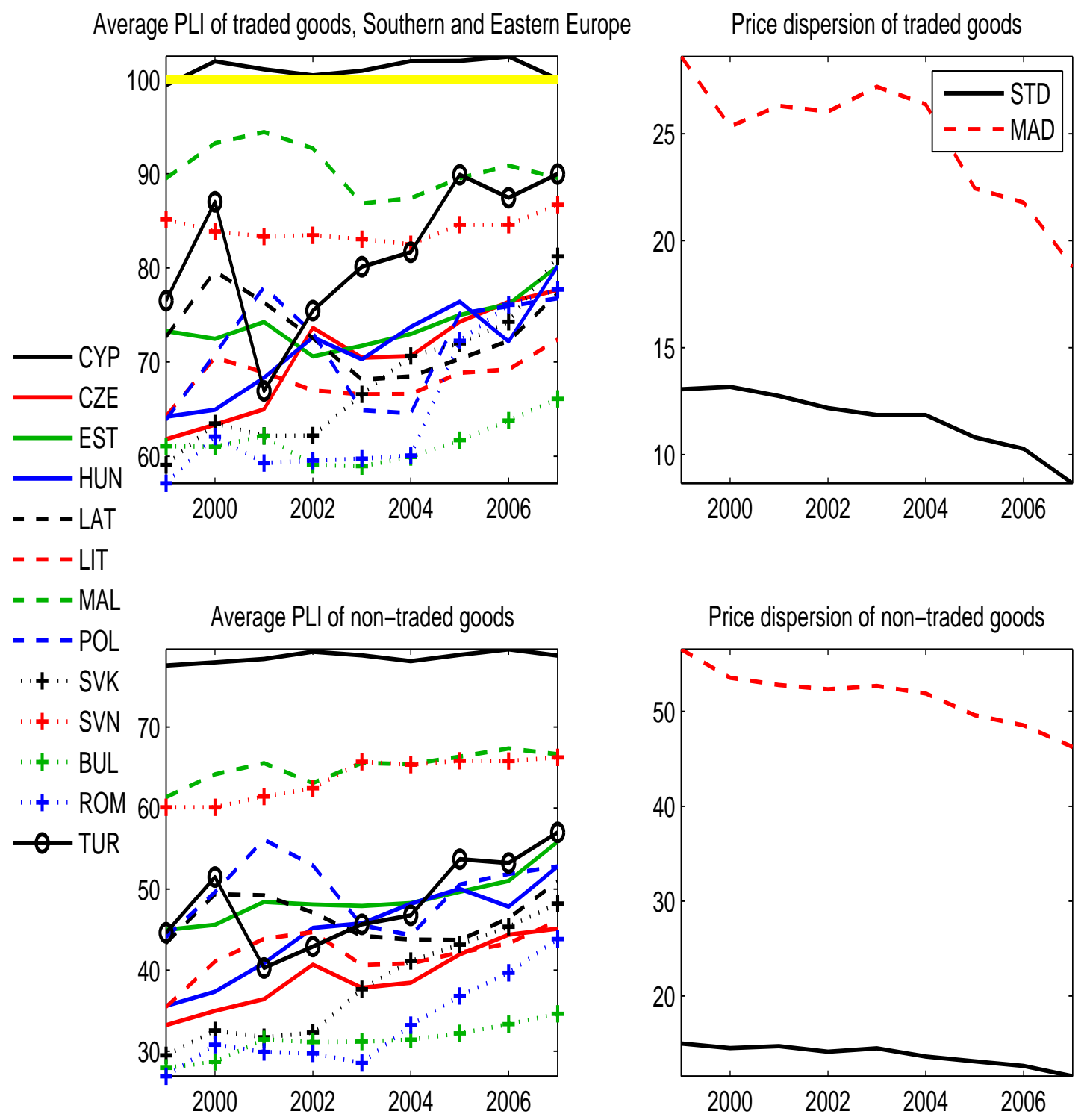

Price dispersion of non-traded goods

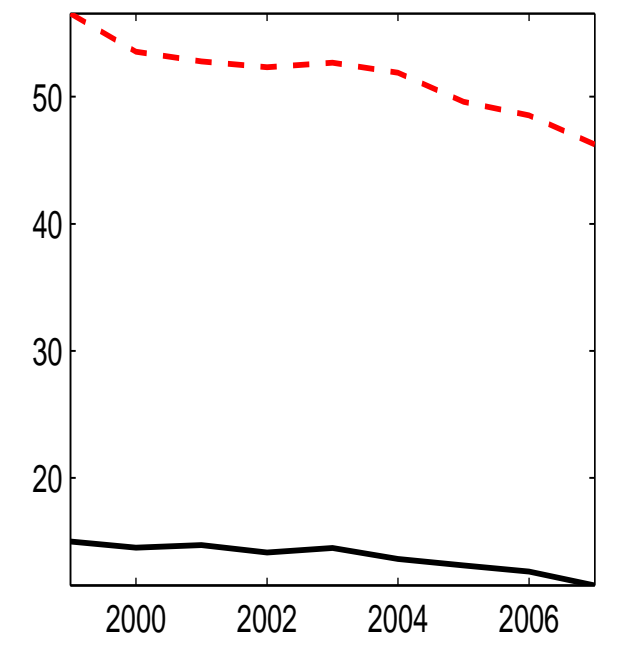


Figure 13: Relative GDP per capita and average PLI's in Western Europe
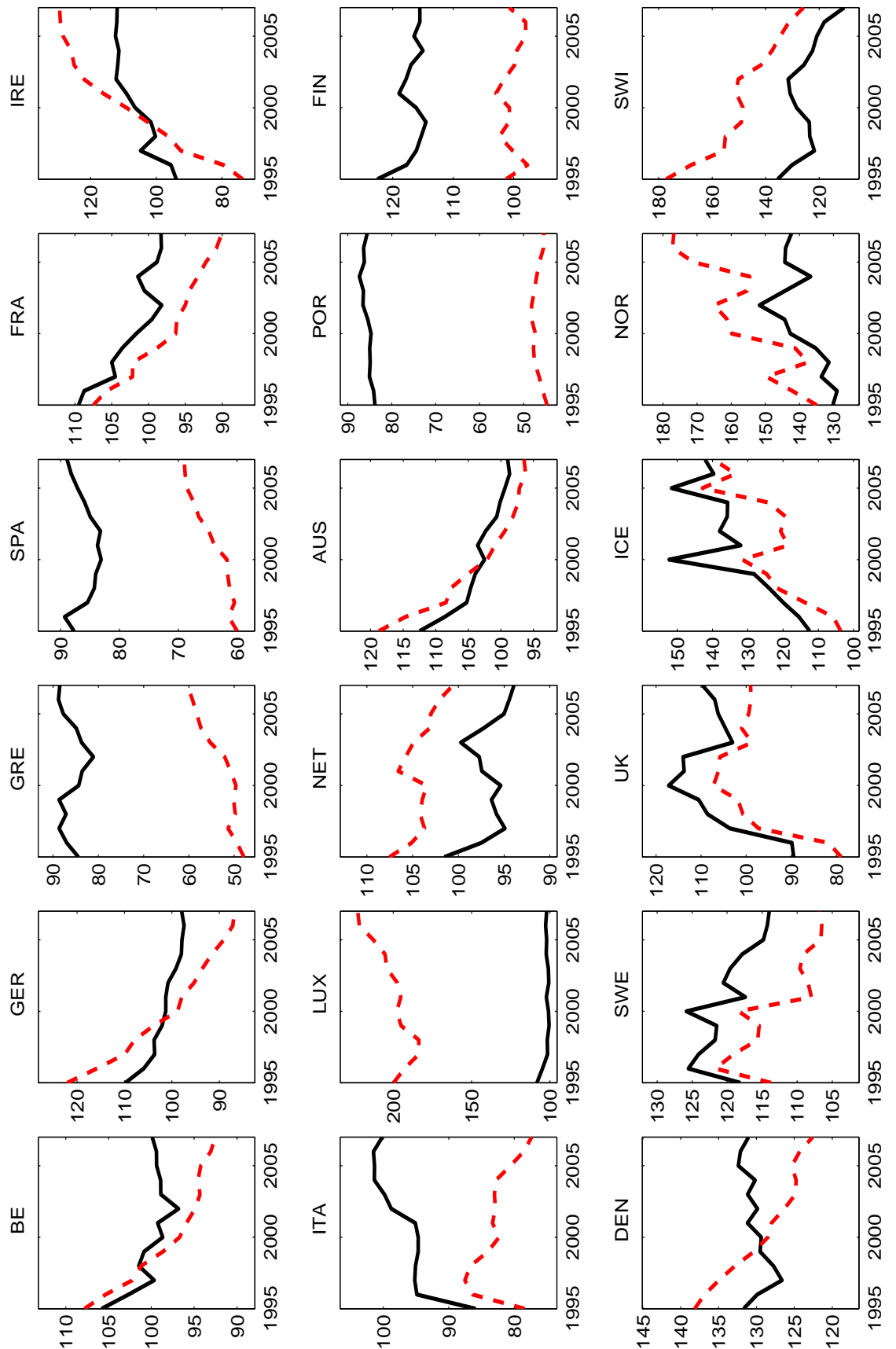

1 
Figure 13 continued: Relative GDP per capita and average PLI's in Southern and Eastern Europe
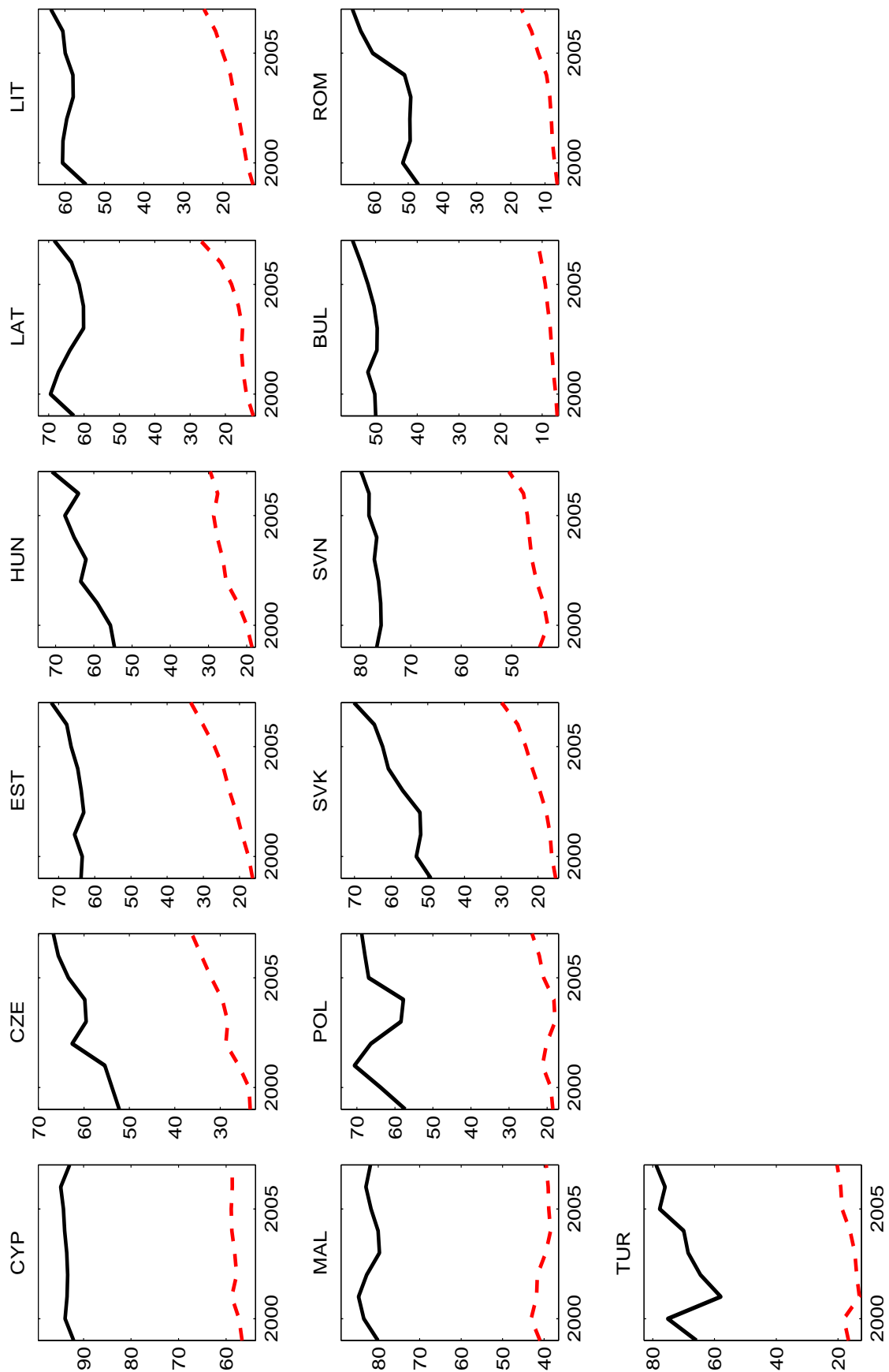

$\left.\right|_{1} ^{0}$ 
Figure 14: Real exchange rate and GDP: pooled

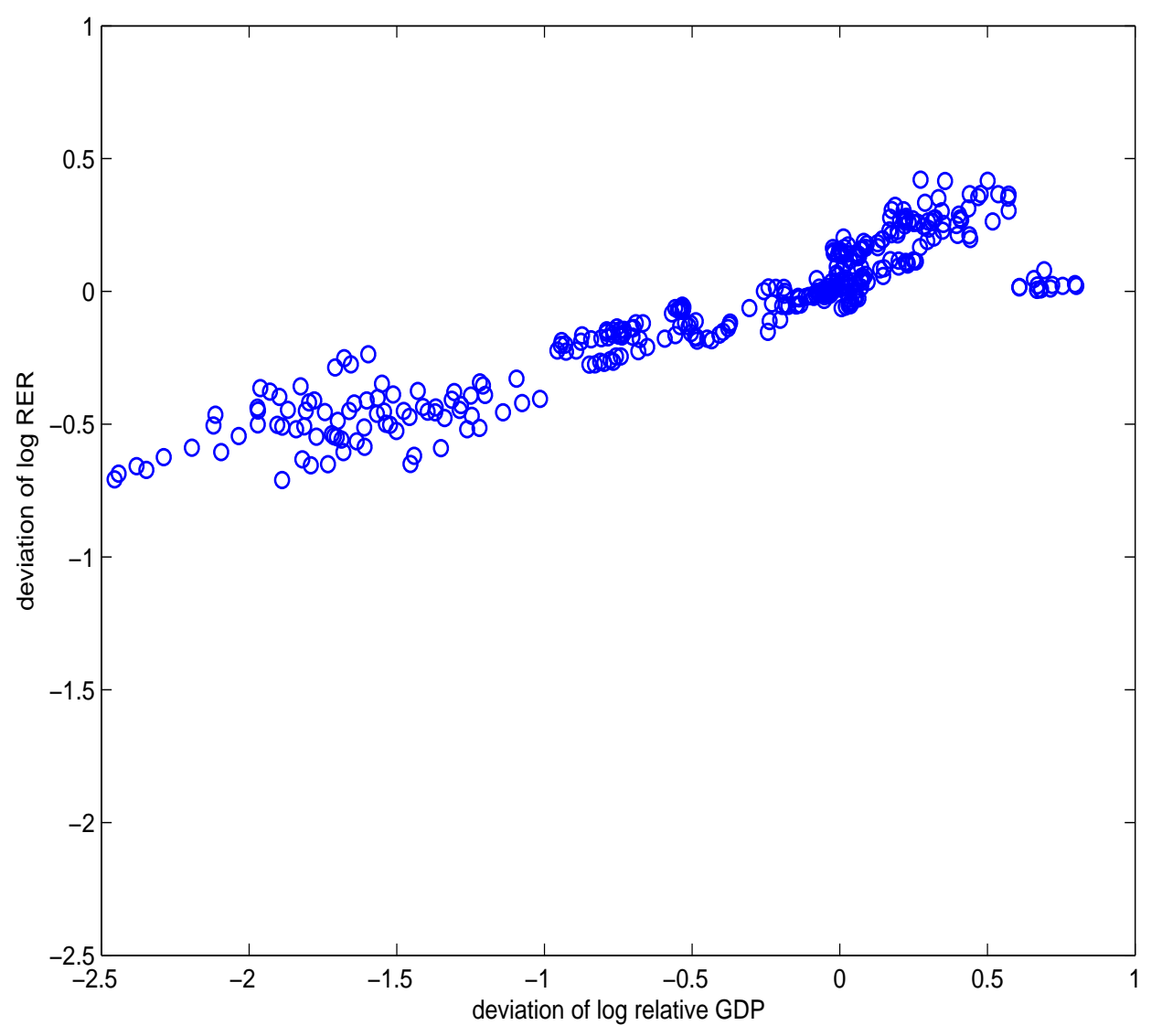


Figure 15: Real Exchange Rate and Nominal Exchange Rate: Western Europe
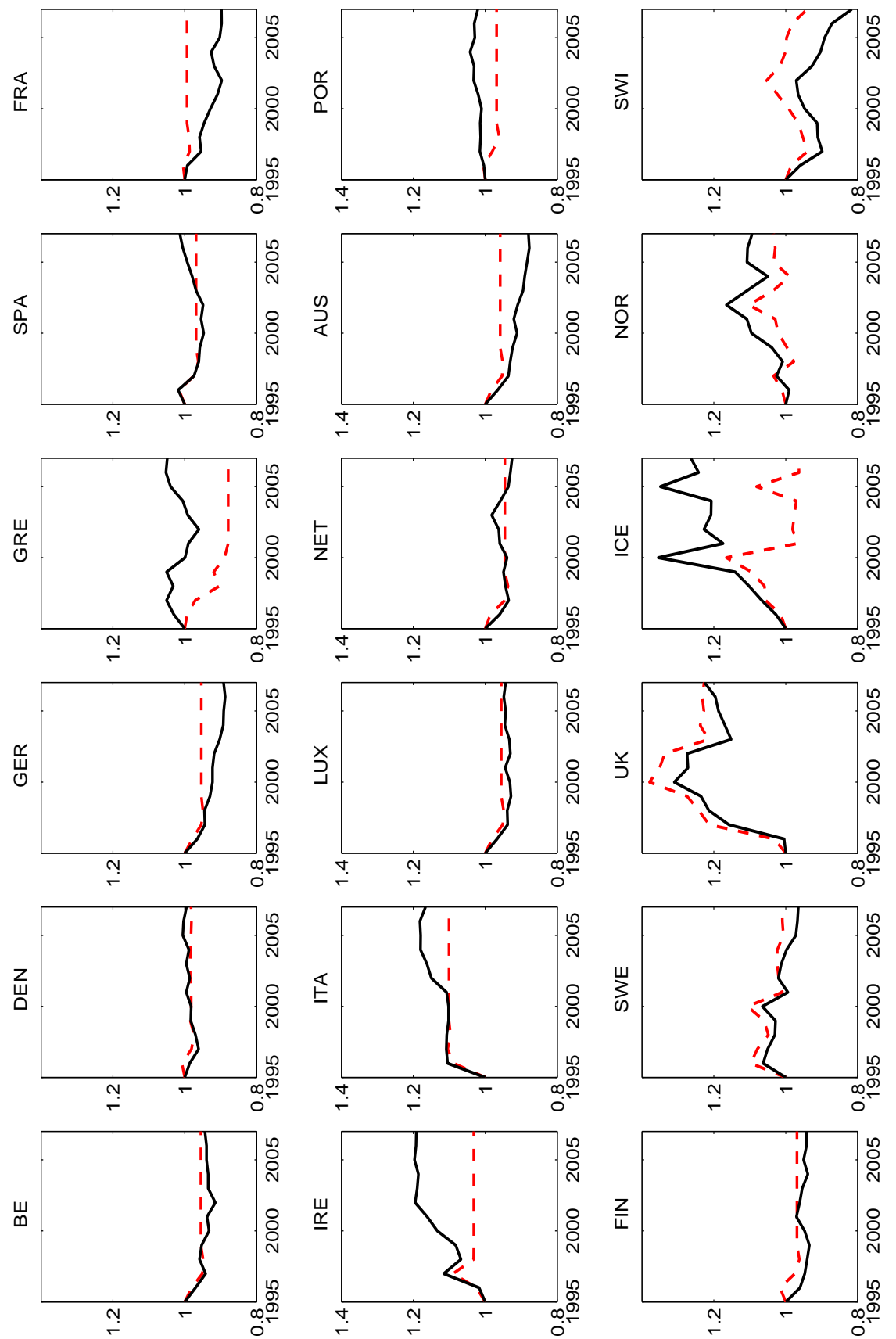

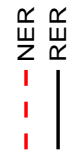


Figure 15 continued: Real Exchange Rate and Nominal Exchange Rate: Southern and Eastern Europe
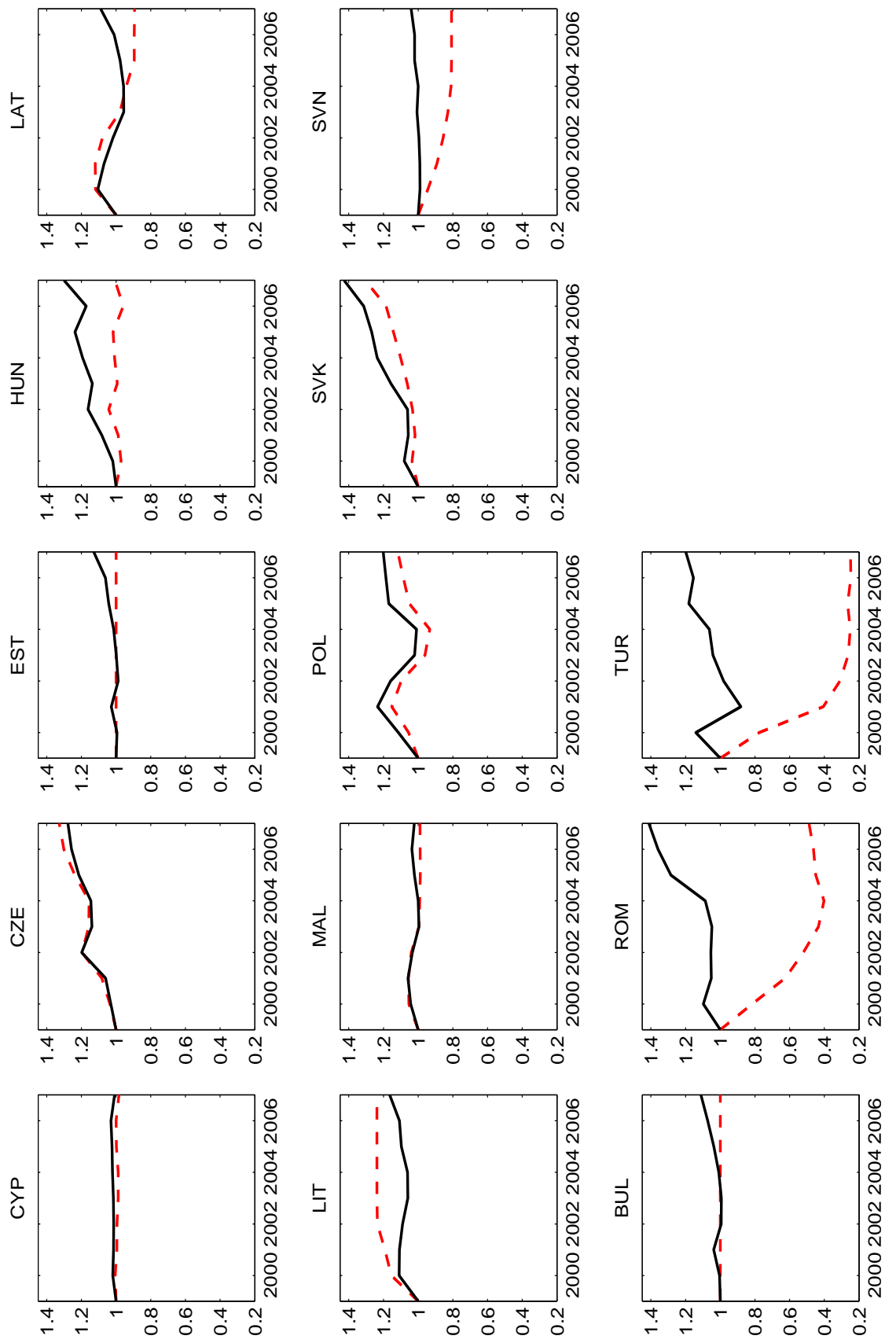

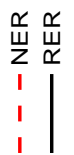


Figure 16: Average monthly prices relative to EU15 mean
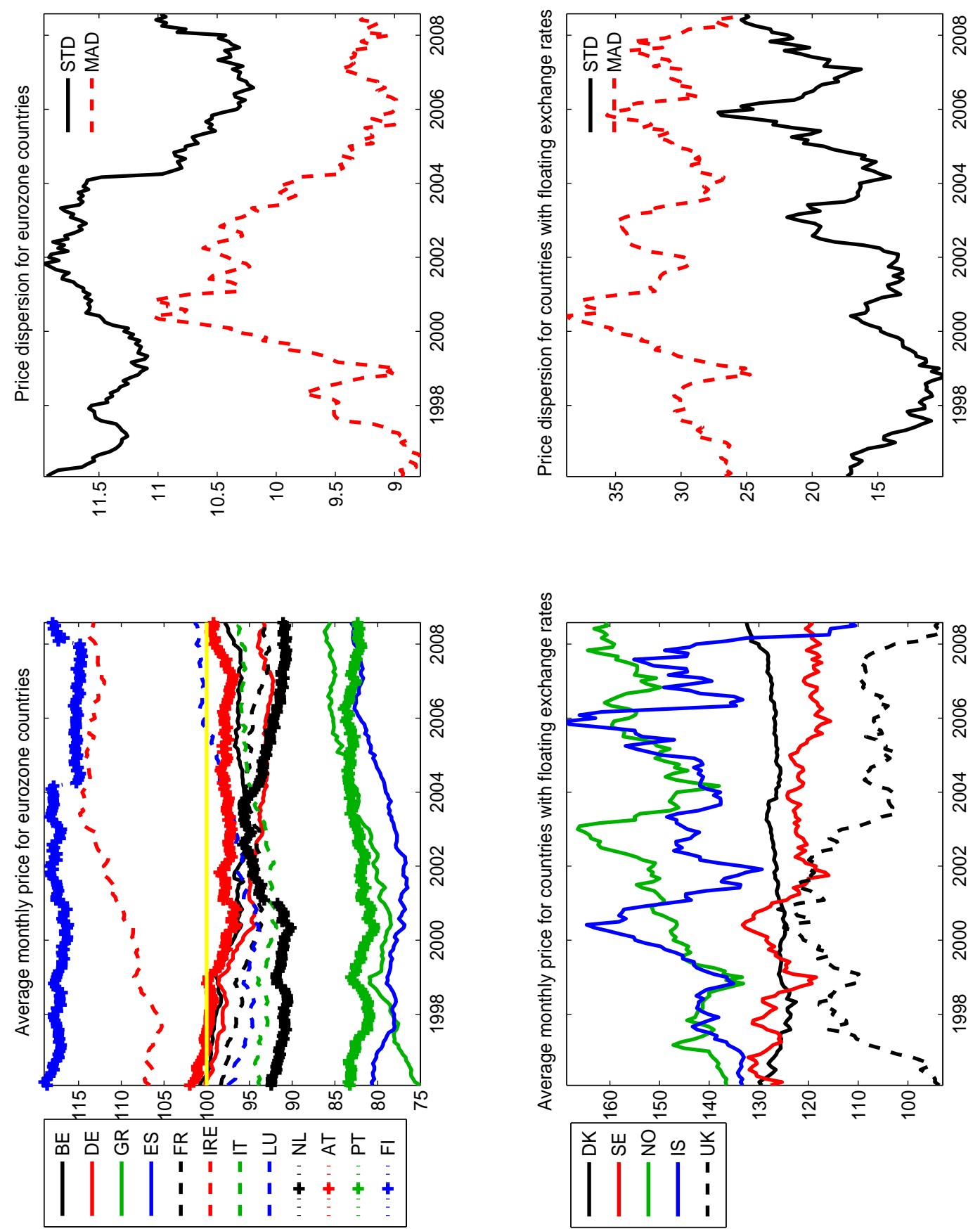
Figure 17: Monthly price dispersion between eurozone countries without Ireland

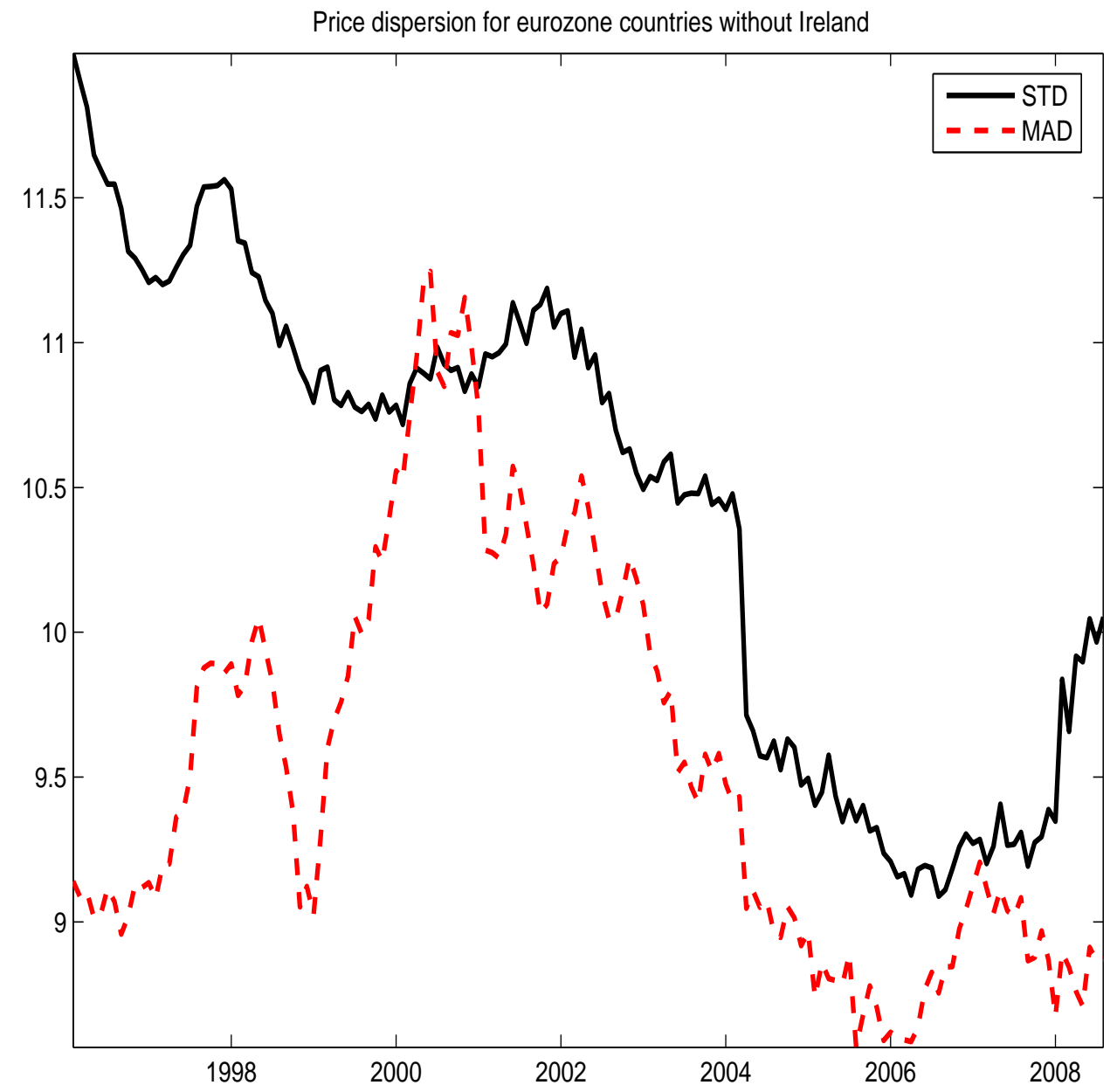


Figure 18: Average monthly prices relative to EU15 mean
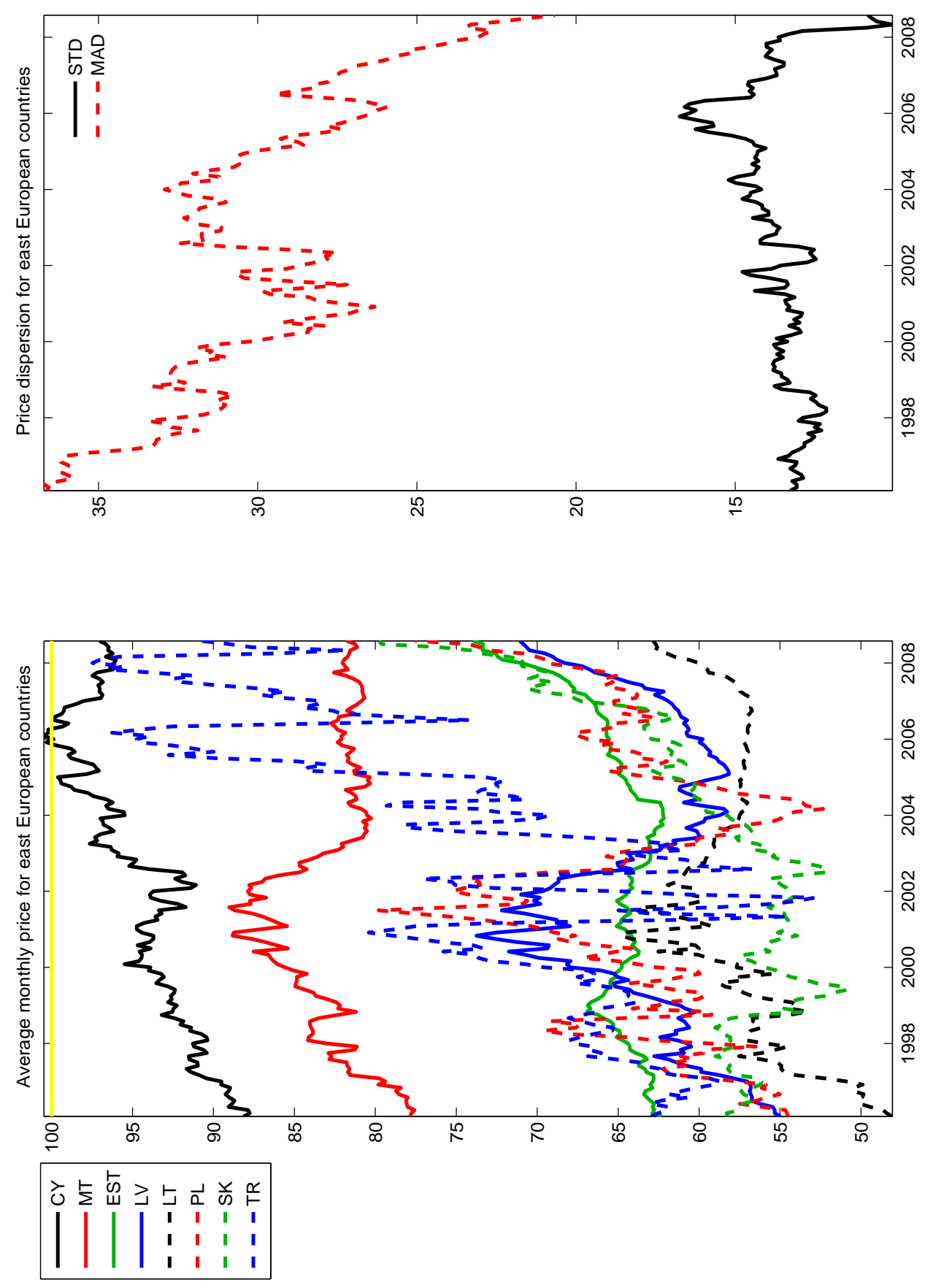
Figure 19: Model elasticity of RER to RGDP
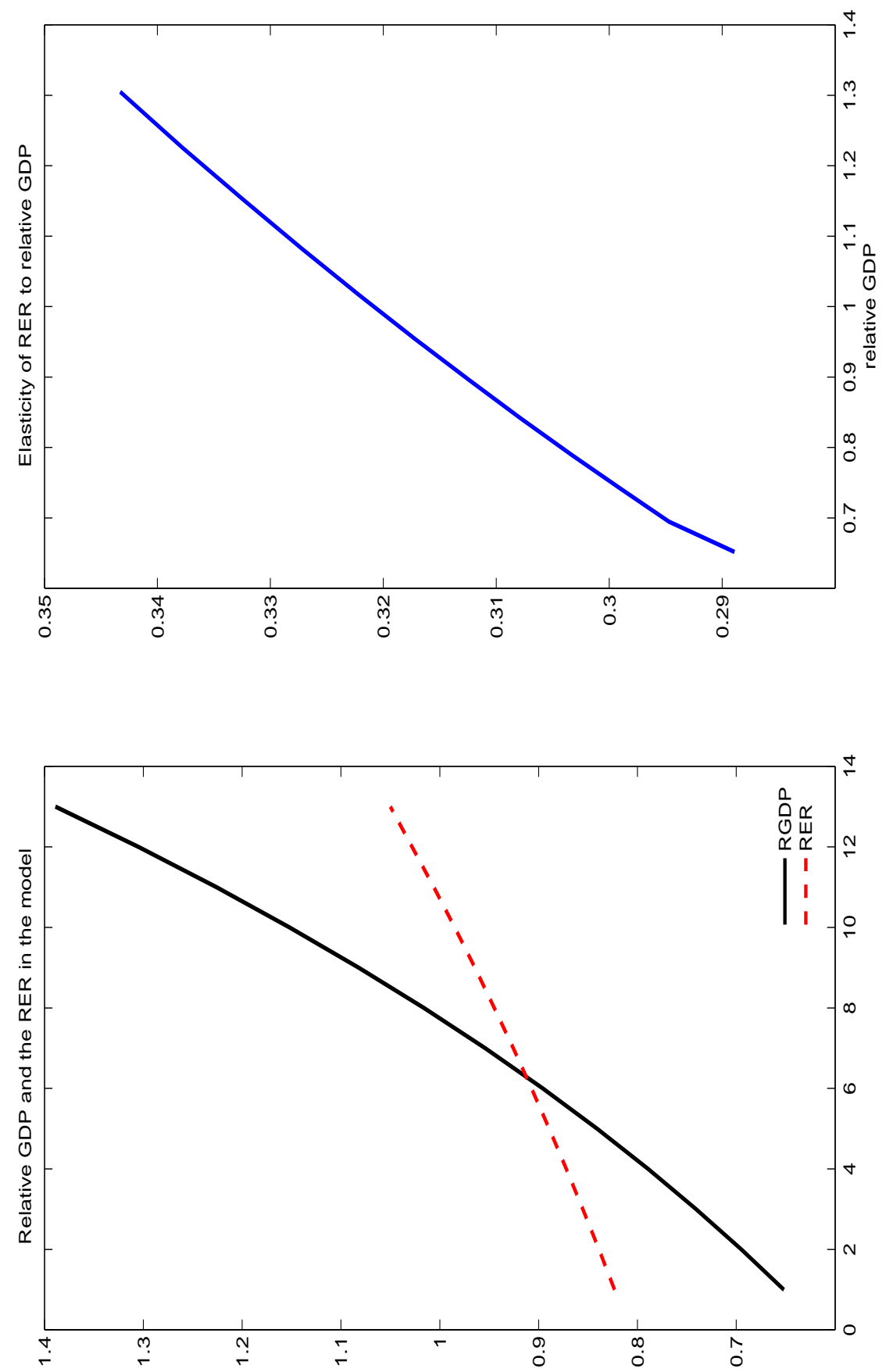
Figure 20: Model prediction and Average PLI's in EU12
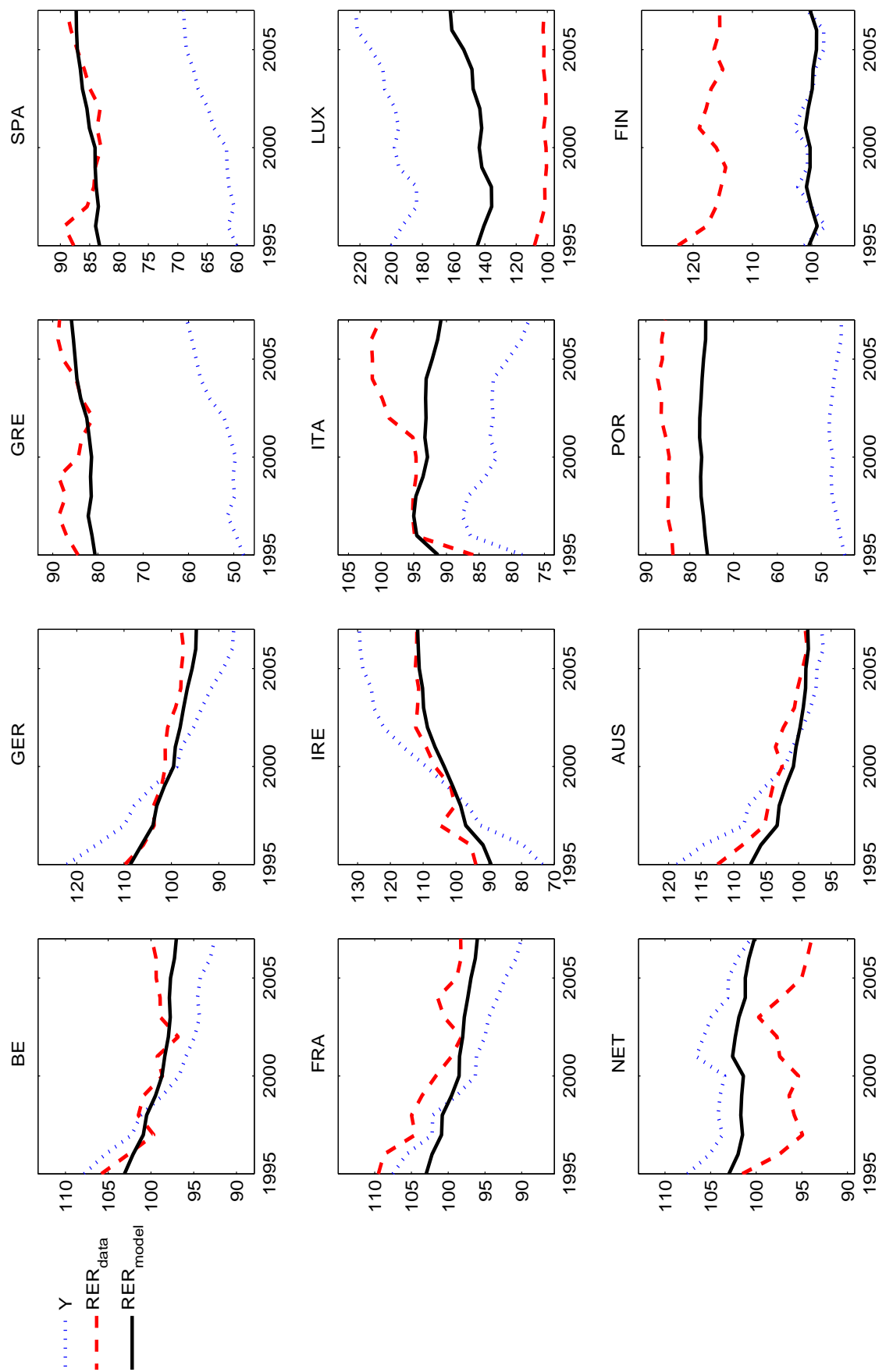
Figure 21: Model prediction and Average PLI's in countries with floating exchange rates
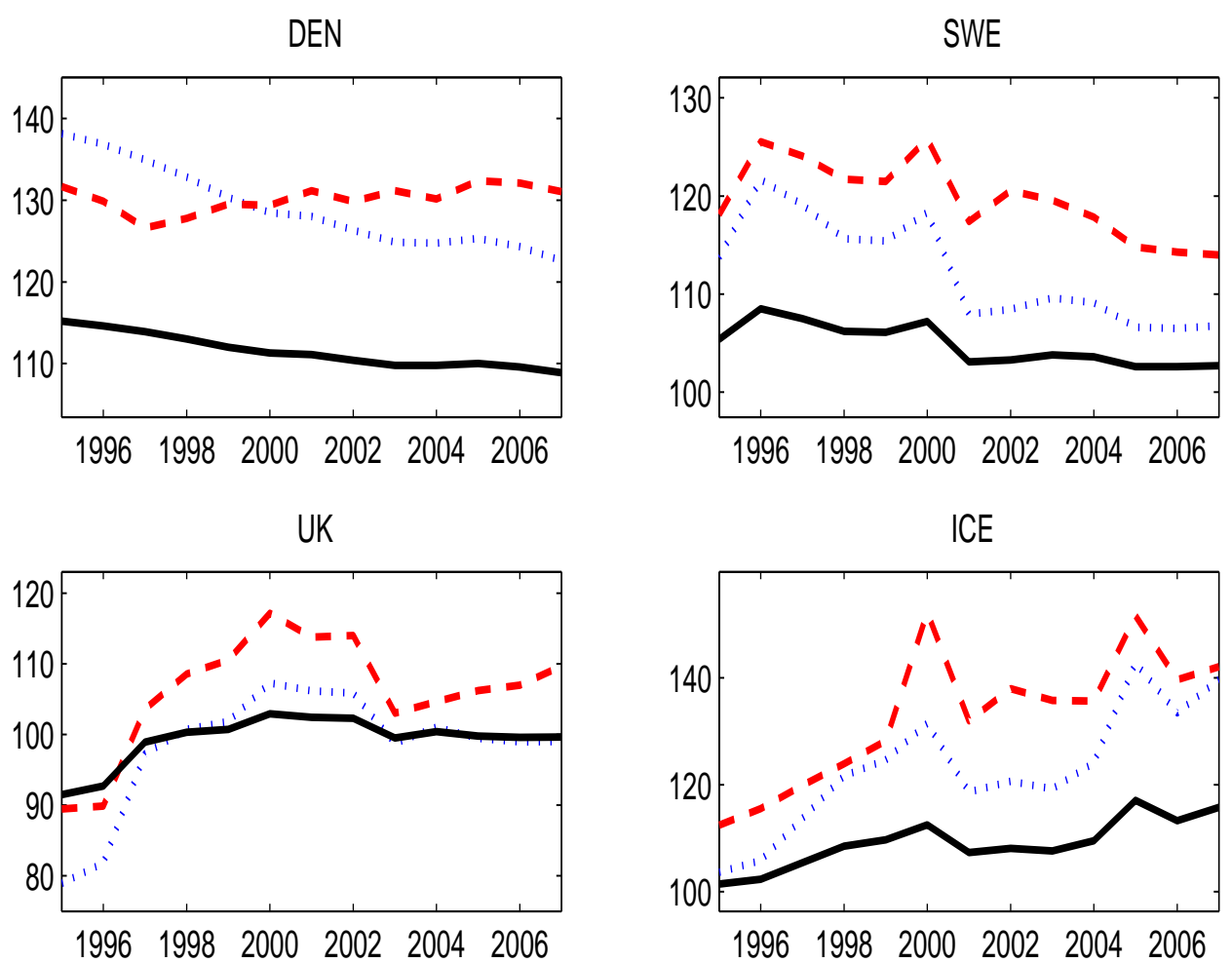

NOR

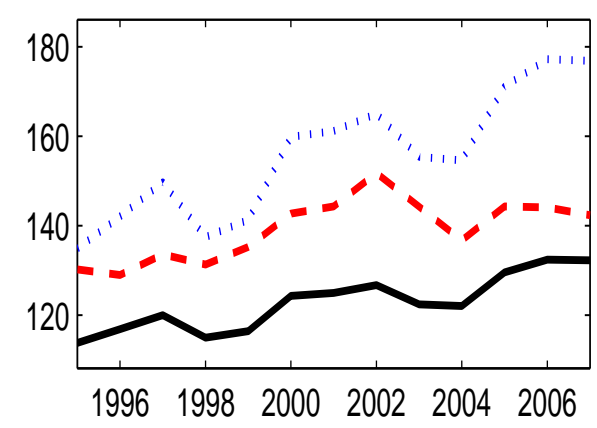

SWI

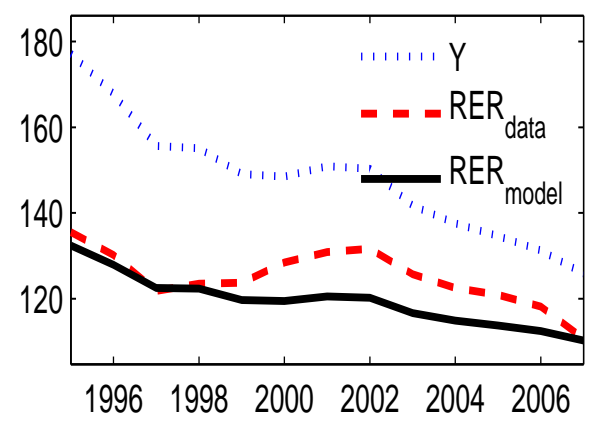


Figure 22: Model prediction and Average PLI's in Southern and Eastern Europe
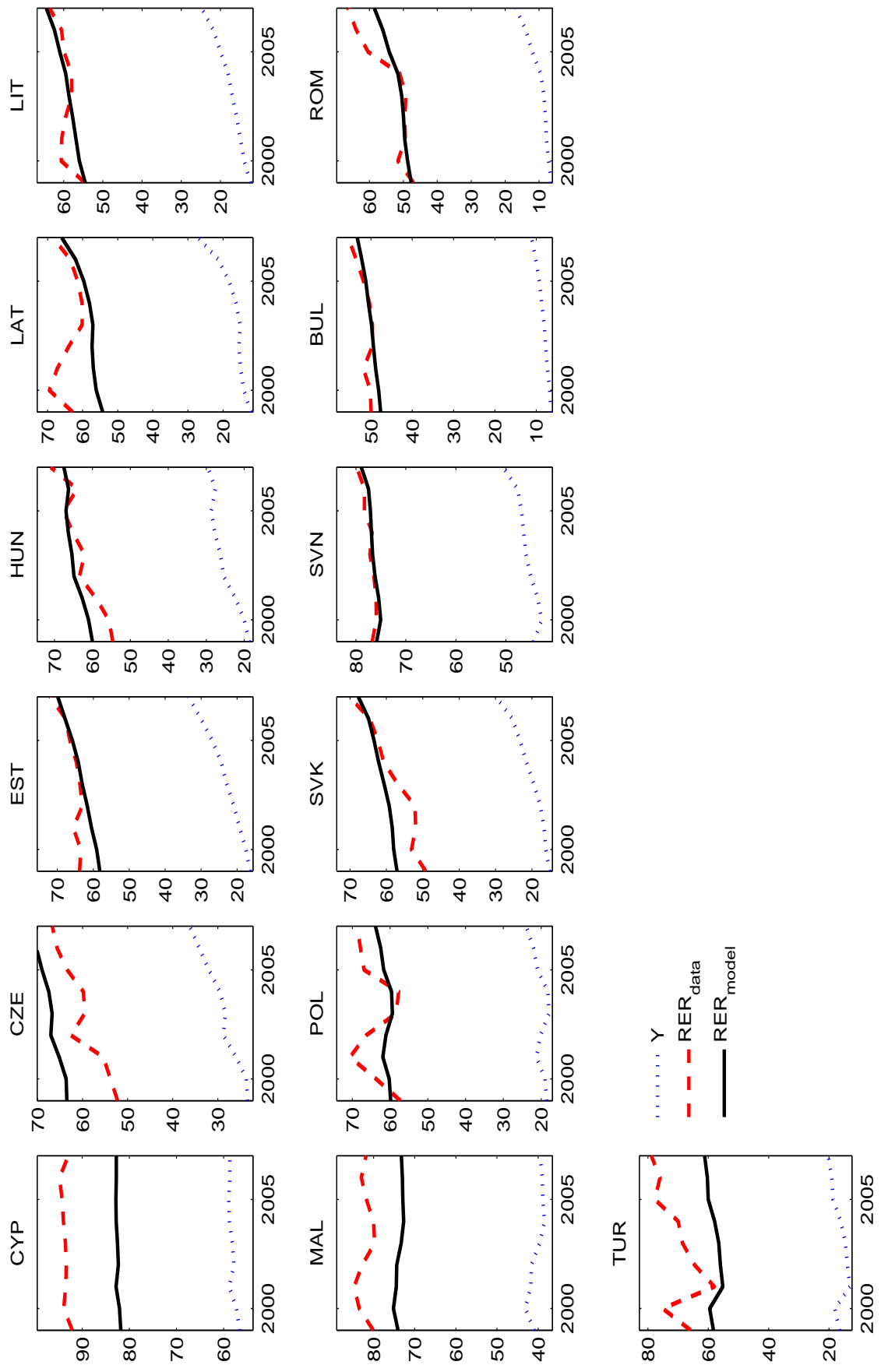
Figure 23: Price of Non-traded to Traded good PLI's in EU12
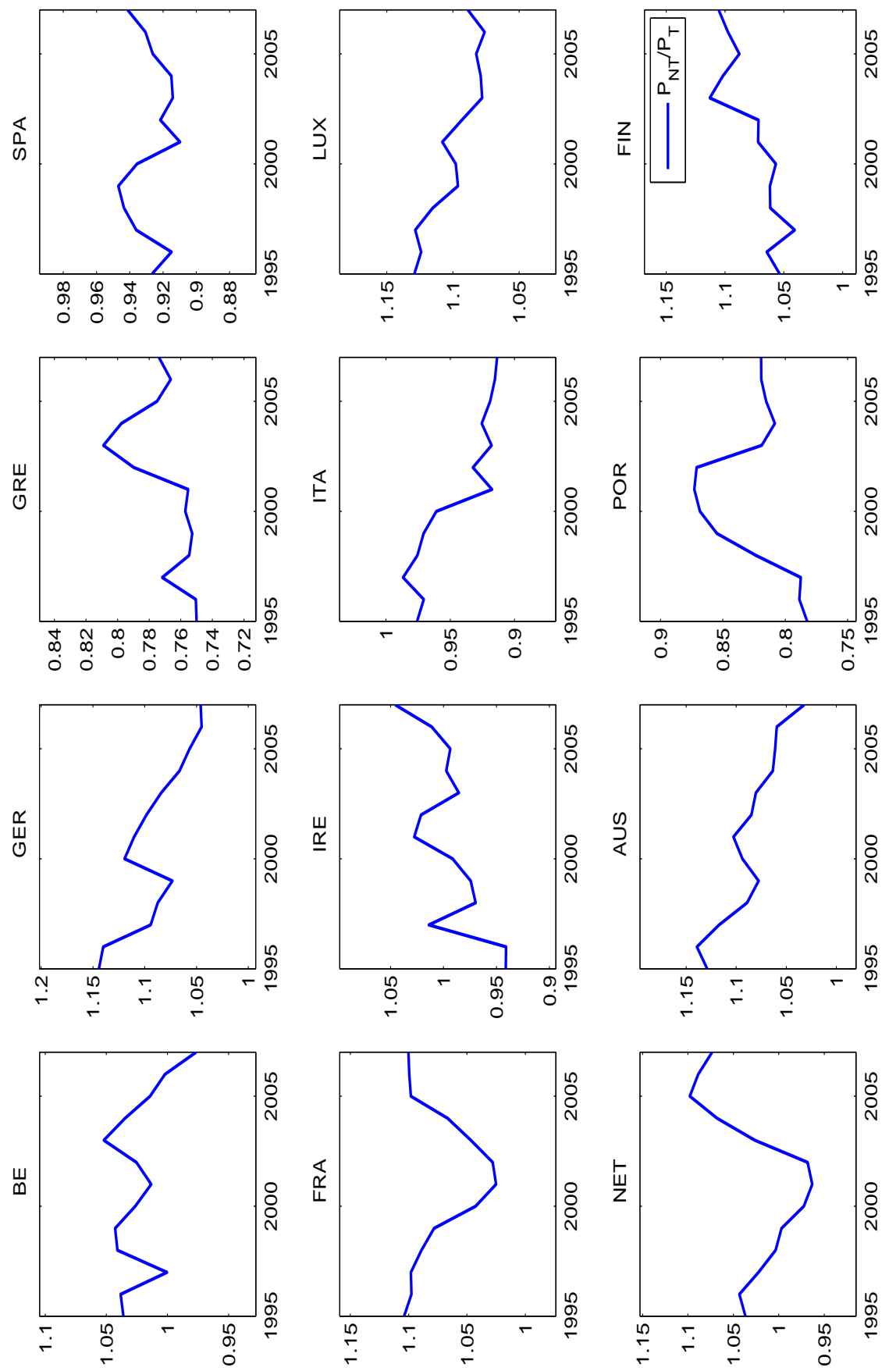
Figure 24: Price of Non-traded to Traded good PLI's in countries with floating exchange rates
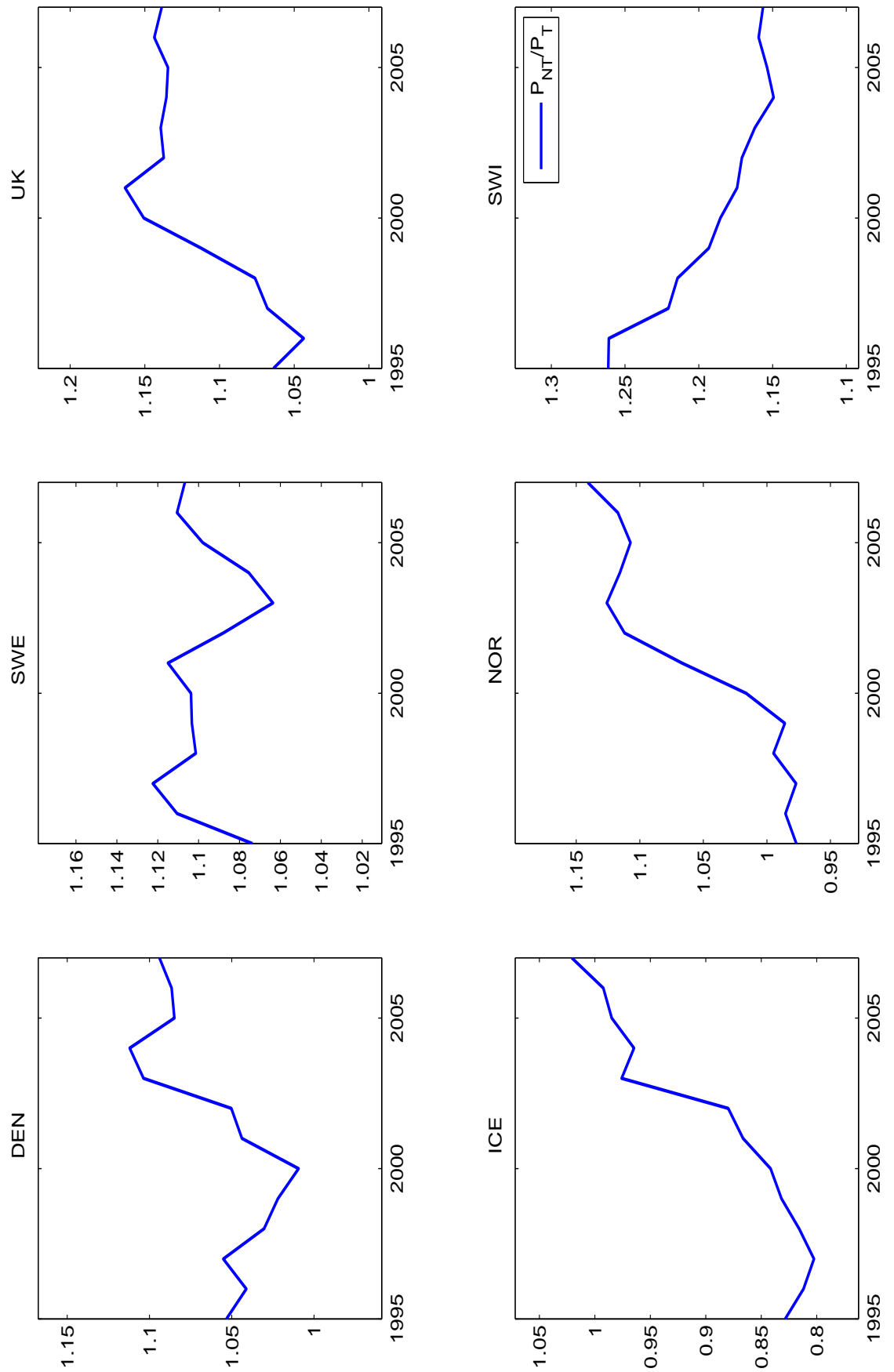
Figure 25: Price of Non-traded to Traded good PLI's in Southern and Eastern Europe
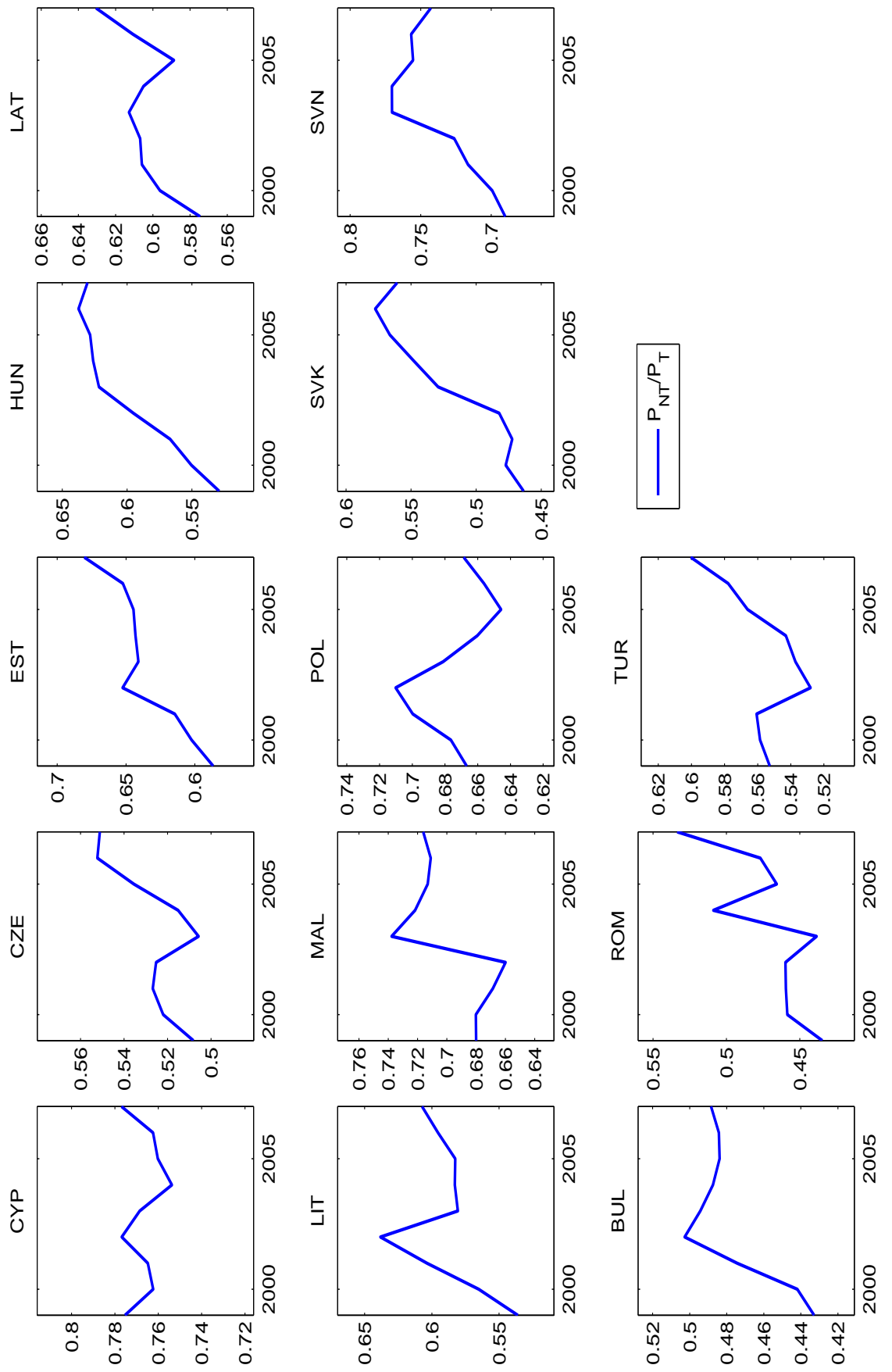
Figure 26: Prediction of model with taxation, and average PLI's in EU12
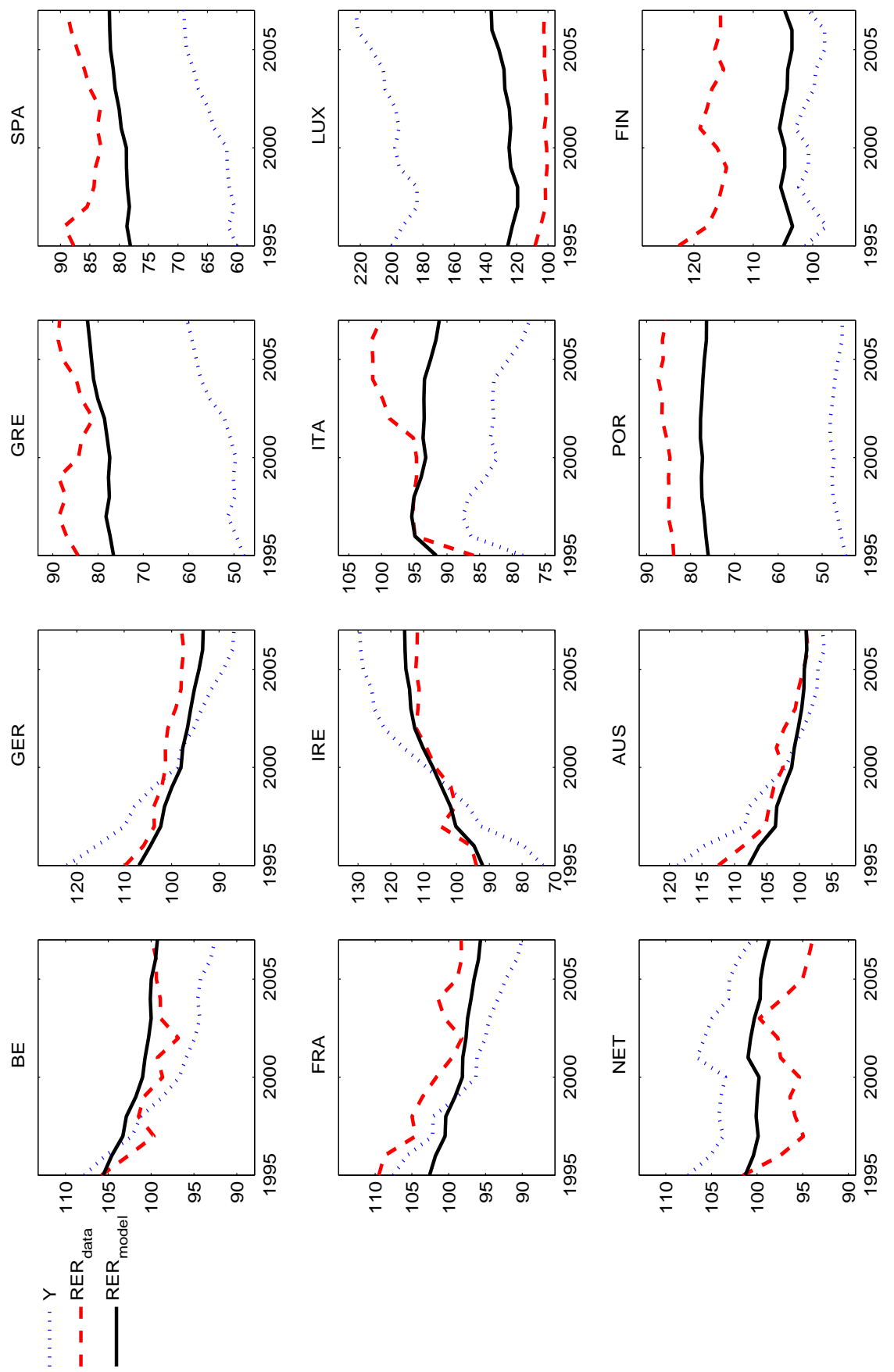
Figure 27: Prediction of model with taxation, and average PLI's in countries with floating exchange rates
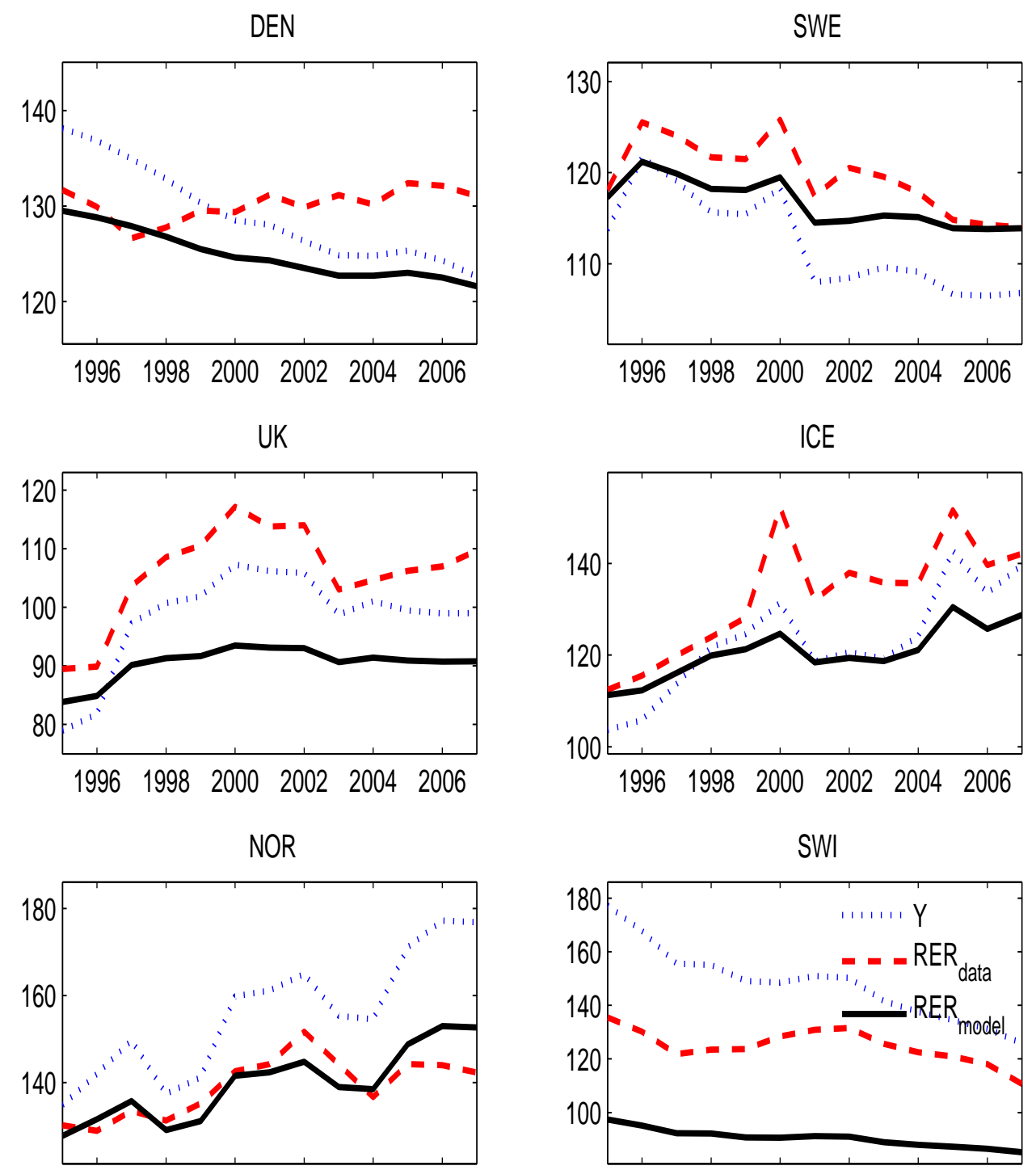

199619982000200220042006

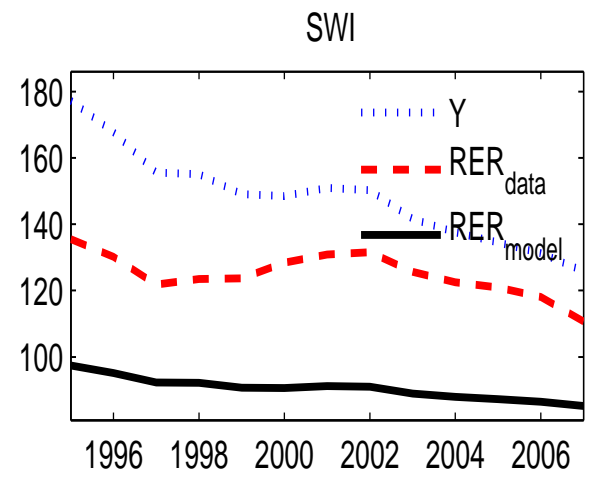


Figure 28: Prediction of model with taxation, and average PLI's in Southern and Eastern Europe
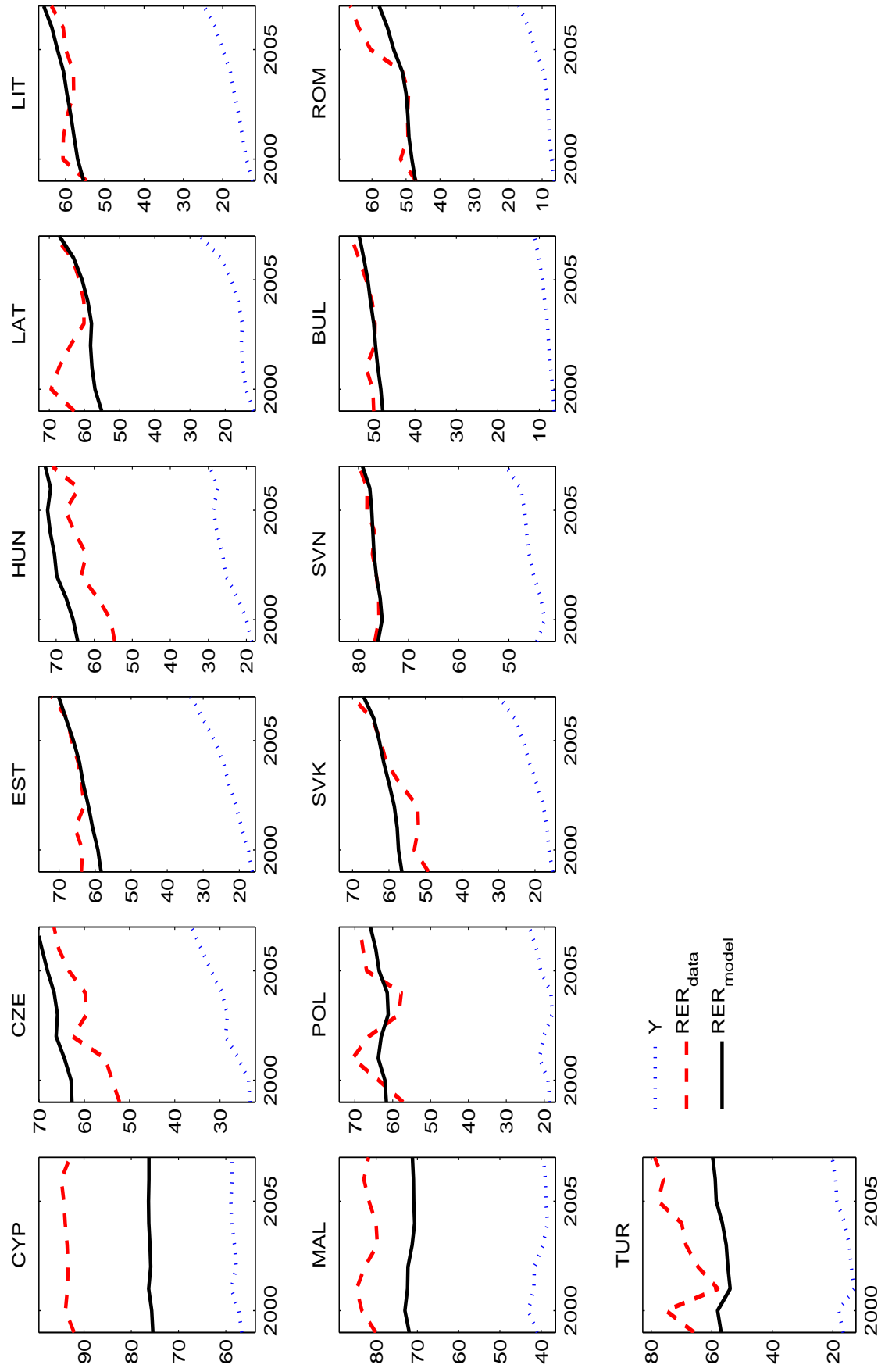